



\section{I premio UDC}

\section{sustentabilidade}

\section{a traballos fin de}

\section{grao e mestrado 2018}

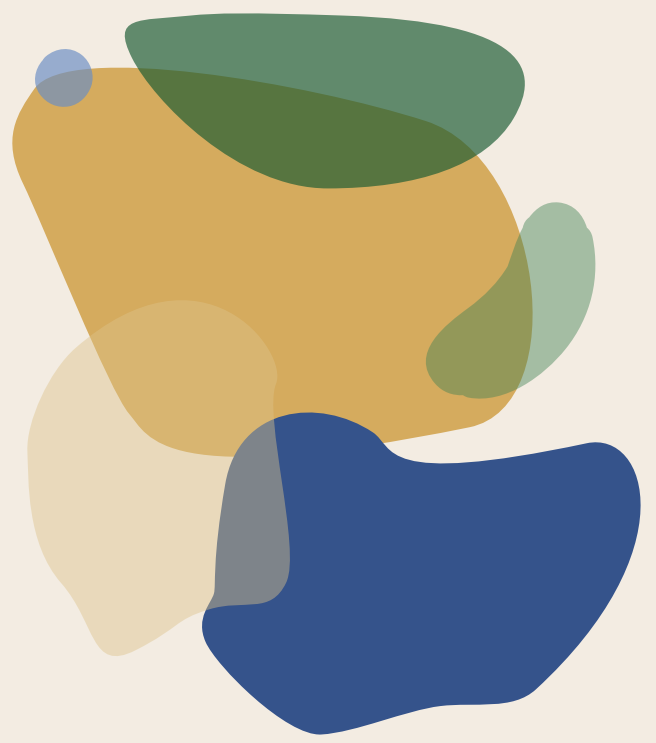

I PREMIO UDC SUSTENTABILIDADE A TRABALLOS FIN DE GRAO E MESTRADO 2018 Oficina de Medio Ambiente

A Coruña, Universidade da Coruña, 2019

Edita Servizo de Publicacións da Universidade da Coruña

Número de páxinas 142 - Índice páxina 5

ISBN 978-84-9749-783-1 · DOI https://doi.org/10.17979/spudc.9788497497831

Depósito Legal C 613-2020 - Deseño e maquetación distrito xermar

(C) da edición Universidade da Coruña - (c) dos textos e imaxes autores/as

cC) 6 Esta obra publícase baixo unha licenza Creative Commons

cC) $1(3)$ Atribución-NonComercial-Compartirlgual 4.0 Internacional

BY NC SA (CC BY-NC-SA 4.0) 


\section{Índice}

\section{-Presentación • 7 •}

Domingo Calvo Dopico, Pedro Vega Marcote e Manuel Soto Castiñeira

- Aprendizaje y servicio para proteger el medio ambiente:

plásticos y microplásticos $\cdot \mathbf{1 3}$.

Pablo Marcos Pachego

- Estudio de viabilidad técnico-económico para sistema de trigeneración a partir de biogás en explotación ganadera • 37 •

María Fandiño Sánchez

- Consumamos valores. Proxecto educativo sobre consumo

responsable e cultura da sustentabilidade.

Dende e para unha UDC libre e ecolóxica $\cdot 47$.

Eva Paola Bermúdez Porras

- Análisis de una construcción con bambú y adobe.

Propuesta para la construcción de una

escuela en Quibdó (Chocó, Colombia) • 53 •

\section{Daniel Alejandro Franco García}

- De la vivienda tradicional a la passive house.

Unidades residenciales en San Vicente de Elviña • 67 .

Lucía Uña Canteli

- Synthesis and study of new materials with barocaloric properties $\mathbf{8 9}$. Alba Martínez Muíño

• Estudo da contaminación aérea no Porto da Coruña no 2017 • 103 •

\section{Alberto Carril Vidal}

- Sistema domótico de eficiencia energética en el hogar con interfaz de realidad aumentada $\mathbf{1 2 1}$.

Óscar Blanco Novoa

- Bases. I premio UDC sustentabilidade a traballos

fin de grao e mestrado $2018 \cdot \mathbf{1 3 9} \cdot$ 



\section{Presentación}

Presentamos nesta colección os oito traballos premiados nesta primeira convocatoria, e que foron recoñecidos no acto de entrega de premios o pasado 5 de xuño de 2019, dia Mundial do Medio Ambiente. Nese mesmo acto, o reitor da UDC informou da declaración institucional do estado de emerxencia climática e ecolóxica, aprobada polo Consello de Goberno da Universidade da Coruña, por unanimidade, o día anterior. Recoñece así a UDC o problema ambiental, o cambio climático, o esgotamento de recursos e a contaminación como o verdadeiro desafío das xeracións actuais. Un desafío de dimensión global e local ao que a UDC non debe nin pode permanecer allea.

A convocatoria dos "Premios UDC sustentabilidade a traballos fin de grao e mestrado" da Universidade da Coruña xurdiu dunha proposta recibida desde o comité do programa Green Campus da Facultade de Ciencias da Educación, e que finalmente a Oficina de Medio Ambiente materializou. Esta convocatoria busca avanzar na sustentabilidade curricular, fortalecer a vinculación co currículo do traballo en sustentabilidade nos centros da UDC e promover a sensibilización e participación activa do estudantado.

A UDC vén desenvolvendo nos últimos anos un programa de mellora continua para a sustentabilidade no marco da Guía para a sustentabilidade na UDC (2011) e do Plan estratéxico da UDC 2013-2020. Este obxectivo incluíu a creación de comités ambientais nos centros (Programa Green Campus), a elaboración de diversos plans sectoriais. No marco destes plans desenvólvense iniciativas tales como a mellora da recollida selectiva de residuos, a compostaxe de residuos orgánicos, a introdución de equipamentos e prácticas de aforro e uso eficiente da enerxía e da auga, instalacións de produción de enerxía renovable, o préstamo de bicicletas e outras accións de fomento da mobilidade sustentable, a conservación e mellora da biodiversidade nos espazos fluviais e forestais do campus universitario, a introdución de recomendacións e contidos relativos a sustentabilidade nas guías docentes, a promoción da saúde e dos hábitos de vida saudable, ou o programa de sensibilización e voluntariado ambiental.

No momento da convocatoria desta primeira edición, a UDC contaba con bandeiras Green Campus en 5 centros. Varios centros máis estaban 
xa incorporados ao programa, o que levaría a acadar nese mesmo ano 7 bandeiras e un total de 12 centros recoñecidos. Súmase a isto que, por terceiro ano seguido, o ranking internacional GreenMetric de sustentabilidade nas universidades mantivo a UDC entres as primeiras 100 universidades a nivel mundial e as 10 primeiras a nivel do Estado español.

O indicador GreenMetric ten posto de manifesto o bo nivel da UDC nos eidos de ensino e a investigación. Consciente desta significativa achega á sustentabilidade ambiental na UDC, estes premios buscan recoñecer e potenciar aqueles estudos e traballos que contribúen a un mellor coñecemento e á adopción de medidas e prácticas de sustentabilidade no ámbito dos campus e os centros universitarios, en particular, e ao desenvolvemento sustentable no ámbito galego ou ao coñecemento e sensibilización dos problemas ecolóxicos globais e a educación ambiental.

Esta primeira edición dos premios dirixiuse a traballos realizados nos anos 2017 e 2018. Presentáronse un total de 26 traballos, deles 17 de grao e 9 de mestrado. Os traballos presentados procederon de 15 centros diferentes e de catro das cinco grandes áreas de coñecemento, ausente nesta primeira convocatoria unicamente a área de Artes e humanidades.

Seguindo os criterios da convocatoria, a comisión avaliadora valorou a calidade da memoria publicable, a relación coa temática da sustentabilidade ambiental e a orixinalidade, así como a achega aos obxectivos de desenvolvemento sustentábel (ODS) da ONU e ao compromiso social da UDC, e a aplicabilidade dos estudos e as investigacións aos propios campus da UDC. A temática da sustentabilidade ambiental estivo presente na grande maioría dos traballos (90\%), seguíndolle en menor medida a relación explícita cos ODS (35\%), a aplicabilidade aos campus da UDC (27\%) e o compromiso social da UDC (20\%).

Agardamos que esta iniciativa se consolide e contribúa a manter e mellorar o pulo pola sustentabilidade na UDC.

Pola Comisión de avaliación:

Domingo Calvo Dopico Vicerreitor de Economía, Infraestruturas e Sustentabilidade

Pedro Vega Marcote Profesor da UDC Experto en educación para a sustentabilidade ambiental 


\title{
I Premio UDC sustentabilidade a traballos de fin de grao e mestrado 2018
}

\section{Relación de traballos premiados}

\author{
Modalidade traballos fin de grao (TFG)
}

\section{Premio}

Nome Pablo Marcos Pacheco - Título Aprendizaje y Servicio para proteger el Medio Ambiente: Plásticos y microplásticos • Grao/Centro Grao en Química Facultade de Ciencias - Área Ciencias - Titoras Alatzne Carlosena Zubieta e María del Carmen Prieto Blanco

O traballo fixo uso da metodoloxía de Aprendizaxe e Servizo (ApS) e trata un tema de interese social e ambiental como a problemática dos plásticos no medio natural. Buscou coñecer a realidade social e as necesidades educativas dun centro de menores en Ferrol. Deseñouse un paquete de actividades sobre a referida problemática: charla expositiva, xogos e experimentos sinxelos. Excelente exemplo de como tratar as competencias transversais referidas ao exercicio dunha cidadanía crítica e solidaria e de proxección universitaria para adolescentes cunha problemática específica.

\section{Premio}

Nome María Fandiño Sánchez - Título Estudio de viabilidad técnicoeconómica para Sistema de trigeneración a partir de biogas en explotación Ganadera - Grao /Centro Grao en Enxeñaría Electrónica Industrial e Automática/Escola Universitaria Politécnica • Área Enxeñaría e Arquitectura - Titorxs María Sonia Bouza Fernandez e Antonio Couce Casanova

A alumna realizou unha análise técnica e económica para implantar un sistema de tri-xeración (electricidade, calor e frío) a partir de biogás nunha explotación láctea de Curtis. Valorou diferentes opcións técnicas dispoñibles no mercado e esbozou un plan económico para a opción elixida. Todo isto co obxectivo dobre de reducir os costes de produción e aforrar enerxía aproveitando os residuos orgánicos da granxa. 


\section{Accésits}

Nome Eva Paola Bermúdez Porras - Título Consumamos valores. Proxecto educativo sobre consumo responsable e cultura da sustentabilidade. Dende e para unha UDC libre e ecolóxica - Grao/Centro Grao en Educación Social/Facultade de Ciencias da Educación - Área Ciencias sociais e xurídicas · Titora Araceli Serantes Pazos

Trata do problema socio-ecolóxico e a necesidade de cambiar de paradigma e tomar parte activa no cambio, con relevancia dos movementos sociais e do papel da Universidade e a Educación como motor de cambio. "Consumamos valores" é un proxecto educativo para a comunidade universitaria que pretende unha UDC e unha cidadanía críticas e comprometidas.

Nome Daniel Alejandro Franco García - Título Análisis de una construcción con bambú y adobe. Propuesta para la construcción de una escuela en Quibdó (Chocó, Colombia) · Grao/Centro Grao en Arquitectura Técnica/ EUAT · Área Enxeñaría e Arquitectura • Titor Santiago López Piñeiro

Analiza diferentes técnicas construtivas tradicionais da zona baseadas na utilización de bambú, e estuda os posibles criterios bioclimáticos a ter en conta para garantir unha adaptación óptima ao clima local e reducido consumo enerxético. Concrétase nunha proposta construtiva para un edificio de uso escolar baseándose nas necesidades da comunidade de Quibdó (Colombia). Todo o traballo de campo grazas a unha bolsa PCR da OCV.

\section{Modalidade traballos fin de mestrado (TFM)}

\section{| Premio}

Nome Lucía Uña Canteli - Título De la vivienda tradicional a la Passive House. Unidades residenciales en San Vicente de Elviña • Mestrado/Centro Mestrado en arquitectura/ETSA · Área Enxeñaría e Arquitectura - Titores Jorge Aragón Fitera e Jorge Vicente Meijide Tomás

Proxéctase un conxunto de 5 Unidades Residenciais para investigadorxs de longa estadía e con familia, que precisan tanto espazos de vivenda como de traballo. Complétase con espazos comúns de reunión e un local social aberto á veciñanza. Son criterios de referencia o lugar e a súa historia, a capacidade de adaptación a diferentes persoas usuarias, a construción modular e o estándar passivhaus. A demanda de calefacción fica en $10 \mathrm{kWh} / \mathrm{m}^{2}$.ano, case 10 veces menos que unha vivenda convencional. A passive house está más cerca do que pensamos, conclúe. 


\section{Premio}

Nome Alba Martínez Muíño - Título Synthesis and study of new materials with barocaloric properties. Mestrado/Centro Double master in complex materials: thermal analysis and rheology and physiscs of soft matter /CICA - Área Ciencias - Titorxs Socorro Castro García (UDC, CICA), Jorge José López Beceiro (UDC, EPS), Alain Ponton (UPD 7, CNRS)

Tanto a mitigación como a adaptación ao cambio climático fan necesarios novos materiais refrixerantes que aumenten a eficiencia enerxética e non danen a capa de ozono. Entre as alternativas destaca o potencial das chamadas perovskiñas híbridas, que poden presentar efectos barocalóricos intensos a baixa presión. Este traballo mostra que as propiedades barocalóricas e a transición de temperatura das perovskiñas sintetizados poden modificarse como se desexa coa dopaxe con bromo, para adaptalas ás diferentes posibilidades das aplicacións.

\section{Accésits}

Nome Alberto Carril Vidal - Título Estudo da contaminación aérea no porto da Coruña no 2017 - Mestrado/Centro Mestrado en Enxeñaría Mariña/ETS Náutica e Máquinas - Área Enxeñaría e Arquitectura - Titor Ángel Martín Costa Rial

Calculáronse as emisións provocadas polos buques mercantes e de pasaxe durante as súas visitas ao porto da Coruña en 2017. Foi necesario estudar entradas e saídas, seleccionar os buques obxecto e súas características, e determinar os tempos de manobra e de estadía, para cuantificar as emisións de gases de combustión procedentes dos sistemas de propulsión e de xeración de enerxía eléctrica. Isto permitiu gañar conciencia do impacto sobre a calidade do aire na cidade da Coruña e identificar puntos de mellora.

Nome Óscar Blanco Novoa - Título Sistema domótico de eficiencia energética en el hogar con interfaz de realidad aumentada - Mestrado/Centro Mestrado Universitario en Enxeñería Informática/FIC · Área Enxeñaría e Arquitectura • Titorxs Tiago M. Fernández Caramés e Paula Fraga Lamas

No marco do sistema de tarificación de Prezo variable para o pequeno consumidor, este pode contribuír a reducir os picos de demanda e estabilizar a curva de consumo ao tempo que reduce a súa factura eléctrica. Este proxecto desenvolveu un sistema domótico modular baseado nunha serie de enchufes intelixentes capaces de obter o coste da enerxía en tempo real e tomar decisións sobre o momento óptimo de acender cada aparato. Incluíuse unha novidosa aplicación de realidade aumentada para a interacción co sistema. 



\title{
Aprendizaje y servicio para proteger el medio ambiente: plásticos y microplásticos
}

\author{
Pablo Marcos Pacheco ${ }^{1}$
}

\section{Resumen}

En este Trabajo de Fin de Grado se aplica la metodología de Aprendizaje y Servicio (ApS) a un tema de interés social como es la problemática ambiental derivada de los plásticos, siendo los receptores de la actividad los jóvenes de un centro de menores (Centro de Menores Ferrol I, Xunta de Galicia). Para ello se realizó un análisis de la información científica y se contrastó con la proporcionada a través de los medios de comunicación para conocer las carencias existentes en la divulgación de esta problemática. El alumno y las tutoras del TFG visitaron el centro de menores, se entrevistaron con la directora y educadoras para conocer la realidad social de los jóvenes así como sus necesidades educativas. Con toda esta información se diseñó una actividad ApS compuesta de varias partes: charla expositiva, juegos y experimentos sencillos de laboratorio sobre la contaminación que generan los plásticos en nuestro entorno. La actividad fue valorada muy positivamente por los responsables del centro receptor, quienes destacaron al estudiante universitario como un referente para los adolescentes, que suelen abandonar los estudios a una edad temprana.

Con este trabajo, siguiendo los principios del ApS, se colaboró en la divulgación del problema ambiental de los plásticos y microplásticos y se han podido adquirir competencias transversales referidas al ejercicio de una ciudadanía crítica y solidaria. Algunos de los objetivos de sostenibilidad de la

\footnotetext{
${ }^{1}$ Directoras del TFG: Alatzne Carlosena Zubieta y María del Carmen Prieto Blanco.

*Datos para citación: Marcos Pacheco, Pablo (2019). “Aprendizaje y servicio para proteger el medio ambiente: plásticos y microplásticos". En Oficina de Medio Ambiente UDC (ed.), I Premio UDC Sustentabilidade a traballos fin de grado e mestrado 2018. A Coruña: Universidade da Coruña, 13-35. DOI de la obra: https://doi.org/10.17979/spudc.9788497497831.
} 
ONU como la producción y consumo sostenible, conservación de los océanos y promoción de oportunidades de aprendizaje han sido también abordados en este TFG.

Palabras clave: aprendizaje y servicio, medios de comunicación, plásticos, microplásticos, contaminación.

\section{Introducción}

El objetivo de este trabajo es la aplicación de la metodología educativa denominada Aprendizaje y Servicio (ApS) con objeto de adquirir aquellas competencias transversales que más dificultades presentan cuando se usan las metodologías docentes convencionales. El tema a tratar es el impacto ambiental de la producción y uso de los plásticos y microplásticos. Se analizará tanto la bibliografía científica como la información divulgada a través de los medios de comunicación (prensa y TV). Con toda la información recabada y teniendo en cuenta las necesidades educativas de los jóvenes de un centro de menores, se diseñará e impartirá una actividad ApS.

\section{El plástico}

En este trabajo se estudia, además de otros aspectos, el impacto que pueden causar los plásticos en el medio ambiente. Es importante conocer la cantidad de plástico que se produce y el efecto de otras sustancias que se añaden a los plásticos y que también pueden provocar un gran impacto medio ambiental.

El término plástico abarca un amplio rango de materiales sintéticos o semisintéticos que contienen compuestos orgánicos altamente maleables, que se pueden moldear en una gran variedad de objetos sólidos. Debido a su versatilidad se utilizan en numerosas aplicaciones, aunque el embalaje constituye su mayor uso (Da Costa, 2018).

Las características de los plásticos vienen dadas por su naturaleza química. Están fundamentalmente constituidos por polímeros, caracterizados por una estructura de cadena larga formadas por unidades estructurales químicamente repetitivas (monómeros). Su masa molecular (a partir de miles de gramos $/ \mathrm{mol}$ ) y su grado de polimerización presentan valores típicos para cada polímero. Los principales tipos de plásticos usados en productos de consumo, así como algunas observaciones sobre su síntesis y características se recogen en la Tabla 1. 
Según sus características físicas los materiales plásticos se pueden clasificar en termoplásticos y plásticos termoestables. En el primer tipo se encuentran aquellos plásticos que por acción del calor se reblandecen y endurecen con el enfriamiento sin perder sus propiedades. Algunos de los termoplásticos más utilizados son el polietileno (PE), el PP, PVC, PS o el PET. En un segundo grupo estarían los plásticos termoestables que se endurecen irreversiblemente como el poliuretano (Andrady, 2017).

\subsection{Producción e incidencia en los residuos generados}

La producción mundial de plástico aumenta aproximadamente un $3 \%$ cada año y, excluyendo la producción de fibras de plástico, se alcanzaron los 322 millones de toneladas métricas en 2016 (Gasperi et al., 2018). De los distintos tipos de plásticos, el polietileno y el polipropileno representan el $38 \%$ y el $24 \%$ respectivamente de la producción global y consecuentemente estarán presentes en mayor proporción en los residuos generados.

Tabla 1. Tipos de plásticos, síntesis y características.

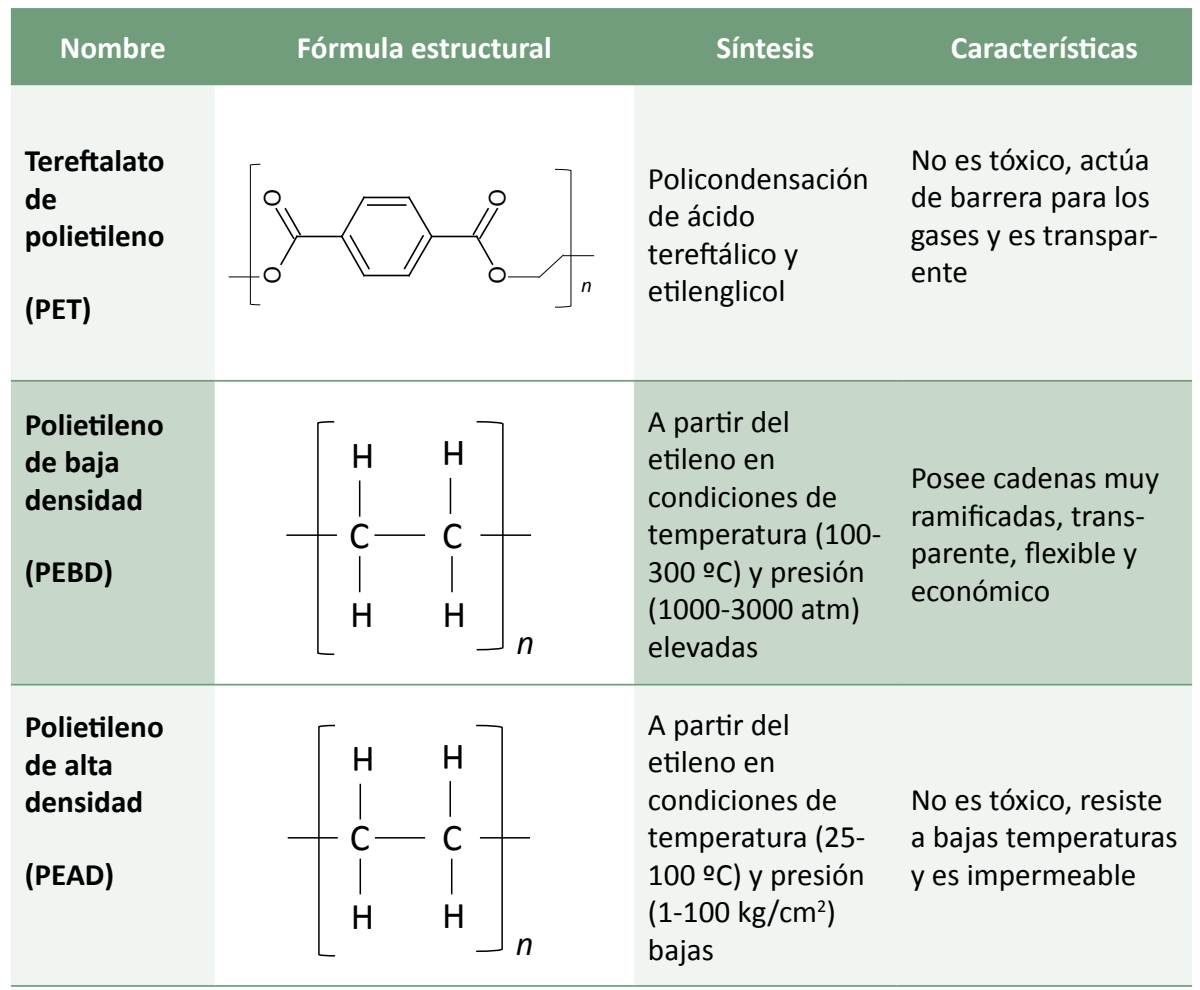




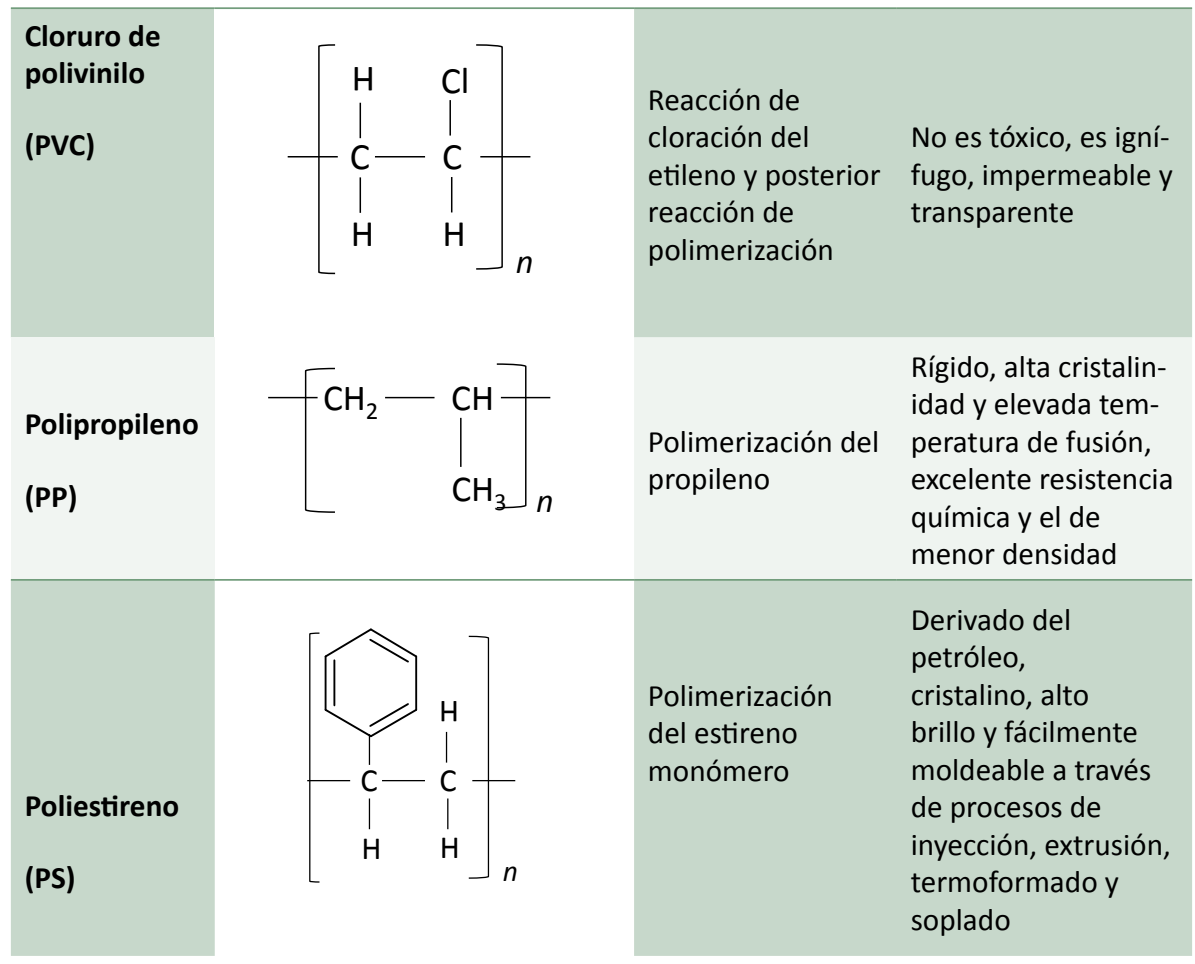

El uso de estos materiales da lugar a su acumulación en el medio ambiente y la mayor parte son enviados a vertederos, siendo una fracción muy pequeña la que se recicla.

La basura marina se concentra en zonas costeras o cerca de los ríos. La producción mundial de dos de los plásticos más consumidos, PE y PP, creció hasta un 8,7 \% por año (periodo 1950-2012), lo que aumenta la fracción que también termina como basura marina (Andrady, 2017).

Uno de los sectores donde se está incrementando en una mayor proporción la producción de plástico es en el de las fibras textiles, en concreto más de un $6 \%$ anualmente, llegando aproximadamente a un $16 \%$ de la producción global de plástico.

\subsection{Aditivos}

Los plásticos que se producen en la actualidad incorporan normalmente productos químicos denominados aditivos, que se añaden intencionalmente a los plásticos durante su proceso de fabricación para mejorar sus propiedades (Andrady, 2017). Estos aditivos se clasifican en 17 categorías, entre las que se encuentran los acelerantes, antiespumantes, colorantes, antidegradantes, antioxidantes, antiozonantes, retardantes de llama, plastificantes, bisfenol, 
estearatos, estabilizadores, aceites vegetales, ftalatos, agentes de expansión, agentes de acoplamiento, agentes de enlace cruzado y los denominados "ayudas de proceso". Estos aditivos confieren a los plásticos propiedades necesarias para su fabricación y/o posterior uso. Los materiales plásticos están constituidos por el polímero principal y otros productos químicos que intervienen modulando sus propiedades.

Muchos de estos aditivos son de bajo peso molecular y no están enlazados químicamente al material polimérico por lo que se puede producir su liberación del producto plástico bajo determinadas condiciones (Da Costa, 2018). Una de las rutas de exposición humana a estos productos químicos es su ingestión a través de bebidas y alimentos que han estado almacenados en materiales plásticos (Gasperi et al., 2018).

\subsection{Legislación}

La legislación referente a los plásticos se engloba en un marco amplio, así podemos mencionar legislación española y europea referida a la recogida, reutilización y reducción de residuos domésticos y también de equipamiento eléctrico y electrónico. En el Plan Nacional Integrado de Residuos para el período 2008-2015 (PNIR) ya se contemplaron varias medidas para lograr la progresiva reducción de residuos plásticos y la sustitución de plásticos no biodegradables. Medidas similares también se incluyeron en la Ley 22/2011, de 28 de julio, de residuos y suelos contaminados.

En relación a los residuos domésticos, la Directiva 2008/98/CE tiene como uno de sus objetivos principales la obligación de aumentar a partir del año 2020 como mínimo hasta un 50 \% global de su peso la preparación para la reutilización y el reciclado de residuos de materiales como el papel, los metales, el plástico y el vidrio de los residuos domésticos. Además, a partir de ese año también deberá aumentarse hasta un mínimo del $70 \%$ de su peso la preparación para la reutilización, el reciclado y otra valorización de materiales, incluidas las operaciones de relleno que utilicen residuos como sucedáneos de otros materiales (Directiva 2008/98/CE, 2008).

El pasado mes de mayo se publicó el Real Decreto 293/2018, de 18 de mayo, sobre reducción del consumo de bolsas de plástico y por el que se crea el Registro de Productores, transponiendo la Directiva (UE) 2015/720 del Parlamento Europeo y del Consejo, de 29 de abril de 2015, por la que se modifica la Directiva 94/62/CE en lo que se refiere a la reducción del consumo de bolsas de plástico ligeras.

También existe legislación relativa a los materiales plásticos que entran en contacto con alimentos. En este caso, el mayor riesgo para la salud se deriva de monómeros que no hayan reaccionado o lo hayan hecho de forma 
incompleta, o bien de aditivos de bajo peso molecular que se ceden a los alimentos mediante migración a partir del material plástico. Es por ello que se han establecido límites de migración para garantizar la seguridad del producto. El límite de migración global de componentes de materiales y objetos plásticos a los productos alimenticios no puede ser superior a $10 \mathrm{mg}$ por $1 \mathrm{dm} 2$. En el caso de que sean embalajes pequeños, donde la relación entre superficie y volumen es mayor, la migración será más alta (Reglamento, 2011).

La Directiva 94/62/EC (1994) tiene por objeto eliminar o reducir la cantidad de 32 metales pesados en materiales plásticos destinados al envasado de alimentos, fijando que la suma total de $\mathrm{Pb}, \mathrm{Cd}, \mathrm{Hg}$ y $\mathrm{Cr}$ (VI) no puede exceder de $100 \mathrm{mg} / \mathrm{kg}$. Con posterioridad la UE ha establecido límites de migración específica para el $\mathrm{Ba}, \mathrm{Co}, \mathrm{Cu}, \mathrm{Fe}, \mathrm{Li}, \mathrm{Mn}, \mathrm{Sb}$ y $\mathrm{Zn}$, con objeto de garantizar la seguridad del material en base a la evaluación de riesgos (Reglamento, 2011).

\section{Microplásticos}

\subsection{Definición de microplástico}

En general, se consideran microplásticos aquellas partículas de material plástico con un tamaño menor de $5 \mathrm{~mm}$. Sin embargo, la GESAMP (Grupo Mixto de Expertos en aspectos científicos sobre la contaminación del mar) propuso una clasificación de los plásticos en función del tamaño y de la técnica de visualización, que se resume en la Tabla 2 (Andrady, 2017).

Tabla 2. Clasificación de los plásticos según el tamaño y técnica de visualización.

\begin{tabular}{|lccc|}
\hline Clase & $\begin{array}{c}\text { Rangos de tamaño } \\
\text { (GESAMP) }\end{array}$ & Visualización & Técnica \\
\hline Macroplásticos & $10 \quad 0-2,5 \mathrm{~cm}$ & Ojo humano & Conteo visual \\
\hline Mesoplásticos & $2,5-0,1 \mathrm{~cm}$ & $\begin{array}{c}\text { Ojo humano o } \\
\text { microscopio óptico }\end{array}$ & Criba \\
\hline Microplásticos & $0,1 \mathrm{~cm}-1 \mu \mathrm{m}$ & Microscopio óptico & $\begin{array}{c}\text { Microfiltros }<1 \mu \mathrm{m} \\
\text { de separación }\end{array}$ \\
\hline Nanoplásticos & $<1 \mu \mathrm{m}$ & Microscopio electrónico & Nanofiltros
\end{tabular}

Los microplásticos son un problema medio ambiental global que necesita el consenso de los científicos para establecer metodologías aplicadas al muestreo, al tratamiento de la muestra y al análisis de los datos (Costa et al., 2018). 
El estudio de la contaminación de los microplásticos se incrementó desde el inicio del siglo XXI con el desarrollo de técnicas de muestreo y caracterización de estos contaminantes en el medio ambiente. El tamaño de las partículas estudiadas decreció hasta la escala de nanoplástico y los problemas en la detección de la contaminación que generan los nanoplásticos ayudaron a impulsar su investigación (ter Halle et al., 2017).

Uno de los problemas que presentan los plásticos micrométricos y nanométricos es que no se ven a simple vista. Estas pequeñas partículas presentan propiedades particulares como su movilidad o su biodisponibilidad que hacen que sea un problema para los ecosistemas marinos, siendo necesario el desarrollo de alternativas para su identificación en muestras naturales.

\subsection{Origen y clasificación de los microplásticos}

Los microplásticos se pueden clasificar en primarios y secundarios. Los primarios son aquellos que se generan con una finalidad, normalmente para ser utilizados como abrasivos, mientras que los secundarios se derivan de la fragmentación de desechos plásticos más grandes y son los más abundantes (Da Costa, 2018).

Los microplásticos primarios pueden ingresar en el medio ambiente de diversas fuentes: productos cosméticos y de limpieza, materias primas industriales usadas en la fabricación del plástico (que pueden entrar en el medio ambiente a través de emisiones durante la fabricación, el transporte o el uso), resinas plásticas usadas en el aire comprimido, fibras textiles liberadas en los procesos de lavado y secado y, por último, mediante la impresión 3D.

En el medio marino los microplásticos primarios normalmente entran a través de las aguas residuales, mientras que los secundarios son introducidos a través de fuentes adicionales, siendo una de las más importantes la degradación de basuras de plásticos en las playas, encontrando en ellas altas concentraciones de elementos peligrosos y, en particular, los metales tóxicos Cd y Pb (Massos \& Turner, 2017).

Los microplásticos pueden encontrarse principalmente en el compartimento marino y el atmosférico. Son comunes en todos los océanos del mundo y se pueden encontrar ubicuamente en el aire, en las aguas, en la biota, así como en sedimentos.

En los océanos, los microplásticos son acumulados por un sistema de corrientes oceánicas rotatorias Ilamadas giros. El mayor número de microplásticos se encuentra en el giro del Pacífico Norte donde se espera que, con el tiempo, este parche de basura crezca. Un estudio reciente de ter Halle et al. (2017) 
sobre microplásticos recogidos en el giro del Atlántico norte sub-tropical indica que los más comunes son los de polietileno y polipropileno.

La incidencia de los microplásticos en sedimentos se ha estudiado a partir de la arena de las playas y de los sedimentos recogidos a decenas o cientos de metros de profundidad. Aproximadamente, la mitad de los plásticos fabricados tienen mayor densidad que el agua y una mayor velocidad de sedimentación, por lo que es menos probable que se transporten a gran distancia (Obbard, 2017). Sin embargo, en estudios realizados por Munari et al. (2017) encontraron altas concentraciones de microplásticos en las ubicaciones más cercanas a la costa de Terra Nova Bay (Mar de Ross, Antártida).

Los microplásticos también han sido encontrados en el hielo marino. Este se puede mover a grandes distancias de donde se ha formado, por lo que transporta los contaminantes y los deposita en la temporada de derretimiento, cuando los organismos marinos comienzan a alimentarse.

Una de las preocupaciones en las investigaciones actuales es la posibilidad de acumulación de microplásticos en las zonas polares, ártica y antártica. Los microplásticos aparecen en regiones polares con zonas muy poco pobladas y esto debe estar relacionado con el transporte remoto y a largo alcance. En estudios recientes de Cózar et al. (2017) se informó de que el 37 \% de la zona circumpolar se encontraba libre de plástico, pero este dato pudo ser debido al método de recolección usado.

En el agua dulce son muy pocos los estudios realizados de microplásticos y algunos de ellos muestran que los niveles de contaminación son tan graves como en el ambiente marino (Wang et al. 2017).

En conclusión, es muy difícil poder determinar el destino de los micro- y nanoplásticos en los océanos y en el resto de compartimentos ambientales, no solo por su tamaño sino también por los tiempos de degradación que presentan estos materiales. Están limitaciones son aún mayores al no disponer de métodos de estandarización en el muestreo y en el análisis, y una definición universal de los micro- y nanoplásticos.

\subsection{Impacto en la salud humana y en el medio ambiente}

Los posibles efectos adversos de los microplásticos están reforzados por los contaminantes que puedan transportar adsorbidos, procedentes del entorno circundante, debido a la superficie hidrofóbica que presentan. En los entornos urbanos pueden llevar asociados hidrocarburos aromáticos policíclicos (HAP) y metales de transición que podrán llegar a nuestro organismo a través de la inhalación o ingestión (Gasperi et al. 2018). 
Estos elementos peligrosos, en particular los metales pesados como el cadmio y el plomo, están presentes en plásticos primarios y secundarios, y la ingestión de estas partículas permite una ruta potencial de exposición a un gran número de organismos marinos (Massos \& Turner, 2017). En función de los datos obtenidos en diferentes estudios de la adsorción a largo plazo de metales por parte de los microplásticos, se concluyó que la mayoría de los metales pesados transportados en los microplásticos se derivan de una carga inherente (Wang et al., 2017).

Uno de los mayores problemas para el tratamiento de estos contaminantes es su dificultad para lograr determinar e identificar estas partículas debido a su tamaño, variedad, forma, color y grado de degradación. Normalmente no hay un gran número de réplicas y se deben realizar múltiples muestreos, no solo espacialmente sino también a escala temporal. Tampoco existen métodos para poder determinar la edad de los microplásticos por lo que no se puede estimar la duración de la exposición a estos desechos de plástico.

\section{Aprendizaje y servicio como metodología educativa}

Se aplicó la metodología educativa de Aprendizaje y Servicio (ApS) realizando una actividad de divulgación que ha tenido como receptora una entidad colaboradora de la UDC. El Centro Universitario de Formación e Ensino (CUFIE) ha llevado la gestión de esta colaboración. El tema sobre el que se centró la actividad fue la incidencia de los plásticos en el medio ambiente. Como paso previo y dentro de la detección de las necesidades de servicio, se llevó a cabo un estudio de la información que reciben los ciudadanos a través de los medios de comunicación (prensa y TV) sobre el tema que se pretende divulgar.

El ApS es una acción educativa en la que los estudiantes, previa identificación de una necesidad, realizan y amplían su sentido de responsabilidad social (Lorenzo Moledo et al., 2017).

Esta metodología se lleva utilizando ampliamente en la enseñanza básica y secundaria, y con menor profusión en el ámbito universitario. En el área de la química, se comienza a institucionalizar esta metodología como es el caso de la Universidad Católica de Chile que realizó una experiencia desarrollada en el curso "Química en la naturaleza y la sociedad". Esta experiencia consistió en desarrollar actividades didácticas para niños de cuarto año de enseñanza primaria en establecimientos de alta vulnerabilidad. De este modo, fue posible trabajar en el desarrollo de habilidades genéricas en los estudiantes de química, tales como el trabajo en equipo y el compromiso social y a la vez conseguir en los estudiantes aprendizajes significativos referentes a los objetivos asociados a la asignatura. 
En países iberoamericanos y en EEUU, ApS está ampliamente implementada (Sáenz de Jubera Ocón et al., 2016). En Europa también se ha comenzado a aplicar, aunque con cierto retraso con respecto a América. En las universidades españolas su profusión es menor y, es por ello que éstas deben sufrir una modernización que incorpore prácticas de aprendizaje, estableciendo vías que faciliten la construcción de una comunidad que promueva la sostenibilidad y responsabilidad social universitaria.

En Galicia, el ApS se ha incluido en los programas de formación del profesorado de enseñanzas no universitarias y se ha incorporado dentro del programa de formación docente de la Universidad de Santiago de Compostela. Aun así, se trata de una metodología cuya expansión dependerá de que sus aspectos se vayan aprovechando en la relación escuela-comunidad.

\section{Estudio de la información divulgada por los medios de comunicación}

\subsection{Materiales y método}

En este apartado se estudia la información que proporcionan los medios de comunicación, especialmente la prensa, desde el punto de vista de los contenidos y de los aspectos formales. Se han seleccionado diferentes documentos y noticias relacionadas con los plásticos para conocer la información que se transmite a un público no especializado. La selección se ha realizado desde junio del 2017 hasta abril del 2018 intentando reproducir la lectura de periódicos de las comunidades autónomas y nacionales que pudiera hacer un lector regularmente informado.

El objetivo de este apartado es conseguir resultados cuantitativos y cualitativos, los cuales influyen en la actividad divulgativa realizada en este trabajo de fin de grado. Respecto a los contenidos, la mayoría de la información recogida aborda temas sobre la producción de plásticos, hábitos de consumo, riesgos para la salud y el medioambiente, tratamiento como residuos, etc. También se indican las fuentes de información utilizadas: artículos científicos, informes técnicos de organismos diversos, entrevistas con investigadores, etc. Además, se detallan los distintos medios de comunicación en los que se ha transmitido la información: periódicos (La Voz de Galicia, El País, La Opinión, etc.), televisión (programas de la Sexta), charlas divulgativas, etc.

\subsection{Noticias de prensa y televisión}

Para el estudio de contenidos y los aspectos formales se han separado las noticias en dos grupos, uno de ellos con noticias de periódicos de dos 
comunidades autónomas (Galicia y Cataluña) y otro grupo con periódicos de tirada nacional. El análisis cuantitativo se ha realizado calculando las veces que aparece cada ítem seleccionado en el grupo de artículos considerados (\% artículos con el ítem considerado con respecto al número total de artículos).

A nivel nacional, existen numerosas noticias de prensa donde se muestra el impacto que producen los plásticos en el medioambiente y la cantidad de residuos que se producen, además de los efectos sobre la salud. Se analizaron los aspectos formales (Figura 1), encontrando erratas relacionadas con la terminología científica como por ejemplo "naplástico" o "polietinelo" (en lugar de poliestileno o polietileno) (Roldán, 2018). También se ha encontrado terminología, como mínimo imprecisa, en declaraciones atribuidas a un investigador, referidos a los microplásticos "Absorben as substancias tóxicas que hai na auga, como os carburantes, que acumulan e transportan". Seguramente se debería sustituir carburantes por hidrocarburos o más concretamente HAPs.

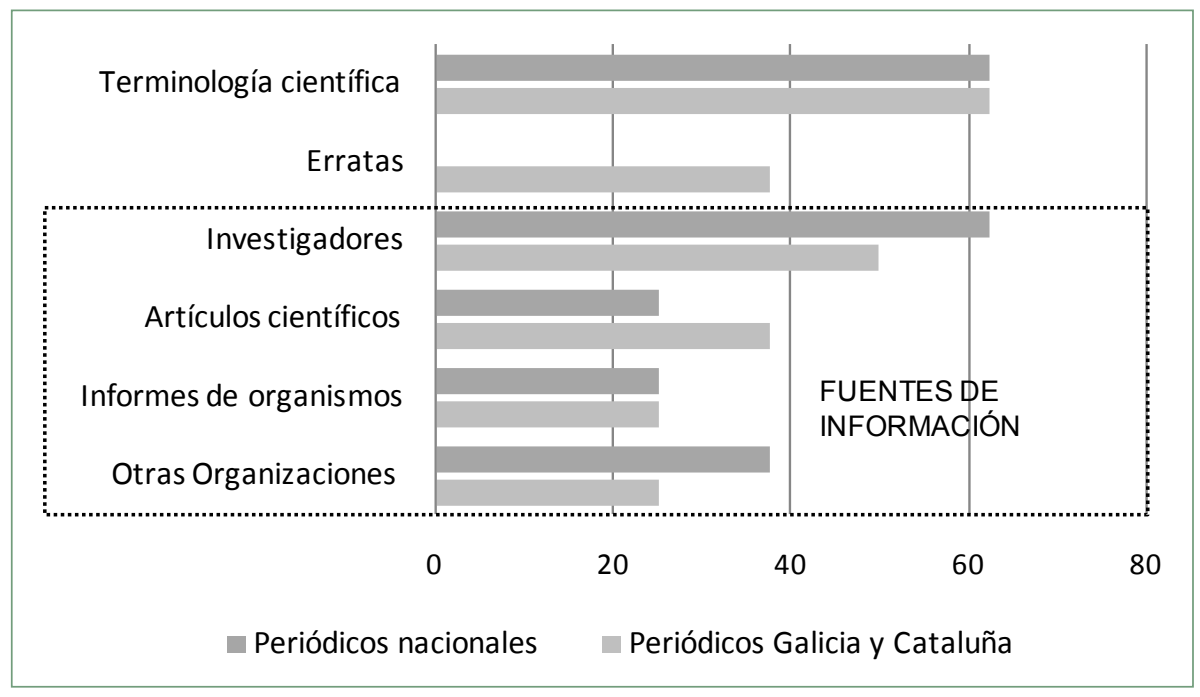

Figura 1. Frecuencia de terminología y diversas fuentes de información en artículos de prensa relacionadas con los plásticos.

Para el análisis de contenidos, se han considerado aquellos ítems relacionados con el plástico como material de producción, uso, consumo y desecho (Figura 2). Por otra parte, se ha analizado la frecuencia de la información sobre microplástico y el impacto en el medio marino de plásticos, los riesgos en la biota y sobre la salud humana (Figura 3). La información sobre microplásticos es pequeña, aun considerando los casos en los que se citan como microfragmentos o micropiezas. En cuanto a los aditivos, se citan con muy poca frecuencia y además nunca asociados con toxicidad ni con microplásticos. 


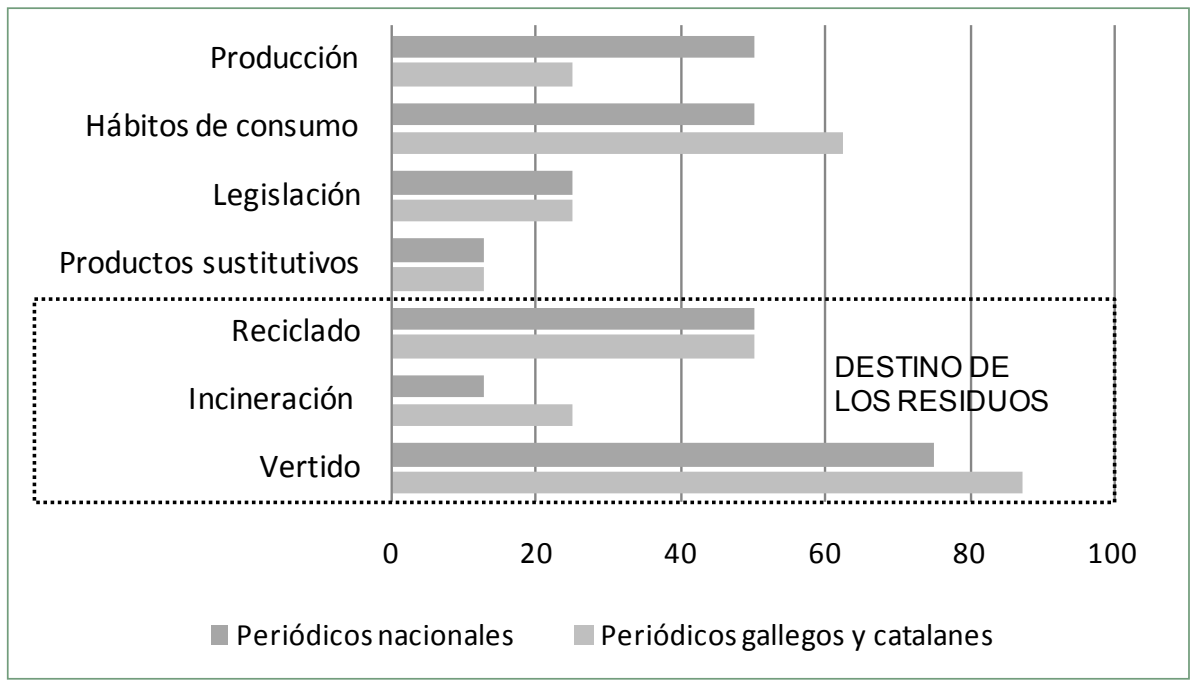

Figura 2. Frecuencia de diversos contenidos (producción, hábitos de consumo, destino de los residuos...) en artículos de prensa relacionados con los plásticos.

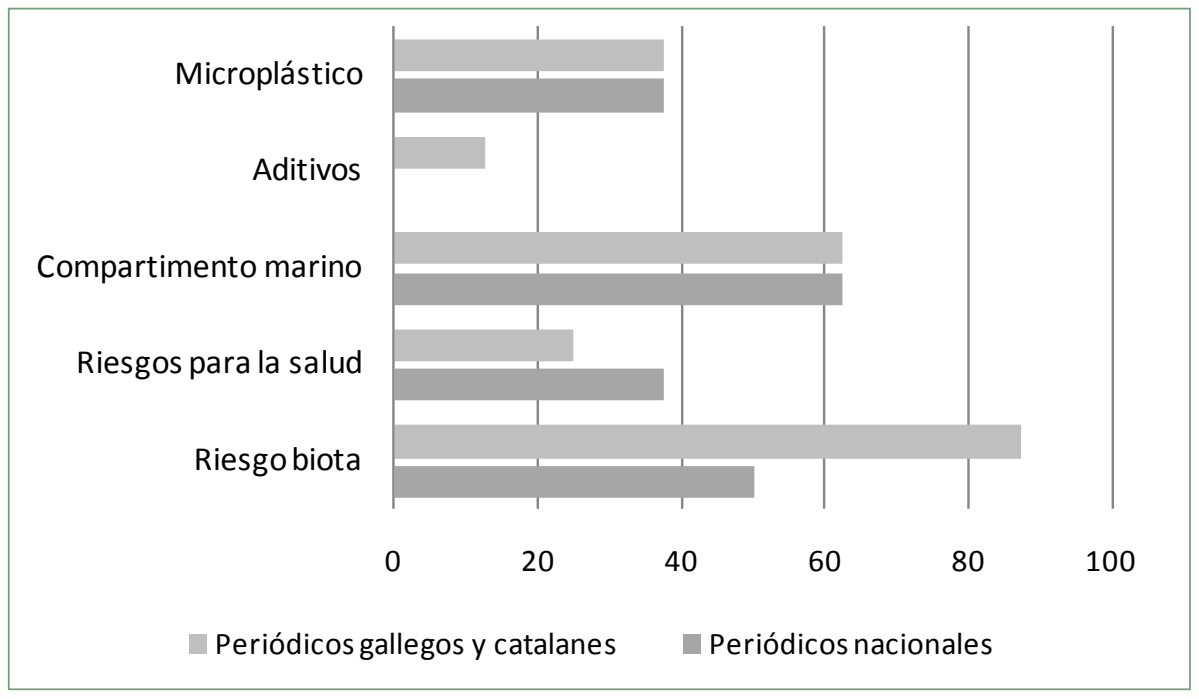

Figura 3. Frecuencia de diversos contenidos (microplásticos, compartimento marino, riesgos...) en artículos de prensa relacionados con los plásticos.

En los programas de televisión, sin tener en cuenta los programas de noticias en los que no se ha realizado seguimiento, no se informa con la misma frecuencia que en las noticias de prensa, pero el impacto que generan en la 
sociedad es mucho mayor ya que, al mostrarse videos e imágenes se consigue concienciar más al público sobre este problema. Como coloquialmente se suele decir "Una imagen vale más que mil palabras".

Uno de los programas de televisión en el que se ha encontrado información actual sobre el tema a tratar ("La era del plástico", 2017) habla sobre la contaminación que producen los plásticos y los microplásticos en el medioambiente y sus posibles efectos negativos sobre la salud.

A la vista de los resultados obtenidos de este análisis, se puede comprobar que hay aspectos relacionados con los plásticos que se tratan con frecuencia como es el caso del vertido de residuos, producción, hábitos de consumo, reciclado, riesgo para la biota. Esto indica que en la mayor parte de las noticias informan sobre la producción masiva de estos residuos y que pueden provocar numerosos efectos nocivos sobre los organismos. Asimismo, se puede concluir que la vía más común de obtención de la información por parte de los medios de comunicación es mediante entrevistas a investigadores, siendo los artículos científicos e informes de organismos un recurso menos utilizado.

En otros aspectos se puede comprobar que los medios de comunicación no informan sobre ciertos aspectos como es el caso de residuos plásticos en la industria agrícola, aun siendo una de las principales fuentes de contaminación. La problemática de los aditivos de los plásticos solamente se ha encontrado en los programas de TV. Se informa con poca frecuencia sobre posibles productos sustitutivos del plástico, indicando que todavía se están desarrollando y, aunque se obtengan avances, no se ha encontrado un producto que pueda sustituirlo completamente.

\section{Actividad ApS diseñada}

La actividad relacionada con el Aprendizaje-Servicio se ha realizado con la colaboración de la Oficina de Voluntariado de la UDC (Universidad de La Coruña) y se ha desarrollado en el Centro de Menores Ferrol I (Figura 4), que forma parte de la red de Centros de protección de menores de Galicia (Consellería de Política Social, Xunta de Galicia).

Una vez asignado el centro receptor y contactado con su Directora, se le plantea nuestra temática como propuesta de trabajo y comenta que actividades con enfoque medioambiental serían muy interesantes porque no es un tema a tratar entre las charlas que reciben los jóvenes en el centro. De esta forma se plantea que el objetivo principal de esta actividad, sea cubrir algunas de las necesidades educativas de los jóvenes del Centro de Menores, como poder relacionar los conocimientos adquiridos en la escuela con la vida 
cotidiana, concienciarlos sobre los problemas de la sociedad y los efectos que generan los malos hábitos de consumo en el medio ambiente. Otro de los objetivos a cumplir es que los adolescentes consideren que la ciencia puede ser comprensible para todo el mundo.

La actividad que se llevó a cabo se dividió en varias partes. En primer lugar, se impartió una charla divulgativa en la que se habló fundamentalmente sobre la definición de plástico y microplástico y la cantidad que se produce, los aditivos en los plásticos, de dónde proceden esos plásticos y que contienen y de los efectos que pueden causar en la salud humana y en el medio ambiente (Figura 5). Para definir los contenidos de la charla se ha tenido en cuenta el análisis de prensa previo y la bibliografía científica. Así se incidió en la problemática de los microplásticos, de los aditivos y los procesos de degradación de estos, ya que tienen una menor difusión en los medios de comunicación. Otro aspecto que se intentó resaltar es el papel de la ciencia en la sociedad y cómo puede ser explicada de una forma comprensible.

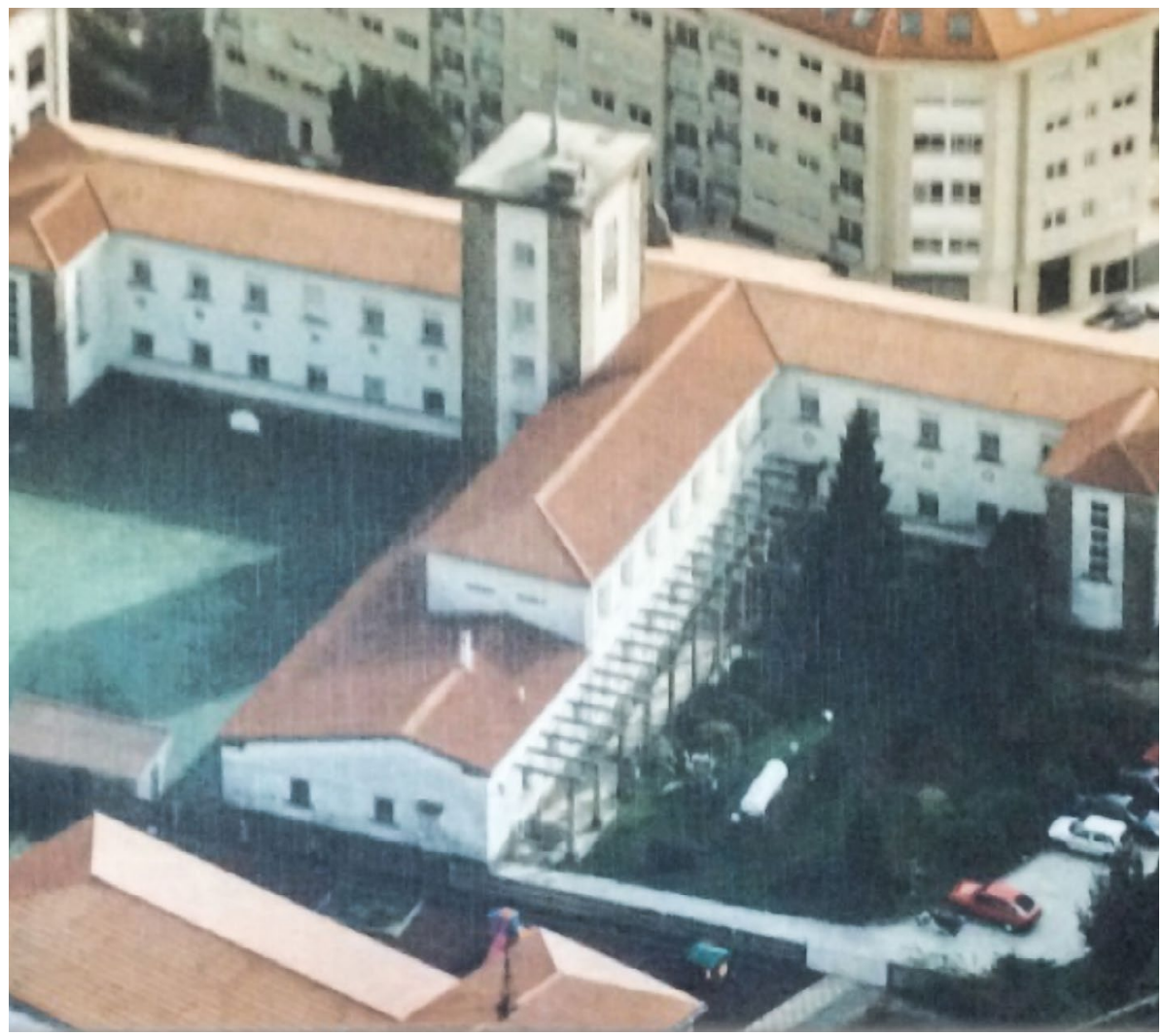

Figura 4. Centro de Menores Ferrol I. 


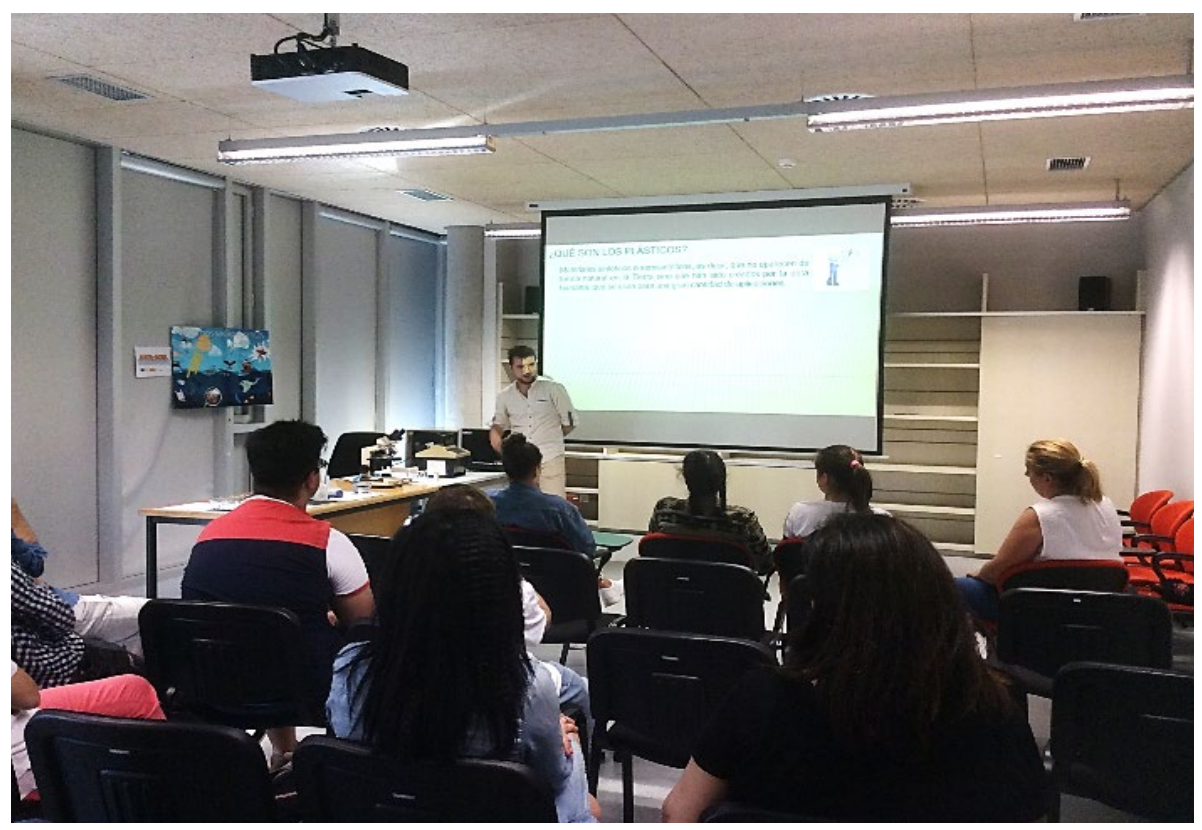

Figura 5. Charla divulgativa dirigida a adolescentes.

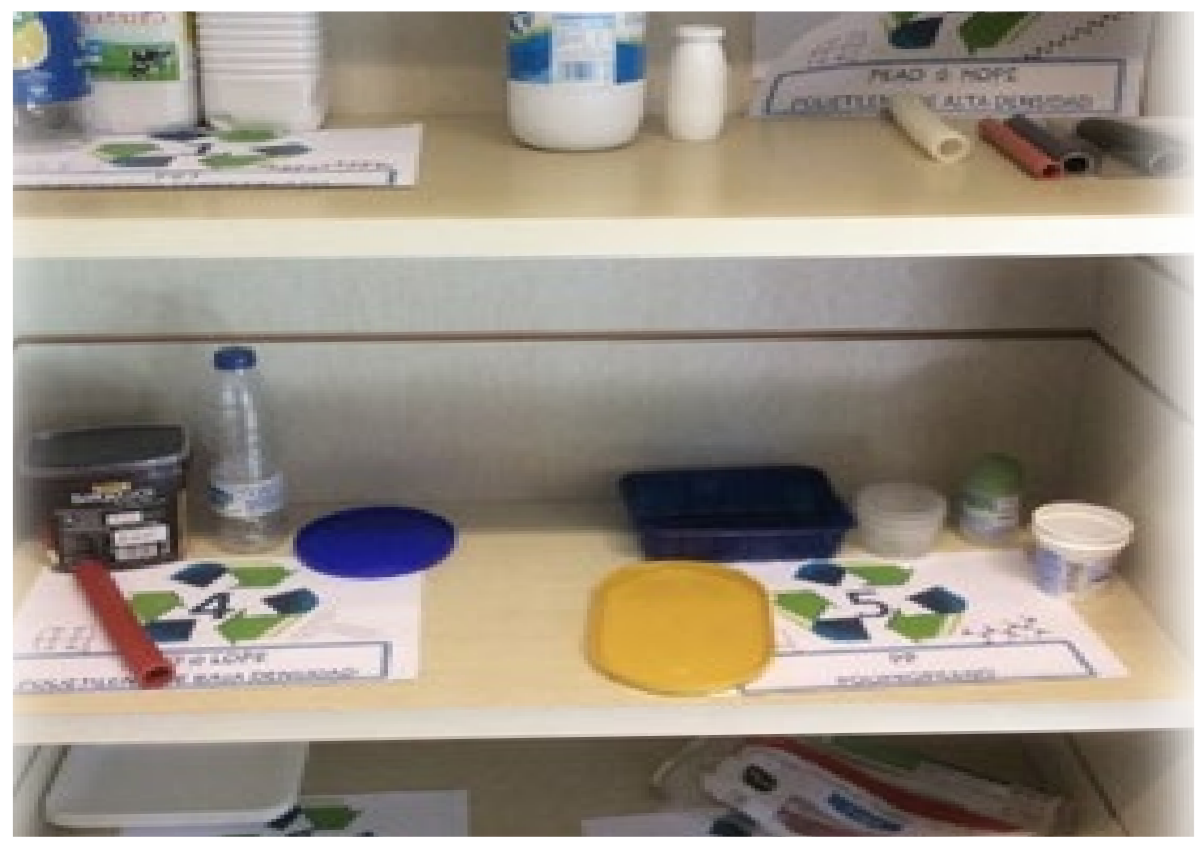

Figura 6. Juego de identificación de los distintos tipos de plásticos. 
En todo momento se fomentó la participación de los jóvenes a través de preguntas dirigidas sobre el tema, sobre sus conocimientos previos, dudas, etc. Una vez finalizada la charla y las preguntas por parte de los adolescentes y monitores, se realizó un taller práctico que constó de varias experiencias.

La primera experiencia consistió en un juego interactivo para que los adolescentes pudieran conocer los distintos tipos de plásticos con los que están fabricados diversos objetos de la vida cotidiana (Figura 6). Para ello se muestra y explica su clasificación, así como algún ejemplo de cada tipo. Aparte, se dejan sin clasificar una serie de envases o utensilios para que sean los jóvenes los que deban en primer lugar averiguar cómo viene identificado en el material el tipo de plástico y así poder clasificarlos. Se aprovecha para que vean qué tipos de plásticos se destinan a determinados usos cotidianos (envases de alimentos, de productos de limpieza, envases en general, tuberías, etc.) y exponerles en cada caso sus posibles riesgos o repercusiones de un mal uso o destino final de estos objetos.

A continuación, se llevan a cabo las siguientes experiencias prácticas de laboratorio, tal como se muestran en la Figura 7. En ellas se pretende que reconozcan la presencia de los plásticos y microplásticos como contaminantes en nuestro entorno, así como mostrarles que en la ciencia hacemos uso desde la simple observación directa hasta distintas técnicas de análisis para poder estudiar e investigar diversas sustancias, compuestos, etc., que pueden ser en unos casos perjudiciales o beneficiosas para el hombre.

Experiencia 1.- Empleo de tamices con distintos luz de malla (desde $2 \mathrm{~mm}$ hasta $63 \mu \mathrm{m}$ ) para tamizar arena de playa. Los jóvenes deben usar estos tamices con la arena de playa y observan como a simple vista la arena parece limpia, pero al tamizarla aparecen residuos de diversos tipos de plástico, que según su tamaño quedan recogidos en los distintos tamices.

Experiencia 2.- Observación bajo el microscopio de los microplásticos presentes en la arena de playa que no se aprecian a simple vista.

Experiencia 3.- Extracción de esferas de microplástico presentes en un exfoliante comercial. Los jóvenes deben lavar mientras tamizan por un tamiz de $50 \mu \mathrm{m}$ una muestra de exfoliante comercial, necesitando una lupa con luz para poder observar las micropartículas de plástico.

Experiencia 4.- Detección bajo luz UV (254 nm y $365 \mathrm{~nm}$ ) de diversas sustancias fluorescentes. Por parejas se muestran diversas muestras, que a simple vista parecen iguales pero que observadas en una cámara oscura bajo luz UV se diferencian por su distinto comportamiento ante esta radiación. 


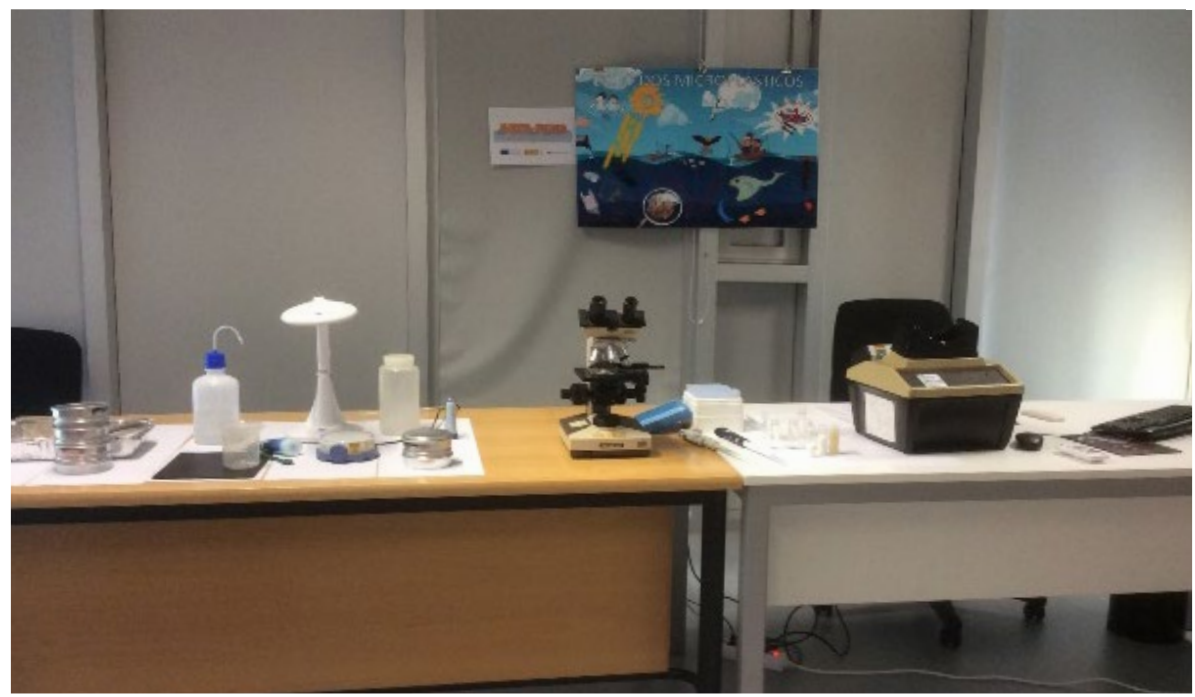

Figura 7. Experimentos relacionados con los plásticos.

\subsection{Valoración de la actividad}

Finalmente, se entregaron unos cuestionarios a los adolescentes y a los monitores del centro para poder conocer su opinión sobre la experiencia y, sobre todo, para saber si la actividad les había ayudado a comprender mejor la problemática que generan los plásticos y microplásticos en el medio ambiente (Véase Anexo 1). El cuestionario fue cubierto por un total de 7 adolescentes y 4 monitores del centro. Alguna de las preguntas podía ser respondida con una valoración del uno al cinco y los resultados se recogieron en las Figuras 8 y 9. En otros casos las opciones eran distintas o se trataban de respuestas de "Si" o "No".

Los adolescentes indicaron que conocían el problema antes de realizar el taller, pero que se trataba de un tema interesante para poder aprender más sobre la contaminación que generan los plásticos en el medioambiente. También valoraron satisfactoriamente el papel de la ciencia en el tema. A la pregunta de si faltaban aspectos a tratar en la charla, la puntuación es aceptable, cercana a 3 indicando algunos de ellos que añadirían ejercicios y videos sobre el tema para que la experiencia fuera más educativa y amena. Asimismo, valoran con una puntuación media de 3 la información proporcionada por los medios de comunicación, pero en lo que respecta a las medidas para evitar la contaminación es la más baja, solo de 2. La mayoría de los jóvenes sabían de la existencia de este problema a través de charlas, televisión o radio (Figura 5). Entre los sitios que pensaban que estaban más contaminados que Ferrol mencionan lugares como 
A Coruña, Madrid, Barcelona, Pekín, Maldivas o África. Finalmente, indicaron que este tipo de talleres se los recomendarían principalmente a sus familias y amigos y en menor medida a monitores y profesores.

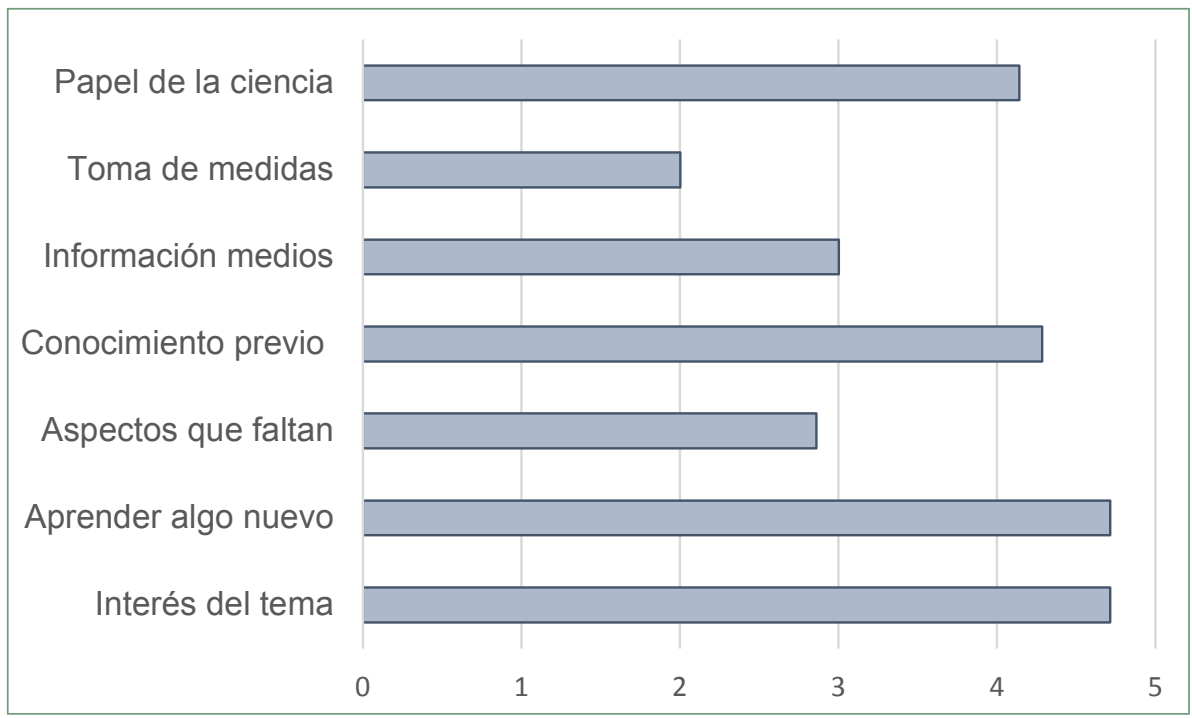

Figura 8. Resultados de la encuesta realizada a los jóvenes del Centro de Menores Ferrol I.

Las monitoras del centro indicaron que el taller estuvo bien organizado y se desarrolló de manera amena y divertida, aunque señalaron que la duración de la charla fue algo escasa. Además, se les pidió que valoraran la contribución en la formación de los jóvenes de ciertos aspectos abordados en el taller como el contacto con los problemas de la sociedad, la concienciación con hábitos de consumo y con el medio ambiente o la compresión de la relación entre el aprendizaje en la escuela y la vida cotidiana (Figura 9).

La mayoría de las monitoras mostraron su conformidad con todos estos aspectos, indicando que la comprensión de la ciencia a nivel global puede suponer una mayor dificultad. En cuanto a la edad más adecuada para realizar el taller, no hubo una respuesta unánime ya que algunos de los monitores creen que debería ir enfocado a un público más adulto mientras que otros prefieren que vaya dirigido a público de cualquier edad para lograr una concienciación de toda la sociedad en este problema de contaminación.

Como propuestas de mejora, indicaron que sería conveniente una mayor duración de la parte práctica, combinando la realización de juegos con charlas interactivas para un desarrollo más ameno del taller. 


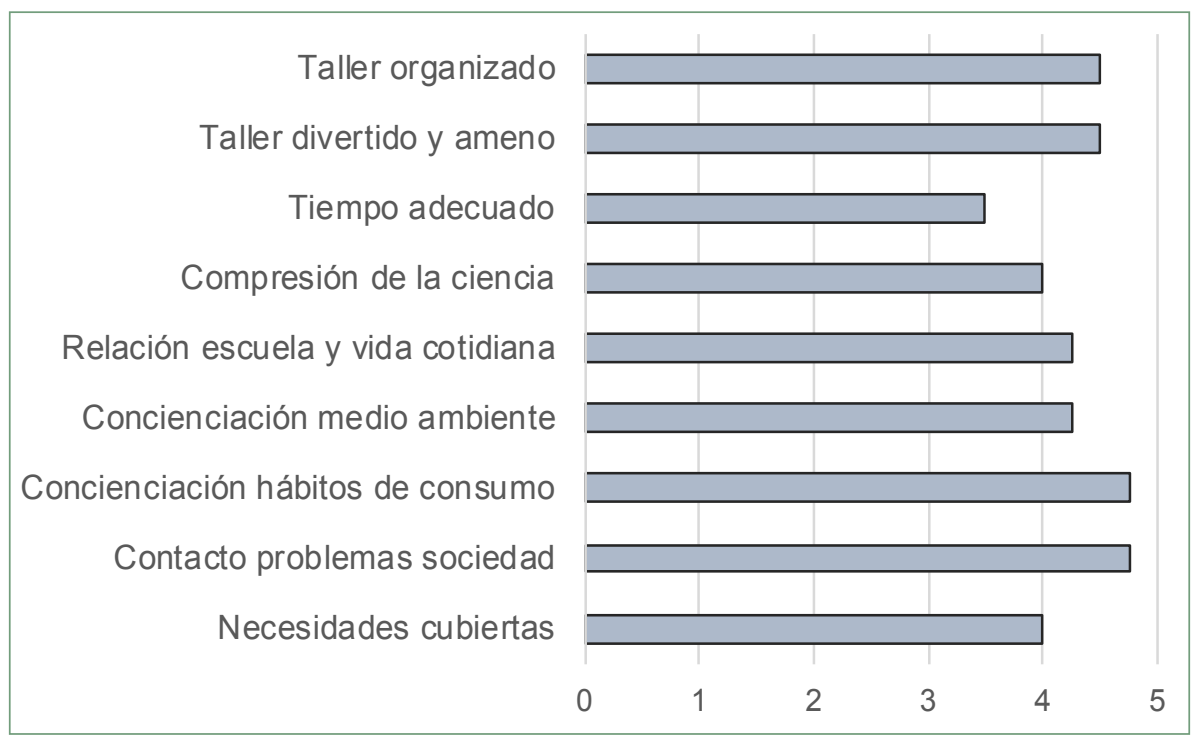

Figura 9. Resultados de la encuesta realizada a los monitores del Centro de Menores Ferrol I.

Se puede concluir que los integrantes del Centro de Menores Ferrol I obtuvieron un alto grado de satisfacción en la actividad realizada. El personal del centro considera muy positivo que la actividad de divulgación estuviera realizada por un estudiante universitario ya que consideran necesario que los adolescentes del centro tengan referentes para poder orientar sus futuros estudios.

En las encuestas también se recogió la demanda del personal del centro por una mayor participación e implicación en este tipo de actividades relacionadas con el ApS, aunque no explicitado por quién, posiblemente de la universidad y de la sociedad en general. Finalmente, sería conveniente mejorar algunos aspectos como incluir propuestas por parte de los jóvenes de nuevos temas de interés.

\section{Conclusiones}

Las principales conclusiones derivadas de este trabajo de fin de grado son las siguientes:

Se ha logrado aplicar la metodología ApS profundizando en las competencias transversales, especialmente, aquellas referidas al "ejercicio de una ciudadanía crítica y capaz de analizar la realidad", que ha sido desarrollado 
en la búsqueda de la información sobre un tema científico en los medios de comunicación. Además, se ha trabajado en "el ejercicio de una ciudadanía culta, comprometida y solidaria" (competencia transversal C4 de la UDC) al impartir la actividad de divulgación de un tema con bases científicas para un colectivo con determinadas necesidades educativas.

Los profesionales del centro han destacado al estudiante universitario como un referente para los adolescentes del centro. Además, han sugerido que sería necesario implicar más a los jóvenes en la propuesta de temas de su interés para futuras actividades.

Varios de los objetivos de sostenibilidad de la ONU han sido abordados en este TFG como la producción y el consumo sostenible, la conservación de los océanos y la promoción de oportunidades de aprendizaje. Así, los materiales y actividades preparadas han estado dirigidas a concienciar a los jóvenes del consumo responsable, la minimización de residuos, el reciclado y la contaminación en el medio marino. El estudiante de TFG ha podido reflexionar sobre la situación y las dificultades de inclusión social de los adolescentes del Centro de Menores. También ha podido comprobar como el aprendizaje a través de juegos y experimentos ha sido más efectivo que otras didácticas más formales.

\section{Bibliografía}

Andrady, A. L. (2017). The plastic in microplastics: A review. Marine Pollution Bulletin, 119(1), 12-22. doi:10.1016/j.marpolbul.2017.01.082.

Costa, M. F., Da Costa, J. P. \& Duarte, A. C. (2018). "Sampling of micro(nano)plastics in environmental compartments: How to define standard procedures?". Current Opinion in Environmental Science \& Health, 1, 36-40. doi:10.1016/j.coesh.2017.10.001.

Cózar, A., Martí, E., Duarte, C. M., García-de-Lomas, J., van Sebille, E., Ballatore, T. J., ... Irigoien, X. (2017). The Arctic Ocean as a dead end for floating plastics in the North Atlantic branch of the Thermohaline Circulation. Science Advances, 3(4), e1600582. doi:10.1126/sciadv.1600582.

Da Costa, J. P. (2018). Micro- and nanoplastics in the environment: Research and policymaking. Current Opinion in Environmental Science \& Health, 1, 12-16. doi:10.1016/j.coesh.2017.11.002.

Directiva 94/62/CE del Parlamento Europeo y del Consejo, de 20 de diciembre de 1994, relativa a los envases y residuos de envases. Diario Oficial de las Comunidades Europeas. Luxemburgo, 31 de diciembre de 1994, núm. L 365, pp. 10-23.

Directiva 2008/98/CE del Parlamento Europeo y del Consejo, de 19 de noviembre de 2008, sobre los residuos y por la que se derogan determinadas Directivas. Diario Oficial de la Unión Europea. Luxemburgo, 22 de noviembre de 2008, núm. L 312, pp. 3-30.

Gasperi, J., Wright, S. L., Dris, R., Collard, F., Mandin, C., Guerrouache, M. \& Tassin, B. (2018). Microplastics in air: Are we breathing it in? Current Opinion in Environmental Science \& Health, 1, 1-5. doi:10.1016/j. coesh.2017.10.002. 
La era del plástico [Programa de televisión]. (2017). En Equipo de Investigación. San Sebastián de los Reyes: Atresmedia Corporación de Medios de Comunicación.

Ley $22 / 2011$, de 28 de julio, de residuos y suelos contaminados. Boletín Oficial del Estado. Madrid, 29 de julio de 2011, núm. 181, pp. 84650-85705.

Lorenzo Moledo, M. M., Mella Núñez, Í., García Álvarez, J. \& Varela Portela, C. (2017). Investigar para institucionalizar el aprendizaje servicio en la universidad española. RIDAS. Revista Iberoamericana de Aprendizaje Servicio, 3, 118-130. Recuperado de http://revistes.ub.edu/index.php/RIDAS/article/ view/19112.

Massos, A. \& Turner, A. (2017). Cadmium, lead and bromine in beached microplastics. Environmental Pollution, 227, 139-145. doi:10.1016/j.envpol.2017.04.034.

Munari, C., Infantini, V., Scoponi, M., Rastelli, E., Corinaldesi, C. \& Mistri, M. (2017). Microplastics in the sediments of Terra Nova Bay (Ross Sea, Antarctica). Marine Pollution Bulletin, 122(1-2), 161-165. doi:10.1016/j.marpolbul.2017.06.039.

Obbard, R. W. (2018). Microplastics in Polar Regions: The role of long range transport. Current Opinion in Environmental Science \& Health, 1, 24-29. doi:10.1016/j.coesh.2017.10.004.

Real Decreto, de 18 de mayo, sobre reducción del consumo de bolsas de plástico y por el que se crea el Registro de Productores. Boletín Oficial del Estado. Madrid, 19 de mayo de 2018, núm. 122, pp. 5259152601

Reglamento (UE) n 10/2011 de la Comisión, de 14 de enero de 2011, sobre materiales y objetos plásticos destinados a entrar en contacto con alimentos. Diario Oficial de la Unión Europea. Luxemburgo, 15 de enero de 2011, núm. L 12, pp. 1-89.

Resolución de 20 de enero de 2009, de la Secretaría de Estado de Cambio Climático, por la que se publica el Acuerdo del Consejo de Ministros por el que se aprueba el Plan Nacional Integrado de Residuos para el período 2008-2015. Boletín Oficial del Estado. Madrid, 26 de febrero de 2009, núm. 49, pp. 19893-20016.

Roldán, D. (2 marzo 2018). La necesidad de concienciar sobre el abandono de residuos en la naturaleza. La Voz de Galicia. Recuperado de: https://www.lavozdegalicia.es.

Sáenz de Jubera Ocón, M., Ponce de León Elizondo, A. \& Sanz Arazuri, E. (2016). El aprendizaje-servicio como proyecto de trabajo fin de grado en el marco de la educación del ocio. Revista Interuniversitaria de Formación del Profesorado, 86, 63-76. Recuperado de http://www.redalyc.org/articulo. oa?id=27447325005.

ter Halle, A., Ladirat, L., Martignac, M., Mingotaud, A. F., Boyron, O. \& Perez, E. (2017). To what extent are microplastics from the open ocean weathered? Environmental Pollution, 227, 167-174. doi:10.1016/j. envpol.2017.04.051.

Wang, J., Peng, J., Tan, Z., Gao, Y., Zhan, Z., Chen, Q. \& Cai, L. (2017). Microplastics in the surface sediments from the Beijiang River littoral zone: Composition, abundance, surface textures and interaction with heavy metals. Chemosphere, 171, 248-258. doi:10.1016/j.chemosphere.2016.12.074. 


\section{Anexo 1:}

Plásticos en el medio ambiente

Cuestionario sobre la actividad (19/06/2018)

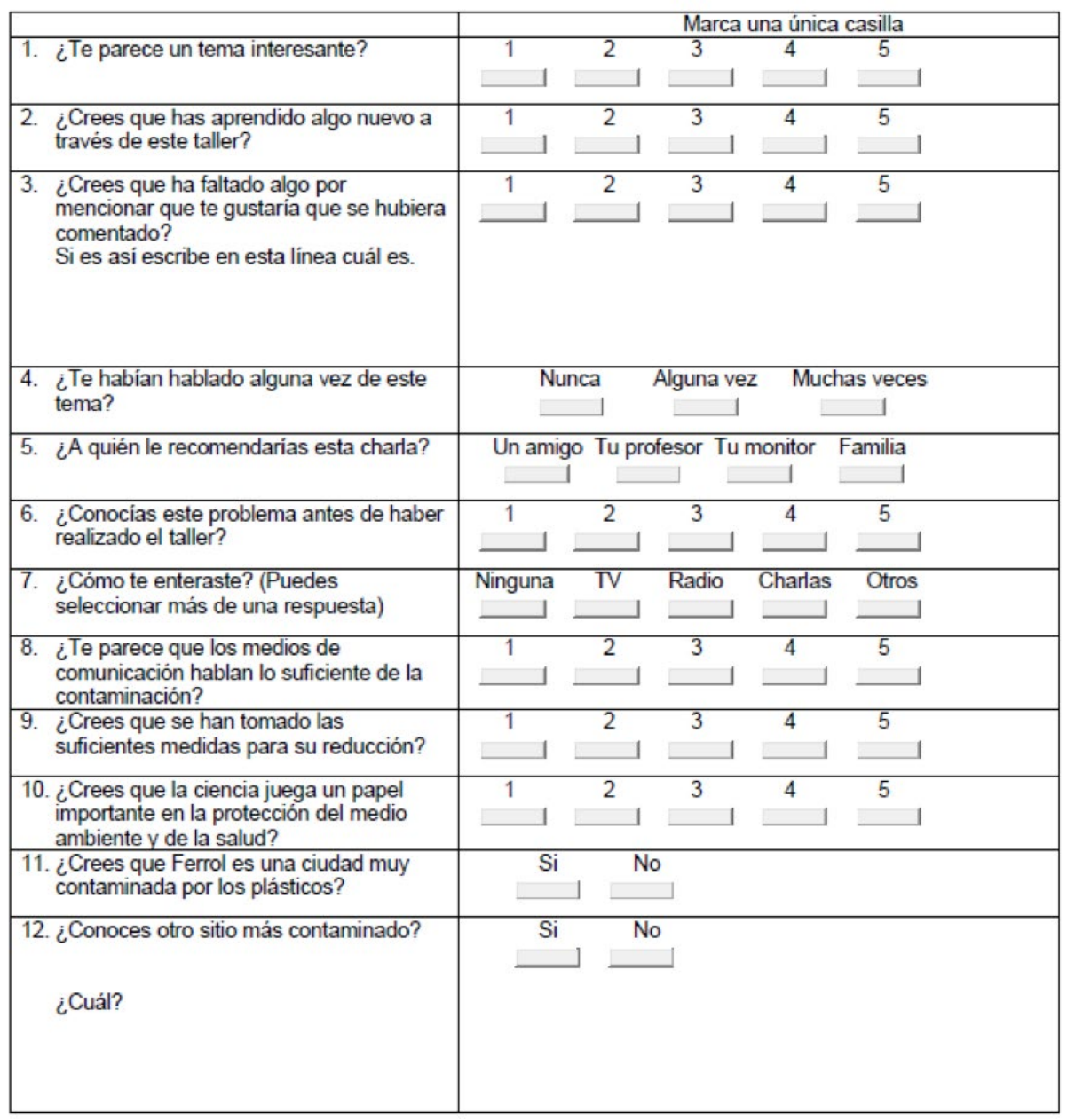


Plásticos en el medio ambiente

Cuestionario sobre la actividad (19/06/2018)

Personal del centro

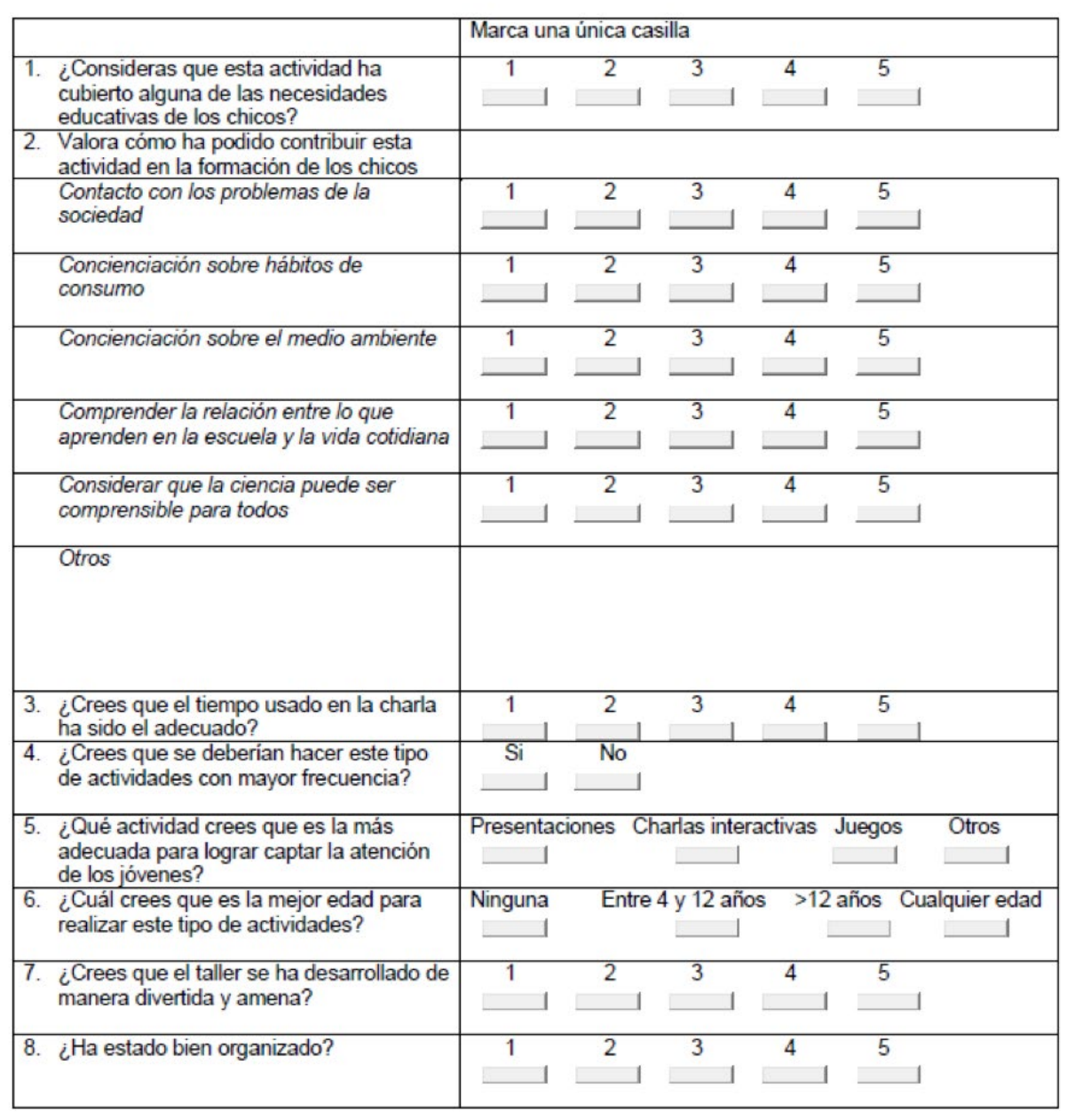





\title{
Estudio de viabilidad técnico-económico para sistema de trigeneración a partir de biogás en explotación ganadera
}

\author{
María Fandiño Sánchez ${ }^{1}$
}

\section{Resumen}

En el presente documento se expone un análisis técnico y económico para implantar un sistema de trigeneración que funcione con biogás en una explotación ganadera situada en Curtis. Actualmente la granja está en activo produciendo leche. Con este proyecto, se pretende reducir los costes de producción de la explotación ahorrando energía producida por la planta de biogás.

A lo largo del trabajo, se valoran las diferentes opciones técnicas disponibles en el mercado y se hace una elección final en base a las ventajas que presente. Finalmente, se hará un plan económico para evaluar la viabilidad del proyecto.

En este caso y aun teniendo en cuenta que el presupuesto estimado era alto, el resultado ha sido viable en cada uno de los escenarios evaluados: un escenario pesimista, un escenario normal y un escenario optimista.

Palabras clave: Purines, biogás, trigeneración, viabilidad económica.

\footnotetext{
${ }^{1}$ Tutores/as del TFG: María Sonia Bouza Fernández e Antonio Couce Casanova.

*Datos para citación: Fandiño Sánchezo, María (2019). “Estudio de viabilidad técnico-económico para sistema de trigeneración a partir de biogás en explotación ganadera". En Oficina de Medio Ambiente UDC (ed.), I Premio UDC Sustentabilidade a traballos fin de grado e mestrado 2018. A Coruña: Universidade da Coruña, 37-46. DOI de la obra: https://doi.org/10.17979/spudc. 9788497497831.
} 


\section{Introducción}

En la actualidad, Galicia se sitúa entre las regiones con mayor producción de leche, ya no solo a nivel estatal sino también a nivel mundial si analizamos la relación entre el volumen de producción y la población. Por todos es sabido, que estamos hablando de un sector sacrificado, en donde cada vez es más difícil sacar beneficios dignos. Estas dificultades vienen generadas, principalmente, por la constante subida de los combustibles fósiles, el aumento de los costes de la alimentación del ganado, la energía eléctrica y el bajo precio de la leche.

Además, por todos es sabido, el efecto negativo que tienen los gases contaminantes provenientes de aerosoles, vehículos o actividades industriales sobre el medio ambiente y el calentamiento global, pero en ocasiones no se tiene tal conocimiento sobre los efectos de los gases que emiten algunos animales como las vacas. El sistema digestivo de las vacas, posee un tipo de bacterias que llevan a cabo un tipo de fermentación y como resultado obtienen el metano. Este metano es eliminado por dichos animales a través de sus excrementos, flatulencias o eructos.

En la fermentación de los purines mueren muchos patógenos, malas hierbas y eliminamos el mal olor característico de dichas deyecciones pero también el digestato es mineralizado de forma que las plantas lo asimilan de forma más sencilla.

El objetivo de este proyecto es analizar la viabilidad técnica y económica de la instalación de una planta de biogás usando los excrementos del ganado bovino. En la planta instalaremos un sistema de trigeneración, es decir, produciremos energía eléctrica, calor y frío. Con el aprovechamiento de este subproducto y tras pasar por un proceso de fermentación, haremos uso del metano y colaboraremos con el cuidado del medio ambiente ya que este compuesto es el principal causante del efecto invernadero. El desarrollo de este proyecto nos permitirá ahorrar la energía que actualmente se consume en la explotación y además seguir teniendo las propiedades de abono antes de sacarle rendimiento.

\section{Análisis de soluciones}

En este proyecto, se han valorado diferentes fuentes de energía renovables como la energía solar, la geotérmica o incluso la eólica, pero fueron descartadas por depender del clima, proporcionarnos calor y no electricidad o por situarse lejos del punto de consumo, respectivamente. Un argumento de peso que hizo decantarse por el uso de la energía proveniente de la biomasa (en este caso el biogás), fue el contenido en metano de dicho subproducto 
(mal llamado a veces "residuos") y además es una fuente continua ya que las vacas están estabuladas. Pero, antes de seguir: ¿Qué es el biogás?

El biogás es un gas que se forma gracias a la degradación de la biomasa en condiciones de ausencia de oxígeno. Este proceso se denomina digestión anaeróbica y el componente en la que se lleva a cabo se llama digestor anaeróbico. El biogás está formado aproximadamente por:

- $50-75 \%$ de metano

$\cdot 25-50 \%$ de $\mathrm{CO}_{2}$

- Trazas de vapor de agua, oxígeno y sulfuro de hidrógeno $\left(\mathrm{H}_{2} \mathrm{~S}\right)$

El biogás se puede transformar en biometano, un gas con $98 \%$ de metano, que puede ser utilizado de la misma forma que el gas natural (Ecobiogás, 2018).

\section{Y por otro lado, ¿Cómo se produce?}

El biogás se produce al introducir en un recipiente hermético, materia orgánica junto con los microrganismos encargados de degradarla. Estos microrganismos se pueden encontrar en el aparato digestivo de los rumiantes. A continuación, se muestra una lista no exhaustiva de algunos productos que se pueden utilizar como materia prima para un digestor anaeróbico.

- Purines, estiércol, excrementos de aves...

- Plantas, hierba, maíz, patatas...

- Restos orgánicos de comida, poda y trabajos hortícolas, restos de mataderos, aceitas usados, suero de leche...

Antes de añadir la materia prima al digestor, es recomendable reducir su tamaño por medios mecánicos a trozos de pocos centímetros (en el caso de que la materia orgánica sea por ejemplo restos de poda). Esto facilita su degradación y acelera el proceso.

El proceso de digestión anaeróbica suele llevarse a cabo o bien en torno a 35으 durante al menos 1 mes (digestión mesofílica) o bien en torno a 55으 durante al menos 1 semana (digestión termofílica).

\section{Solución adoptada y resultados}

Como ya hemos comentado en la sección anterior, nos hemos decantado por el uso de biogás para intentar generar la demanda energética de la 
explotación. Por lo tanto, el objetivo será hacer un análisis de los elementos que componen una planta de biogás, pero sin olvidarnos de la parte económica.

Para comenzar, expondremos las zonas de las que se compone una planta de biogás. Estas se pueden ver en la Figura 1.

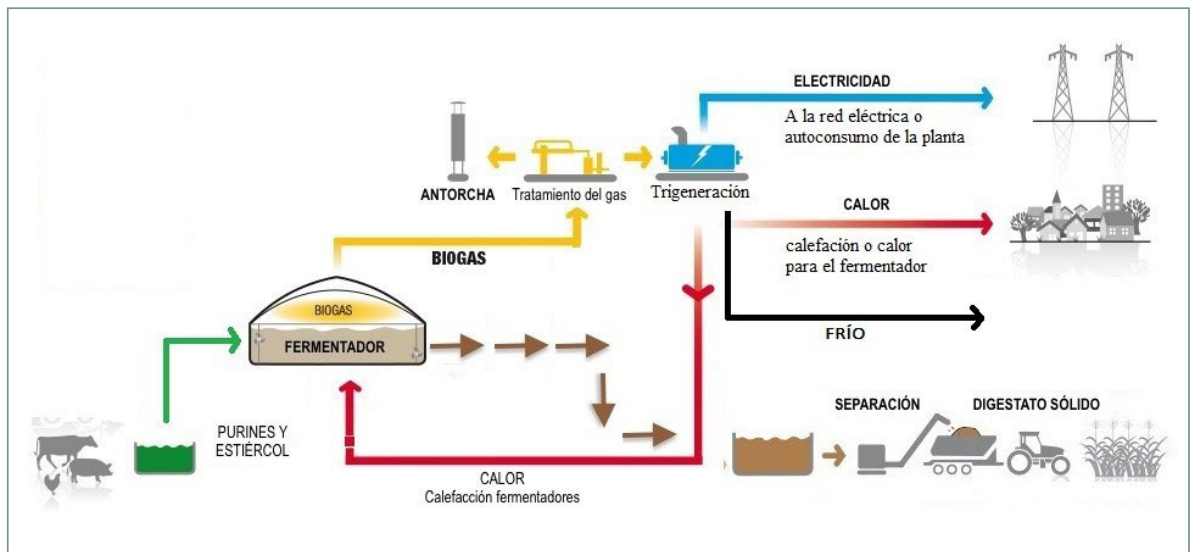

Figura 1. Esquema general de planta de biogás. Fuente: Elaboración propia.

Tenemos en primer lugar una zona en donde, está depositado el purín generado por las reses. La materia orgánica deberá ser trasladada a la siguiente etapa que será la de digestión. En esta etapa, un volumen determinado estará dentro del recipiente (el biodigestor, digestor o a veces llamado también reactor) a una temperatura fijada durante un tiempo determinado (Ilamado tiempo de retención). Tras este proceso que consta de cuatro etapas, procedemos a considerar que menos obtenido el biogás generado por dicha cantidad de materia y por lo tanto podremos vaciar el digestato (término utilizado para referirnos al purín que ha pasado por el proceso de digestión) y dejar paso a una nueva carga de digestor. Este digestato será trasladado par un depósito, fosa o zona de almacenamiento a la espera de que el ganadero haga uso de él como fertilizante para los prados. Por otro lado, tenemos el biogás producido, sin embargo, todavía no está en condiciones óptimas para su uso ya que posee partículas indeseables en su composición. Por ello habrá en la planta una zona destinada para el tratamiento del gas. En esta zona se eliminará el ácido sulfúrico, el contenido en agua y en dióxido de carbono excesivo. Este proceso evitará el daño de las máquinas en un futuro. Una vez tratado el biogás, este podrá ser comprimido y almacenado en tanques para su posterior uso y/o ser consumido en la zona de generación (Bridgewater, 2009). 
En este proyecto, esta zona se compone de un motor de micro-cogeneración (hablamos de micro-cogeneración por estar tratando con potencias inferiores a $50 \mathrm{~kW}$ ) que nos proporcionará energía eléctrica y energía térmica debido al aprovechamiento de los gases de escape del equipo. Por otro lado, contaremos con un grupo de absorción, el cual, nos proporcionará frío. De este modo tendremos el sistema de trigeneración funcionando con el biogás producido en la explotación. La energía eléctrica será destinada para el motor del bombeo de agua que actualmente está instalado, para el motor de ordeño o los motores de limpieza. La energía térmica será usada para calentar el agua de limpieza de las instalaciones y a la vez para calentar el propio biodigestor. El frío generado por el grupo de absorción, lo destinaremos al tanque de frío encargado de conservar la leche.

En este proyecto para trasladar la materia orgánica de la primera zona de almacenaje de materia orgánica a la zona de digestión se ha decidido hacer uso de una bomba de desplazamiento positivo ya que nos cumple las necesidades técnicas y en términos económicos es muy similar al tornillo sin fin. En el caso de la elección de biodigestor, nos hemos decantado por un biodigestor con gasómetro incorporado (permitirá almacenar el biogás además de contar con depósitos para tal fin) consta de 3 orificios uno por donde se introduce la materia orgánica, otro por donde se vacía y otro por donde se extrae el gas. En este caso carece de agitador ya que la mezcla usada es homogénea y la propia generación de biogás genera movimiento en el interior. Existen varios materiales para la construcción de dicho elemento.

En este proyecto nos hemos decantado por un poliéster reforzado ya que es ligero y de gran resistencia, lo que nos cumple con las necesidades técnicas que a la vez nos proporciona buen precio con respecto por ejemplo al acero inoxidable. Todas estas instalaciones contarán con tuberías, válvulas y accesorios preparados para soportar las condiciones ambientales de la zona en la que sean instalados y además quedarán instaladas de forma que el mantenimiento o la sustitución de dichos elementos es sencillo. En cuanto al equipo de micro-cogeneración, será un motor de combustión que funcione con biogás y un equipo de absorción. Además (aunque no está en el alcance de este proyecto), la planta dispondrá de una zona de control en donde tendrá instalado un PLC encargado de tratar todas las señales obtenidas de la planta para tener monitorizado todo el proceso a través de un scada por ordenador y tener las variables controladas.

Para el dimensionamiento del biodigestor tendremos en cuenta la relación 1:1 que deberá cumplir la mezcla de agua y purín, la cantidad de biomasa disponible, el volumen en que esta genera, el volumen en el digestor y el volumen de biogás producido. Sumando los dos factores nombrados obtenemos el volumen del digestor. En este caso los cálculos se pueden 
contemplar con detalle en el documento completo del TFG. En este proyecto el biodigestor tendría un volumen de $168 \mathrm{~m}^{3}$. Para hacernos una idea de las equivalencias y cantidades que manejamos comentaremos que:

- Se estima que cada vaca produce unos $15 \mathrm{~kg}$ diarios de materia orgánica (según el IDAE, 2011, 2018). Es necesario saber que dicha cantidad es conservadora con respecto a la realidad y que aproximadamente el porcentaje de materia seca en el purín es de un $8 \%$ aproximadamente y que el porcentaje de los sólidos volátiles respecto a la materia seca es de un $80 \%$ (Salcedo et al., 2018).

- $15 \%$ equivalen a $0,6 \mathrm{~m}^{3}$ diarios de biogás.

- 0,6 $\mathrm{m}^{3}$ de biogás producen $1 \mathrm{kWh}$ de electricidad (si el equipo de microcogenereración tiene un rendimiento estimado del 37\%).

En nuestro caso para satisfacer la demanda eléctrica necesitamos unos $30 \mathrm{~m}^{3}$ de biogás y según los cálculos realizados (para este caso en concreto de la explotación que tomamos de referencia) diariamente obtendríamos unos $48 \mathrm{~m}^{3}$ de biogás.

Para el dimensionamiento del equipo de microcogeneración, nos fijaremos en la gráfica de la demanda eléctrica actual de la explotación, ignorando el posible pico de demanda que presente (para sacarle el mayor rendimiento al quipo adquirido). Seleccionaremos el equipo de forma que trabajando a pleno rendimiento y por encima de la mitad de las revoluciones totales del equipo sea capaz de generar electricidad para cubrir la mayor superficie por debajo de la curva que describe nuestra demanda. En nuestro caso el equipo de micro cogeneración puede ser de un $10 \mathrm{~kW}$.

Una vez hecho el análisis técnico y valorando los elementos que componen la planta, hemos estimado un presupuesto de aproximadamente $220.000 €$.

Como ya hemos comentado en varias ocasiones, este proyecto consiste en el estudio técnico y económico y tras obtener el presupuesto, nos encontramos en disposición de hacer un plan de viabilidad.

Primero hemos analizado todos los ingresos que tiene la explotación (en este caso exclusivamente de la venta de leche) y posteriormente hemos calculado los gastaos que presenta la explotación. Hemos valorado el proyecto en 3 escenarios diferentes, es decir, un escenario pesimista, normal y optimista, considerando los precios según dichos escenarios. Cabe destacar que también se ha valorado el proyecto financiado por una entidad bancaria sin financiar. En la Figura 2 se presenta un resumen de los principales parámetros económicos utilizados en el análisis y en la Tabla 1 los resultados para cada escenario. 
El primer escenario que se valora es un escenario pesimista. En él, se valoraría la hipótesis de que el precio de la leche alcance mínimos, el precio de la materia prima (pienso, servicios de alimentación de la cooperativa, etc.) sean altos y que el precio de la electricidad (para los picos que la planta no sea capaz de cubrir) sea máximo también. En cuanto a la calidad del purín, consideramos que se trata de una pésima calidad. Temiendo en cuenta esos factores, se concluye que el proyecto es viable tanto si el proyecto es financiado como si no. La diferencia entre los dos casos es el período de recuperación de la inversión. En el caso del proyecto sin financiar serían 4 años y con financiación sería de 2 años.

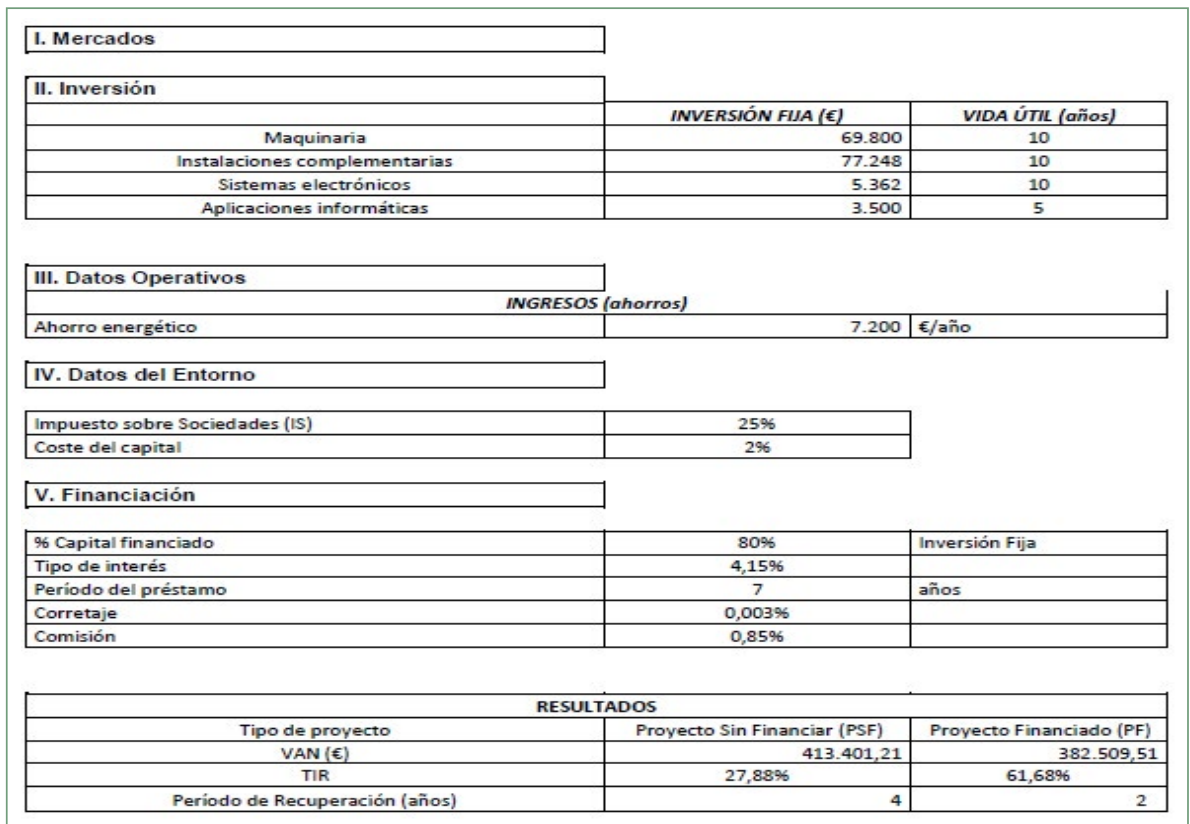

Figura 2. Resumen de los parámetros económicos.

En el escenario normal la conclusión es la misma que en el caso anterior. Se tienen en cuenta precios medios de los últimos 6 años. De nuevo el período de recuperación sin financiar es de 4 años y con el proyecto financiado sería de 2 años. Varía también los valores del Valor Actual Neto pero siempre es muy positivo.

En el escenario restante (optimista) las hipótesis son inmejorables. Se supone que el precio de la leche alcanza máximos, que el purín es de una calidad inmejorable, que el precio de las materias primas es mínimo al igual que 
el de la electricidad. Previsiblemente, y tras haber analizado los escenarios anteriores, se confirma la viabilidad del proyecto. En este caso el período de recuperación de la inversión sería de 3 años en el caso de no financiar el proyecto y de 1 año en el caso de ser financiado.

Tabla 1. Resultados del análisis económicos para cada escenario.

\begin{tabular}{lcc} 
Tipo de proyecto & Proyecto sin financiar (PSF) & Proyecto financiado (PF) \\
Escenario pesimista & $413.401,21$ & $382.509,51$ \\
VAN $(€)$ & $27,88 \%$ & $61,68 \%$ \\
TIR & 4 & 2 \\
Periodo recuperación (años) & $453.908,74$ & \\
Escenario normal & $32,79 \%$ & $420.393,99$ \\
VAN (€) & 4 & $90,42 \%$ \\
TIR & & 2 \\
Periodo recuperación (años) & $513.739,79$ & $479.407,68$ \\
Escenario optimista & $42,09 \%$ & $169,09 \%$ \\
VAN (€) & 3 & 1 \\
TIR & & \\
Periodo recuperación (años) & 4 & \\
\hline
\end{tabular}

Por lo tanto, obtenidos los datos anteriores, observamos que tenemos sobreproducción de biogás y llegará un punto en el que los tanques se llenen. Por ello, es interesante barajar otras alternativas para consumir parte de ese biogás sobrante.

\section{¿Qué alternativas podemos proporcionar?}

- Circuito de calefacción: Podemos aprovechar la energía eléctrica para poner a funcionar un sistema de calefacción como puede ser la aerotermia. La aerotermia, se basa en extraer energía gratuita del aire exterior mediante una bomba de calor invertir de alta eficiencia. Recordemos que, una bomba de calor, extrae energía de un lugar para cederla. Y para ello, se necesita una unidad exterior y una o varias unidades interiores. Cualquier temperatura por encima del cero absoluto $(-273.15 \circ C)$ contiene energía que un equipo de aerotermia puede utilizar.

Este sistema sustituiría al sistema de calefacción actual de la vivienda. Además, existen sistemas que aprovechan los radiadores 
ya instalados en los edificios. Por lo tanto, es una propuesta que no requiere gastos en cuanto a obras, pero sí la inversión del equipo. Generalmente, son equipos discretos y poco voluminosos.

- Verter electricidad a la red: Otra opción que se propone es la venta de nuestra sobre producción a la red eléctrica. Hace pocos años, la totalidad de energía eléctrica generada por particulares y vertida a la red, era comprada a un precio digamos que, generoso. Actualmente, el precio que pagan las eléctricas es mínimo, como se puede consultar en las tarifas en el Real Decreto 66/2007 (BOE, 2007). A esto, le sumamos que la distribuidora eléctrica nos puede exigir la instalación de un centro de transformación para elevar la tensión y verterla en la denominada media tensión. Esta instalación surge de que previamente la distribuidora nos comunique que la línea de baja tensión nos presentaría ciertas dudas y requeriría de un estudio exhaustivo antes de realizar la inversión en los equipos necesarios.

- Combustible (AEB, 2018): En la actualidad, quizás sea la forma más eficaz de reducir el gasto en nuestros coches. Si en el domicilio, disponemos de coches a gasolina, podremos invertir en añadirles un sistema de alimentación en paralelo. El coche conservará la instalación de gasolina pudiendo cambiar en cualquier momento de un combustible a otro. Además, añadiremos que la combustión de este gas es mucho más limpia.

Talleres especializados realizan hoy en día estas modificaciones que rondan los $2500 €$ (sujeto a variaciones según coche, modelo, etc.).

Para que nos hagamos una idea: se estima que la amortización del sistema de alimentación del motor por gas se produce en unos 25.000 km.

- Verter a la red de gas natural (AEB, 2018): Si la localización lo permitiese, aplicando un tratamiento de purificación más exhaustivo del biogás, este podría ser vertido a la red de gas natural.

\section{Conclusiones}

Finalmente, tras el análisis tanto técnico como económico de la instalación de una planta de biogás de las características citadas, podemos concluir que sí que es viable implantarla sea cual sea el escenario a analizar. Por lo tanto, la explotación ganadera puede ser abastecida con la energía generada con el purín del ganado bovino. 


\section{Bibliografía}

BOE (2007). Real Decreto 661/2007, de 25 de mayo, por el que se regula la actividad de producción de energía eléctrica en régimen especial.

IDAE (2018). Biomasa y biogás. IDAE Disponible en: http://www.idae. es/tecnologias/energias-renovables/ uso-termico/biogas. [Consulta 12 Octubre 2018]

IDAE (2011). Situación y potencial de generación de biogás. Estudio Técnico PER 2011-2020. IDAE, Madrid. Disponible en: http://www.idae.es/uploads/documentos/documentos_11227_e16_biogas_db43a675.pdf [Consulta 12 Octubre 2018].

Ecobiogás (2018). Disponible en: http://www.ecobiogas.es/archivos/es/biogas_biogasienergia.php [Consulta 1 Octubre 2018].

Salcedo, G., Martínez-Suller, L., Tejero,I., Rico, C. (2018). Composición química del purín en las explotaciones lecheras de Cantabria y su relación con la nutrición. Disponible en: https://issuu.com/axoncomunicacion/ docs/20-bov-composicion-quimica-purin [Consulta 3 Octubre2018].

AEB (2018). Asociación Española de Biogás. Disponible en: http://www.aebig.org/ [Consulta 25 Octubre 2018].

BRIDGEWATER, A. (2009). Energías alternativas: handbook, 1a ed. Madrid, Paraninfo. 


\title{
Consumamos valores.
}

\section{Proxecto educativo sobre}

\section{consumo responsable e cultura da sustentabilidade. Dende e para unha UDC libre e ecolóxica}

\author{
Eva Paola Bermúdez Porras ${ }^{1}$
}

\section{Resumo}

Alexander von Humboldt, considerado pioneiro da ciencia ecolóxica por Jorge Riechmann, dicía: "Nas montañas está a liberdade. As fontes de degradación non chegan ás rexións puras do aire. $O$ mundo está ben naqueles lares onde o ser humano non alcanza a turbalo coas súas miserias". Quizais non é a afirmación máis idónea para comezar un TFG (xa que podemos poñer en cuestión a segunda afirmación do xeógrafo polímata), pero creo que é a afirmación que máis pode facernos reflexionar.

Este traballo pretende aportar información sobre o problema socioecolóxico e a necesidade de cambiar de paradigma e tomar parte activa no cambio. Sobre a relevancia dos movementos sociais, do papel da Universidade e a Educación como motor de cambio, e finalizará cun Proxecto Educativo para a comunidade universitaria, Consumamos valores, sobre consumo responsable e a cultura da sustentabilidade, que emprega as TICs e as Artes como ferramentas principais e invita ás persoas destinatarias a ser axentes activos en todo momento, reflexionar sobre as verdadeiras necesidades, o valor e o prezo das nosas accións, e cuestionar o sistema.

\footnotetext{
${ }^{1}$ Titora do TFG: Araceli Serantes Pazos

*Datos para citación: Bermúdez Porras, Eva Paola (2019). “Consumamos valores. Proxecto educativo sobre consumo responsable e cultura da sustentabilidade. Dende e para unha UDC libre e ecolóxica". En Oficina de Medio Ambiente UDC (ed.), I Premio UDC Sustentabilidade a traballos fin de grado e mestrado 2018. A Coruña: Universidade da Coruña, 47-52. DOI da obra: https://doi.org/10.17979/ spudc. 9788497497831 .
} 
Este traballo pretende unha UDC libre e unha cidadanía crítica e comprometida. Non queremos unha fábrica.

Palabras clave: consumo, universidade, proxecto educativo, transición ecolóxica.

\section{Introdución}

Hoxe en día escóitase e faise referencia á problemática ambiental diariamente en diversos contextos, como por exemplo: ao falar sobre a deforestación ou a implantación de especies invasoras en Galicia, a problemática dos plásticos nos océanos, a extinción de especies, incluso ao falar de enfermidades faise referencia - de xeito implícito - á problemática ambiental. Tamén ao falar do tempo e o seu desaxuste (unha evidencia sobre o conflito ambiental que non se pode ignorar). Todo o ser humano está afectado por esta problemática, dun xeito ou doutro.

As persoas científicas levan décadas avisando da problemática que está a evidenciarse con máis intensidade, metendo presión aos gobernos (que incumpren sistematicamente acordos previamente firmados en favor de empresas multinacionais e modelos de produción e consumo contraditorios á saúde pública). Pero, cal é a información recibida polo resto da poboación? Ten o alumnado universitario información sobre a problemática? Cales son as accións para mitigar o problema?

Dende o experimentado a nivel persoal, a información relativa ao tema na escola era moi básica: reciclaxe, aforro de auga... E moitas veces insuficiente (xa que nas casas non se apoiaba o traballo ou incluso as propias escolas non o sinalaban máis que puntualmente). Non foi ata o primeiro ano de Educación Social que, grazas á materia de Educación Ambiental e Cultura da Sustentabilidade aumentou a información e, por tanto, a sensibilidade respecto ao tema. Anos máis tarde, nunha pequena estancia en Nepal e pola posibilidade de coñecer outras realidades máis evidentes, intensificouse o interese pola Educación Ambiental, coñecendo unha realidade lastrada polas propias condicións (condicións creadas en Occidente) e o que provocou que a Educación Ambiental fose o punto principal do Traballo de Fin de Grao co que rematar Educación Social. A idea era realizar un proxecto de Educación Ambiental en Nepal, coa intención de, nun futuro, poñelo en marcha. Sen embargo, meses despois (tras moitas conversas e unha visita á Granxa Ecolóxica de Arqueixal) a temática virou coa lóxica de: por que pretender un cambio na outra punta do mundo cando aquí mesmo, tendo as posibilidades, non facemos o necesario para cambiar e transformar o mundo? E así xurdiu a idea 
de realizar un proxecto educativo para a propia Universidade da Coruña. Unha institución idónea para comeza o cambio.

\section{Xustificación teórica}

A problemática ambiental, o principal tema de estudo en liñas xerais, afecta tanto aos ecosistemas como aos seres vivos que neles habitan. 0 ser humano é vítima nesta situación, xa que esta cuestión está a afectarlle gravemente. Pero non só pode considerarse vítima, senón tamén o principal causante, debido ao que se coñece como impacto ambiental "a modificación do ambiente ocasionada polas accións do home ou da natureza" (GRN, 2018). Por isto, á problemática ambiental tamén é definida como unha problemática socioecolóxica (a "ecoloxía" é a rama da bioloxía que estuda as interaccións dos seres vivos co medio ambiente, e a problemática socioecolóxica, como di Ramon Folch, son "conflitos ambientales de orixe social") (Folch, 1998).

O impacto é de tal magnitude que incluso se fala de estar nunha nova era xeolóxica chamada Antropoceno, consecuencia da intersección do despregamento do sistema urbano- agro- industrial a escala global e un incremento esaxerado da poboación mundial totalmente insostible. (Fernández Durán, 2011). Ademais, un sistema económico que (atendendo aos intereses das grandes corporacións e pese ás evidencias e necesidades reais do planeta) precisa "crecer sen fin" mesturado cun planeta finito só pode levar a un colapso socioecolóxico.

Como di José Sacristán de Lama "Se se reduce o consumo, o sistema non funciona, e se non se reduce esgótanse os recursos" (citado en Santiago Muíño, 2016). Mentres se continúe nun sistema que engade dificultades a promover unha aprendizaxe de emerxencia para intentar mitigar os efectos do impacto ambiental, con presións estruturais como a financiarización delirante, a sucesión de burbullas especulativas, a explosión da débeda, a concentración da extrema riqueza, o socavamento da soberanía política, a redución do mercado de traballo, o encarecemento da enerxía e dos materiais básicos, a degradación dos recursos naturais, a hexemonía económica global, os fallos da UE e a perda do poder da clase traballadora, é preciso persoas conscientes da problemática, críticas e comprometidas. Persoas que constrúan unha sociedade que sexa capaz de cambiar de paradigma e superar o analfabetismo ecolóxico e político do que se benefician "os de sempre" e que sufre o resto (Santiago Muíño, 2016).

Coñecer en que consisten os movementos para a Transición Ecolóxica, como o Decrecemento, a Permacultura, o movemento Slow, as Ecoaldeas, e ter o 
dereito e o acceso para aprender sobre Economía Ecolóxica, Ecoloxía Política ou Biomímese.

Aprender dos movementos sociais, que son os que levan á praxe todo o que se teoriza nas aulas de Educación Social, e grazas aos cales están a levarse a cabo tantas loitas. Como os movementos indíxenas (por exemplo, da man de Rosalina Tuyuk), o Ecofeminismo (con Vandana Shiva), o Movemento dos Trabalhadores sen Terra (con persoas involucradas como Marcos Sorrentino ou Simone Portugal) ou o movemento zapatista que creou Escolas que promoven a identidade cultural e o coidado ao medio ambiente con ámbitos como a Agro-ecoloxía, e praxe real con actividades de colaboración coa comunidade (o que se chamaría na universidade occidentalizada, proxectos de ApS) (Roma, 2002).

É preciso aprender sobre a necesidade de Repensar o actual modelo de vida occidental e os seus hábitos de consumo, Reducir (ao máximo posible todo o que realmente non é necesidade), Re-utilizar (recuperar esa práctica de sensatez, ben sexa dando novos usos aos obxectos, realizando intercambios con coñecidos ou coa compra-venta de segunda man), Reciclar (aquelo que de verdade non tivo outra opción anterior). A medio prazo as persoas deberían estar familiarizadas co Rot ('compostar' en inglés) e a longo prazo Reestruturar o sistema económico e Redistribuír as riquezas do planeta.

\section{O papel da Universidade}

Dende a Universidade da Coruña, procúranse maiores niveis de benestar para o conxunto da sociedade mediante a formación unha cidadanía aberta, culta, crítica, comprometida, democrática e solidaria. A UDC conta con materias con temáticas ambientais (sobre Ecoloxía, Sustentabilidade...) en todas as súas áreas de coñecemento (Artes e Humanidades, Ciencias, Ciencias da saúde, Ciencias sociais e xurídicas, e Enxeñería e Arquitectura). Tamén conta coa Oficina de Medio Ambiente (OMA), a cal ofrece unha gran cantidade de servizos, como se pode comprobar mediante as súas Memorias de xestión: Programa de Divulgación ambiental, Programa de préstamo de bicicletas, Programa de compostaxe e residuos, Programa Green Campus... e un Plan de Sustentabilidade (a Guía para a Sustentabilidade Ambiental na UDC) polo cal se debe rexer a Universidade. Varias das Facultades (a de Educación, por exemplo) locen a súa bandeira verde orgullosa de contar co recoñecemento do Green Campus, e incluso participa nos 'rankings' internacionais GreenMetric (onde a organización compara o empeño das universidades cara a sustentabilidade ambiental).

Débese recoñecer o traballo que está a realizar a Universidade, poñelo en valor e dignificar a institución. Pero non pode conformarse co recoñecemento 
formal cando o cambio non foi instaurado nas bases. A Universidade non introduce unha consciencia real nas persoas que pasan polas súas aulas. Hai cambios e melloras, e sobre todo formación sobre temas moi concretos e especializados, pero o sistema continúa a ser o mesmo, e o neoliberalismo (que atenta contra a propia sustentabilidade e a vida en toda a súa concepción) sigue a inculcarse na institución (que procura unha cidadanía crítica pero adaptada ao mercado laboral coa fin de axustarse ao establecido). Polo que o traballo da Universidade non pode ser considerado suficiente, xa que falta o máis importante da sustentabilidade: a pedagoxía para toda a cidadanía. E pódese comprobar esta falta de consciencia nas prácticas das persoas que conforman a institución (basta con acudir a calquera das Facultades para comprobar que o gasto enerxético, o uso dos plásticos, os pésimos hábitos saudables e alimentarios, son contrarios a calquera bandeira verde ou a calquera recoñecemento que se lle queira ofrecer á Universidade, que pode merecela). Porque a institución conseguir cambios formais, mais non de base.

\section{Proxecto Educativo: Consumamos Valores}

Por todo iso, o Proxecto Educativo Consumamos valores trata sobre o consumo responsable e a cultura da sustentabilidade. Está destinado á comunidade universitaria (ao alumnado, o PDI e o PAS) e pretende abarcar diversas temáticas de interese para as persoas participantes, temáticas escollidas por todas de xeito democrático e aberto. Comeza cunha sesión sobre o problema socioecolóxico (onde aprenderemos sobre a temática con información e datos para introducir o tema e continuaremos con actividades para continuar aprendendo mediante o xogo, dun xeito activo e dinámico) e continúa coas sesións establecidas entre todas ese primeiro día (sesións que poden tratar a soberanía alimentaria, a industria téxtil, papelería e material escolar, produtos de hixiene e limpeza, consumo enerxético, transporte ou banca ética).

A última sesión non tratará un tema concreto senón servirá para facer un pequeno resumo sobre as temáticas que non se chegaron a tratar e realizar unha pequena festa- despedida, con comida e bebida que se axuste ao aprendido durante o curso (produtos locais, ecolóxicos e de comercio xusto) e unha pequena exposición de Arte para concienciar onde cada quen pode levar algo realizado durante o curso (xa que contará con diversos obradoiros relacionados coas temáticas das sesións), como algunha escultura, pintura, peza musical... E acompañarase a despedida con música de temática ambiental, coa que gozar e aprender.

Pero ante todo, comprender que o consumo é a mellor arma para combater as desigualdades e inxustizas que derivan dun sistema económico neoliberal e biocida, atentando contra a vida de todo ser. $O$ consumo é o mellor voto. 


\section{Referencias}

1. Fernández Durán, R. (2011). El Antropoceno. La expansión del capitalismo global choca con la biosfera. Barcelona: Virus editorial.

2. Folch, R. (1998). Ambiente, emoción y ética. Actitudes ante la cultura de la sostenibilidad. Barcelona, España: Ariel, S. A.

3. GRN (2018). Impacto ambiental. Impactos medio ambientales. Obtido de: http://www.grn. cl/impacto-ambiental.html (última consulta: 2019/09/30).

4. Roma, P. (2002). Jaque a la globalización. Cómo se crean su red los nuevos movimientos sociales y alternativos. Barcelona: Debolsillo.

5. Santiago Muíño, E. (2016). Rutas sin mapa. Horizontes de transición ecosocial. Madrid: Catarata. 


\title{
Análisis de una construcción con
}

\section{bambú y adobe.}

\section{Propuesta para la construcción de}

\section{una escuela en Quibdó}

\section{(Chocó, Colombia)}

\author{
Daniel Alejandro Franco García ${ }^{1}$
}

\section{Resumen}

Toda edificación, desde su fase de proyección hasta su construcción y utilización, debe tener en cuenta los aspectos culturales, ambientales, técnicos y socioeconómicos del entorno en el que se ejecuta. Por ello, y dadas las características particulares pero similares de los diferentes países de América Latina, surge la necesidad de aportar soluciones técnicas que ayuden a solventar los diversos problemas que presentan la mayoría de infraestructuras de la región.

En este trabajo fin de grado se analizan diferentes técnicas constructivas tradicionales de la zona, principalmente las que se basan en la utilización de bambú en la construcción de edificios de una o dos plantas. Por otro lado, se estudian los posibles criterios bioclimáticos a tener en cuenta para garantizar una adaptación óptima al clima local, que derive en conseguir el confort de los usuarios sin necesidad de un elevado consumo energético.

\footnotetext{
1 Tutor TFG: Santiago López Piñeiro.

*Datos para citación: Franco García, Daniel Alejandro (2019). “Análisis de una construcción con bambú y adobe. Propuesta para la construcción de una escuela en Quibdó (Chocó, Colombia)". En Oficina de Medio Ambiente UDC (ed.), I Premio UDC Sustentabilidade a traballos fin de grado e mestrado 2018. A Coruña: Universidade da Coruña, 53-65. DOI de la obra: https://doi.org/10.17979/ spudc. 9788497497831.
} 
Finalmente, se realiza una propuesta constructiva para un edificio de uso escolar basándose en las necesidades de la comunidad de Quibdó (Colombia) analizadas a través del trabajo de campo gracias a las becas PCR de la OCV. Con todo ello se obtiene un edificio-sostenible- que se adapta de la manera deseada a sus requisitos técnicos, bioclimáticos, ambientales y socioeconómicos.

Palabras clave: Bambú, Guadua Angustifolia Kunth, Muro tendinoso, Bioconstrucción, Sostenibilidad.

\section{Introducción}

El presente proyecto se realiza con el fin de colaborar con la ONG "Corporación Chocó Joven" en el marco de su proyecto educativo CEPA (Centro Educativo Pacifico) teniendo a su vez el apoyo de la Oficina de Cooperación y Voluntariado de la Universidad de A Coruña, que mediante las becas PCR2017 permitieron recabar información y realizar las reuniones oportunas para garantizar un proyecto participativo directamente en terreno.

La Corporación Chocó Joven realiza diferentes proyectos tanto en Quibdó como en zonas rurales del Chocó, siendo su principal proyecto el CEPA, cuyo objetivo es garantizar el derecho a una educación personalizada a niñas y niños provenientes de familias en riesgo de exclusión.

Actualmente el CEPA cuenta con aproximadamente cuarenta alumnos y alumnas entre preescolar y primaria, hasta el grado tercero de primaria, éste incluido. Provisionalmente, la Corporación Chocó Joven tiene en alquiler un edificio ubicado en el barrio de La Esmeralda (Zona Nororiental de Quibdó), que consta de cinco aulas, un despacho, una sala más amplia que se utiliza como salón multiusos y un pequeño patio donde están ubicados los baños y una pequeña estancia aislada que tiene la función de cocina.

El elevado costo que supone para la ONG el alquiler de este edificio no es proporcional al estado del mismo, ya que presenta unas condiciones deficientes para garantizar el confort de los ocupantes, así como para su correcta utilización. El principal problema resulta de una falta de drenaje o canalización de aguas pluviales del terreno en el que está ubicado y sus parcelas colindantes, generando la inundación parcial del edificio cuando la intensidad pluviométrica es media-alta. Esta deficiencia, unida a la característica de que Quibdó está catalogado como uno de los lugares más Iluviosos América, genera un grave problema para el desarrollo normal de la docencia y cualquier otra actividad que se pretenda desarrollar en el CEPA impidiendo así el cumplimiento de uno de los objetivos de sostenibilidad de la ONU, el de la educación de calidad. 
Dada esta situación, mediante este proyecto se pretende aportar unas soluciones constructivas para la ejecución de una edificación cuya utilización principal sea el uso educativo, cumpliendo los siguientes objetivos:

- Utilizar materiales locales, principalmente Guadua Angustifolia Kunth - Emplear técnicas constructivas respetuosas con el medio ambiente - Buscar una solución más económica que la construcción convencional - Aportar soluciones que garanticen el confort según las condiciones climáticas

A su vez, se propone un ejemplo de diseño arquitectónico del edificio que cubra las necesidades del CEPA, para analizar la aplicación de las propuestas constructivas aportadas y el posible cumplimiento o incumplimiento de los objetivos, así como un presupuesto aproximado de la ejecución material de la obra. En la Figura 1 se muestran imágenes del estado actual.
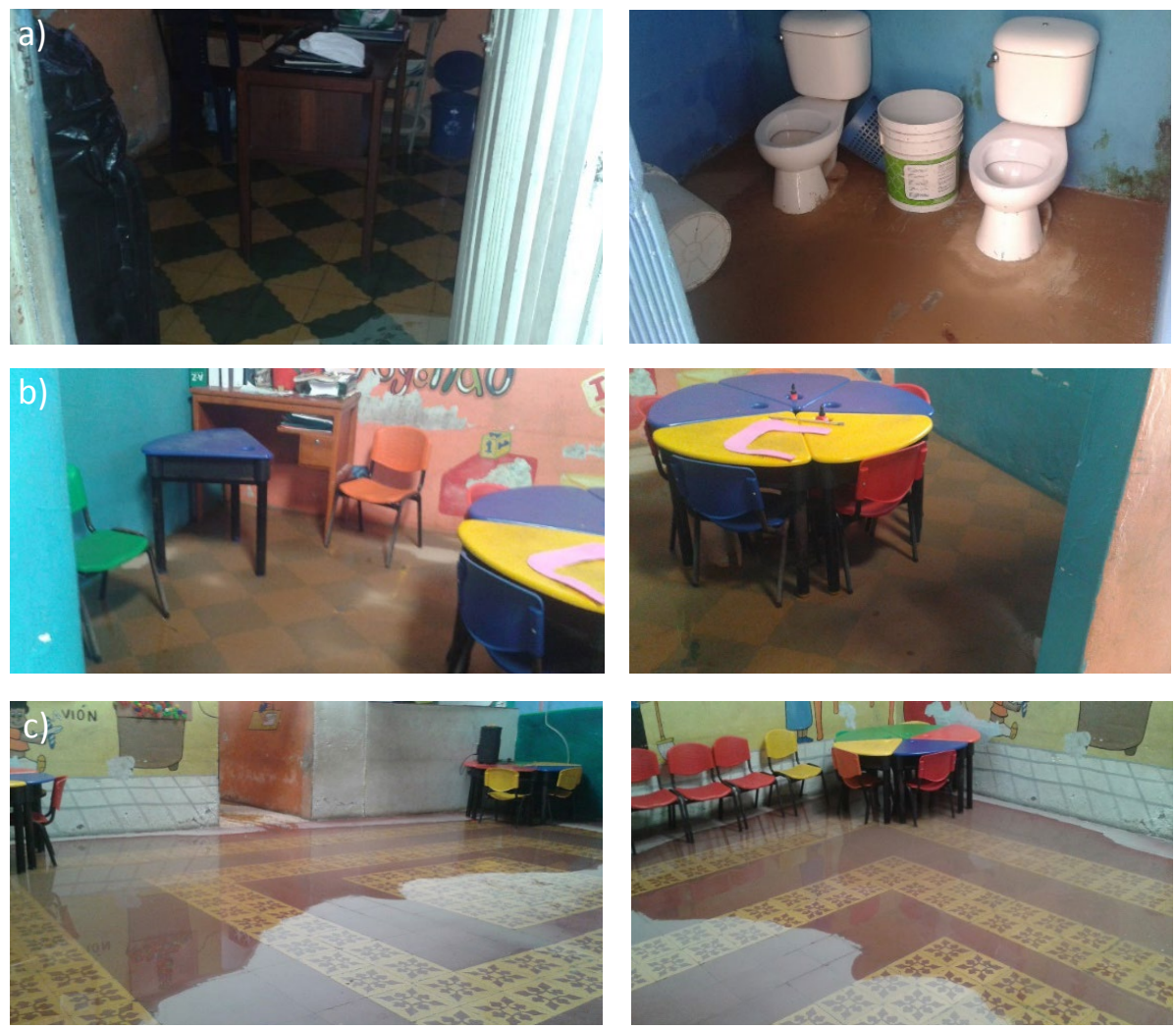

Figura 1. Estado infraestructura tras fuertes precipitaciones. a) Izquierda: despacho de dirección. Derecha: baños alumnos. b) Aulas primaria y preescolar. c) Aula multiusos. 


\subsection{El bambú}

La sostenibilidad es uno de los puntos fuertes del bambú. La posibilidad de ser cosechado sin matar la planta, su rápido crecimiento en menor espacio y con menos recursos que las maderas tradicionales, convierten al bambú en una alternativa a tener en cuenta desde el punto de vista ecológico. Es llamativa la comparación con la madera, ya que mientras el bambú se puede cosechar después de 3 a 5 años, las maderas coníferas necesitan de 10 a 20 años (Broto, 2014).

Según las normas ISO 22156 e ISO 22157-2 en el eje cafetero de Colombia se producen unas 78,3 t/ha/año, mientras que el rendimiento de la madera es aproximadamente de 17,5 t/ha/año. En cuanto a material neto, esto deriva en una producción de bambú de 36 t/ha/año por tan solo 10,8 t/ha/año de madera (Minke, 2012).

Un ejemplo claro lo plantea Eduard Broto en Bambú: Arquitectura y diseño (2014: P. 19): "En Costa Rica cada año se construyen 1.000 casas de bambú cultivado en una plantación de 60 hectáreas. Para generar la madera suficiente para construir el mismo número de casas se necesitarían 500 hectáreas de bosque tropical, en peligro de extinción".

En cuanto al uso de este material en Europa, puede considerarse que su transporte desde Colombia es un factor de costo energético y económico, pero se debe tener en cuenta que, a diferencia de la madera, la recolección y el procesamiento del bambú requiere muy poca energía. Es un material muy ligero, por lo que, al transportarlo en barco, causa poca contaminación ambiental en comparación con la madera. Por lo tanto, se considera que la huella ecológica del bambú importado es más baja que la de la madera (Minke, 2012).

Se pueden distinguir diferentes aportes del bambú a la mejora de su entorno y el medio ambiente global (Minke, 2012):

- Producción de Biomasa: en comparación con el eucalipto, el bambú puede producir mucha más biomasa por hectárea y por año, pudiendo llegar a cantidades de entre 2 a 4 toneladas por hectárea y por año. Esta cualidad des muy importante ya que ayuda a enriquecer y mejorar el terreno (Giraldo, s.d.). La producción de biomasa del bambú depende de diferentes factores por lo que puede presentar variaciones.

- Reducción de la erosión del terreno: el bambú tiene una densa red de raíces o rizomas que anclan la tierra y ayudan a disminuir la erosión producida por la lluvia y las inundaciones.

- Regula el nivel agua del suelo: acumula el agua en su tallo durante la estación lluviosa, usándola más tarde en la estación seca. Mediante los propios rizomas y las hojas desprendidas en el terreno, se produce 
un efecto similar al de una esponja, impidiendo que el agua fluya de manera rápida. De esta manera se genera un ecosistema en las orillas de los ríos cuyo funcionamiento es similar al de una bomba de almacenamiento del agua, por medio de "vasos comunicantes" (Giraldo, s.d.). Por ejemplo, una hectárea de Guadua Angustifolia puede retener hasta 30.000 litros de agua.

- Reduce la temperatura: en las zonas en las que está presente el bambú se produce una reducción de la temperatura del aire a través de la evaporación del agua gracias a sus hojas.

- Captación de $\mathrm{CO}_{2}$ : debido a su rápido crecimiento, el bambú puede asimilar más $\mathrm{CO}_{2}$ que un árbol, influyendo positivamente en el clima global. La Guadua Angustifolia Kunth puede absorber hasta 54 t de $\mathrm{CO}_{2}$ por hectárea durante sus primeros seis años de crecimiento. La función que realiza el guadual consiste en capturar el Dióxido de Carbono que hay en exceso y trasladarlo a su ciclo biológico, reteniéndolo dentro de su propia materia prima o trasladándolo al terreno (Giraldo, s.d.).

- Energía primaria: la producción de bambú consume $300 \mathrm{MJ} / \mathrm{m}^{3}$ de material mientras que la madera llega a consumir el doble, es decir $600 \mathrm{MJ} / \mathrm{m}^{3}$.

Es interesante además destacar las ventajas ambientales que presenta el uso de este material en la industria de la construcción. Un ejemplo de ello son los resultados que arroja la tesis de Felipe Villegas González (2005), en la cual realiza una comparativa del consumo energético necesario para construir una vivienda con Guadua frente a construirla con Hormigón armado.

El resultado que obtuvo fue que la opción del sistema constructivo con Guadua presentaba una reducción del consumo de energía cifrada en 46.482 MJ, avalando con ello que la utilización de este material en la construcción es claramente beneficiosa en términos ambientales.

Se puede decir que la Guadua, en comparación con materiales convencionales como el hormigón o el acero, presenta un ciclo de vida con menor carga medioambiental:

- Obtención de la materia prima: la Guadua es una planta con múltiples ventajas para su entorno, descritas más extensamente en puntos anteriores. Por el contrario, para la fabricación de hormigón o de acero, es necesario recurrir a un proceso industrial altamente contaminante.

- Transporte: al requerirse menor material y ser mucho más ligero, se ven igualmente reducidos los efectos nocivos sobre el medioambiente en esta fase. 
- Ejecución de la obra: por lo general las obras realizadas con Guadua son de menor duración que con materiales convencionales. Esto reduce el tiempo de utilización de equipos auxiliares consumidores de energía. Esto se suma a la menor necesidad de utilización de maquinaria compleja.

- Residuos: al final de su ciclo de vida presenta mayor facilidad para su reciclado o reutilización, ya que es un material orgánico. El matiz a tener en cuenta en este caso es el tipo de tratamiento que haya recibido la caña, para a su vez, saber cómo tratar los residuos.

\subsection{Justificación del proyecto}

A continuación, se presenta la relación directa y detallada entre el presente TFG y varios de los objetivos de sostenibilidad de la ONU:

Fin de la pobreza: ofreciendo un lugar en el que los niños y niñas tienen asegurada la comida. Además, el acceso a la educación les ofrece la posibilidad de un futuro mejor.

Salud y bienestar: puesto que se construye un lugar seguro y apto para el buen desarrollo de las actividades educativas. Así mismo, se promueve una vida saludable a través del deporte, de la alimentación, etc.

Educación de calidad: asegurando el acceso a la escuela en condiciones de igualdad para todos los niños y niñas de la comunidad.

Industria, innovación e infraestructura: a través de la construcción de una infraestructura sostenible, fiable y de calidad que tiene como eje principal el bienestar humano basado en sus necesidades y peticiones. Además, se emplean materiales respetuosos con el medio ambiente como es el bambú y se promueve la innovación teniendo como base las técnicas tradicionales.

Reducción de las desigualdades: garantizando la igualdad de oportunidades para todos los niños y niñas de la comunidad.

Ciudades y comunidades sostenibles: asegurando el acceso de todas las personas a servicios básicos adecuados, seguros y asequibles como lo es la escuela. Esta construcción también favorece la urbanización sostenible reduciendo el impacto ambiental negativo que ya de por si tienen las ciudades.

Además, teniendo en cuenta también el compromiso social de la UDC, este TFG favorece la cooperación entre entidades de diferentes países; en este caso creando lazos entre A Coruña y Quibdó (Colombia) y la cooperación internacional a través del PCR realizado. Gracias a éste pude conocer la situación sociocultural de primera mano y así realizar un TFG mucho más ajustado a la 
realidad teniendo en cuenta las necesidades reales de la población. De hecho, este ha sido el primer PCR realizado en la EUAT, lo que sirve como antecedente y ejemplo para potenciar y motivar al alumnado de esta profesión a presentarse y a interesarse por el ámbito de la cooperación internacional y la sostenibilidad.

\section{Metodología}

Mediante este trabajo se proporciona a la ONG asesoría técnica enfocada en los sistemas constructivos a emplear en la ejecución de la escuela, sirviendo de base para los cálculos necesarios que posteriormente realizarán sus técnicos en terreno. Además, se desea que pueda servir de precedente para futuros proyectos de características similares en la región y contribuir al fomento de estas tipologías constructivas.

Previamente se realiza un estudio sobre la construcción con bambú, específicamente con la especie Guadua Angustifolia Kunth en Colombia, así como de diversos sistemas constructivos basados en el uso de materiales sostenibles como el bambú o la tierra. A su vez, se analizan las diferentes soluciones de construcción bioclimática que puedan garantizar el confort de los usuarios de los edificios teniendo en cuenta las condiciones climáticas de la zona. Se aporta también una valoración económica basada en la propuesta constructiva y enfocada en los sistemas que difieren de la construcción convencional. Para ello, se realizó una exhaustiva investigación bibliográfica, se emplearon programas CAD y se llevó a cabo el PCR.

\subsection{Arquitectura bioclimática}

La globalización de los tiempos modernos ha generado un constante intercambio tecnológico a nivel internacional. A la hora de importar técnicas constructivas es importante tener en cuenta las condiciones locales, ya que muchas de las soluciones occidentales responden a los climas fríos donde se han desarrollado, perdiéndose los conocimientos de técnicas autóctonas y generando problemas serios en entornos con condiciones climatológicas totalmente diferentes (Olgyay, 1998).

Con la arquitectura bioclimática se pretende volver a la optimización de los recursos renovables que ofrece cada entrono, así como la consecución de un nivel aceptable de confort en las edificaciones, adaptando su diseño y geometría a las características del entorno. Al conseguir que el edificio capte o evite energía de manera gratuita, se consigue un control del confort térmico interior sin depender de las instalaciones de climatización. Generalmente el clima se rige por ciclos generados por el movimiento del planeta, como son el día y la noche o el cambio de las diferentes estaciones. Estos ciclos, unidos a otros factores, generan unas 
variables medibles que derivan en una serie de procesos relacionados, como son la evaporación, las precipitaciones, los vientos o las corrientes marinas. Basándose en estos procesos se obtienen las condiciones previsibles del ambiente en una zona determinada, que son las que se analizarán a la hora de realizar el diseño bioclimático de los edificios (Turégano, Velasco y Martínez, 2009).

\section{Resultados}

\subsection{Solución constructiva}

Se propone una edificación de planta rectangular, orientando sus alzados de mayor dimensión perpendiculares al eje Norte-Sur, ejecutada casi en su totalidad con guadua y sistemas alternativos de bioconstrucción, teniendo en cuenta sus beneficios económicos, sociales y ambientales.

La mayoría de la edificación se realiza con el sistema de muros tendinosos, utilizando marco estructural de guadua del país y solucionando los paños con un entramado formado por alambre de espino, costal de fique y mortero de cemento.

El forjado de entresuelo se compone prácticamente en su totalidad de entramado estructural de guadua que se apoya sobre los muros tendinosos, formándose mediante correas de guadua de diámetro $12 \mathrm{~cm}$ con un intereje de $50 \mathrm{~cm}$. Sobre dicho entramado se fija una doble capa de esterilla de guadua que servirá de base para el entablado de madera machihembrada. Se exceptúa el forjado de los baños y la cocina, que se resuelve mediante losa maciza de H.A25 para soportar las grandes cargas que generen los estanques de acumulación de aguas pluviales que se utilizarán para dar servicio a los baños y cocina.

Se plantea una cubierta con aleros dobles a cuatro aguas, utilizando culmos de guadua colocados de manera inclinada para formar la pendiente de los faldones, de $30 \%$ y $37 \%$, sobre los cuales se fijan piezas de guadua en posición horizontal con un intereje de $50 \mathrm{~cm}$ en verdadera magnitud, para finalmente colocar el panel sándwich. Se deja una zona central vacía que se cubrirá con una cubierta elevada que proporcione ventilación e iluminación al edificio, compuesta por cerchas de guadua ancladas mediante pernos y pletinas de acero galvanizado, que se cubrirá con placas de metacrilato trasparente.

\subsection{Resultados 2D y 3D}

Como resultado de este TFG se obtuvo material 2D y 3D realizado con AutoCad y SketchUp respectivamente. Dicho material es la muestra del proyecto de escuela construida con bambú y adobe bajo los principios de la sostenibilidad. 
Un proyecto realizado basándose en las necesidades de una comunidad concreta, la de Quibdó y aprovechando los recursos de la zona, pero que, perfectamente podría ser adaptado para otras zonas y comunidades. En las Figuras 2 a 5 se muestran los resultados.
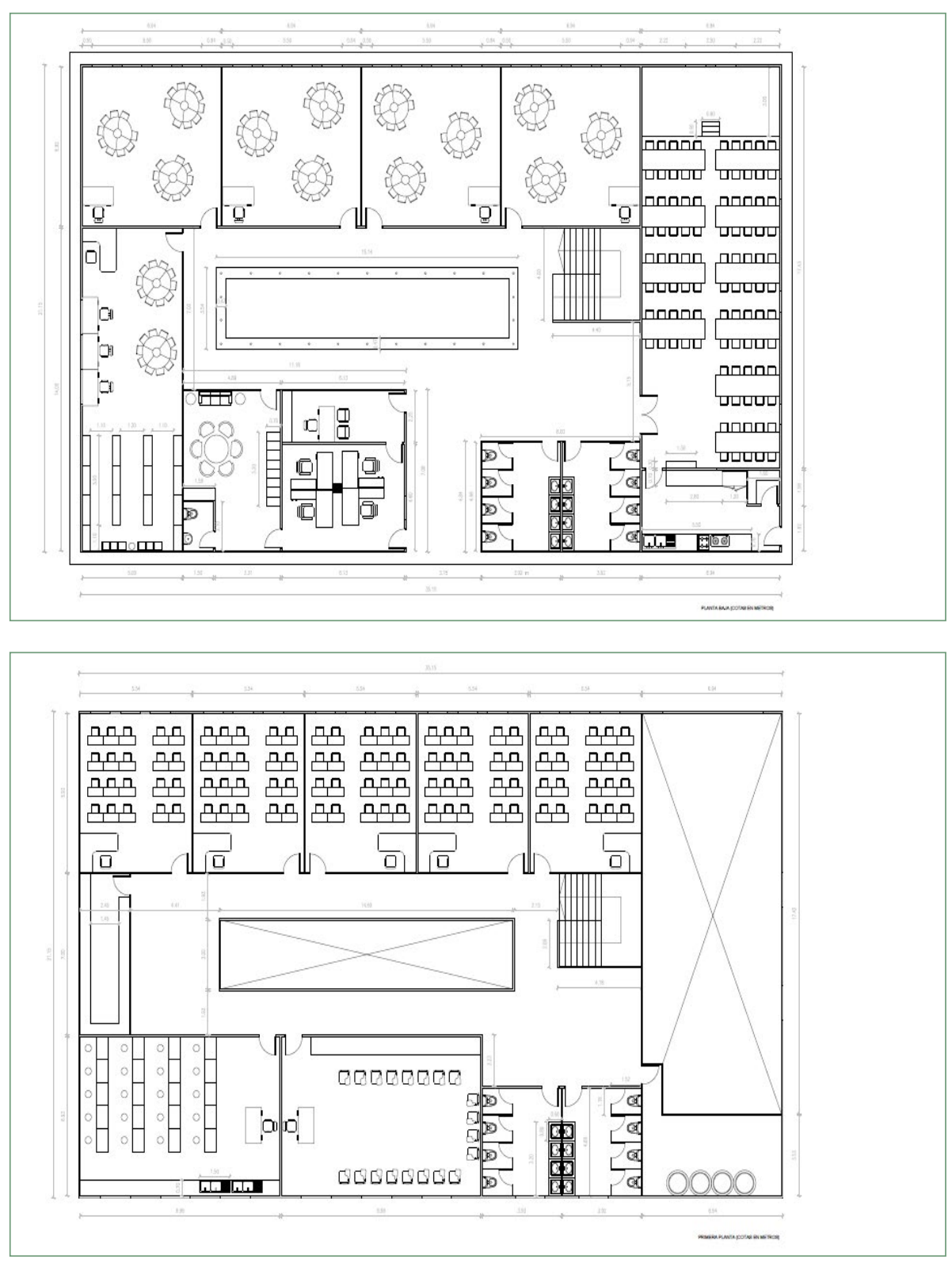

Figura 2. Plano planta baja (arriba) u primera planta (abajo). 

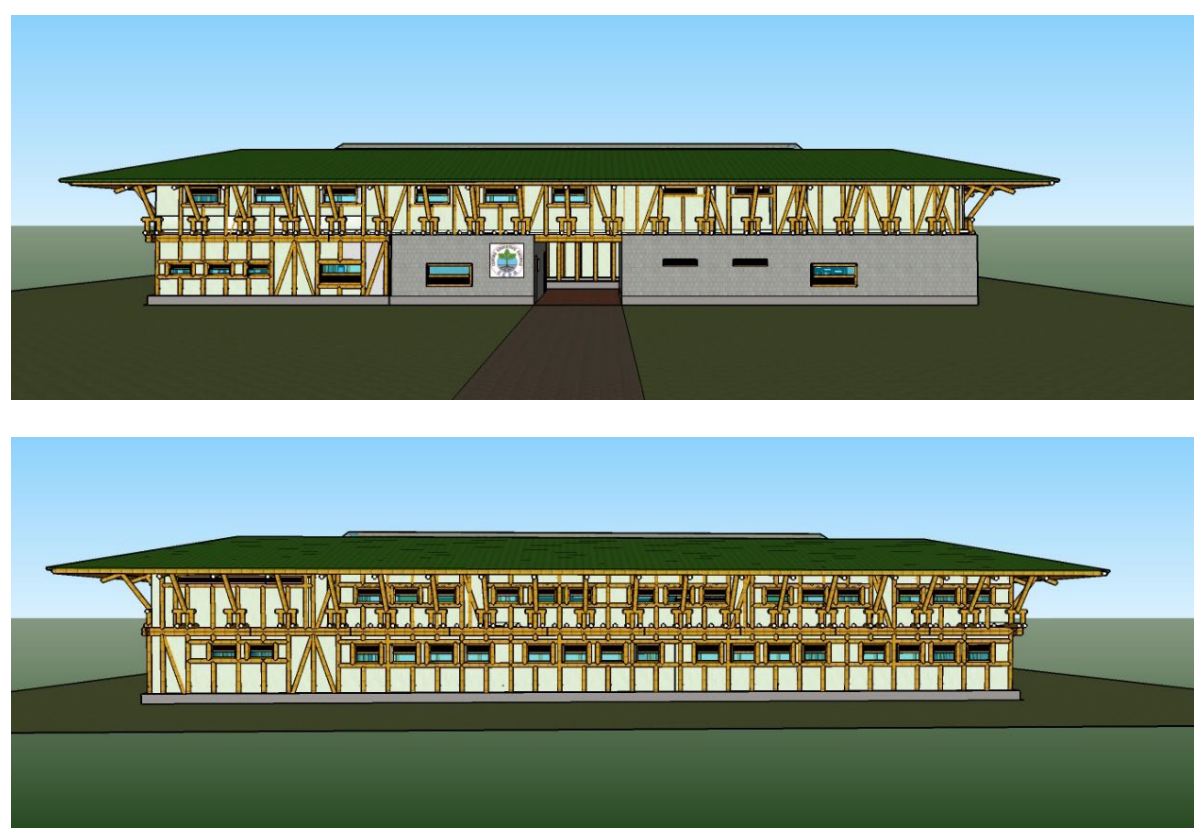

Figura 3: Alzado Sur (arriba) y Alzado Norte (abajo).
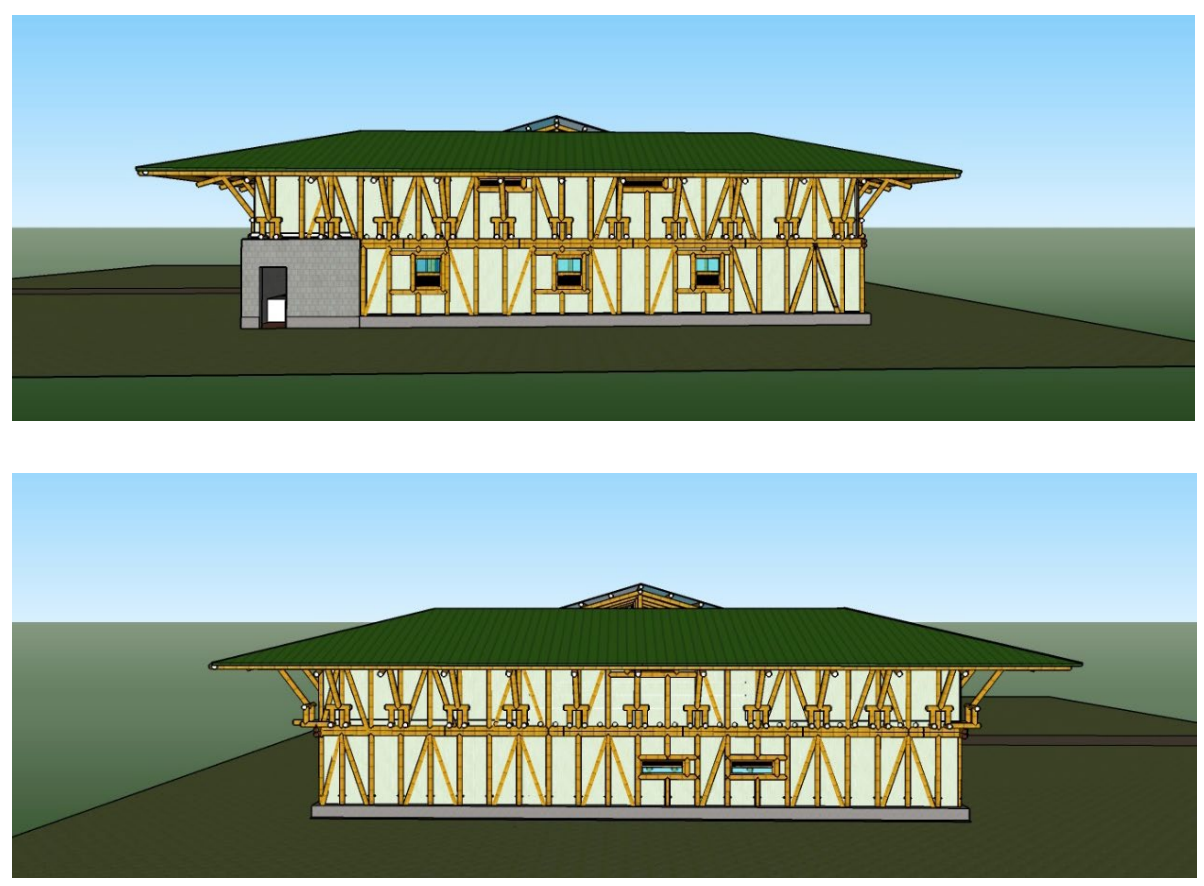

Figura 4. Alzado Este (arriba) y Alzado Oeste (abajo). 

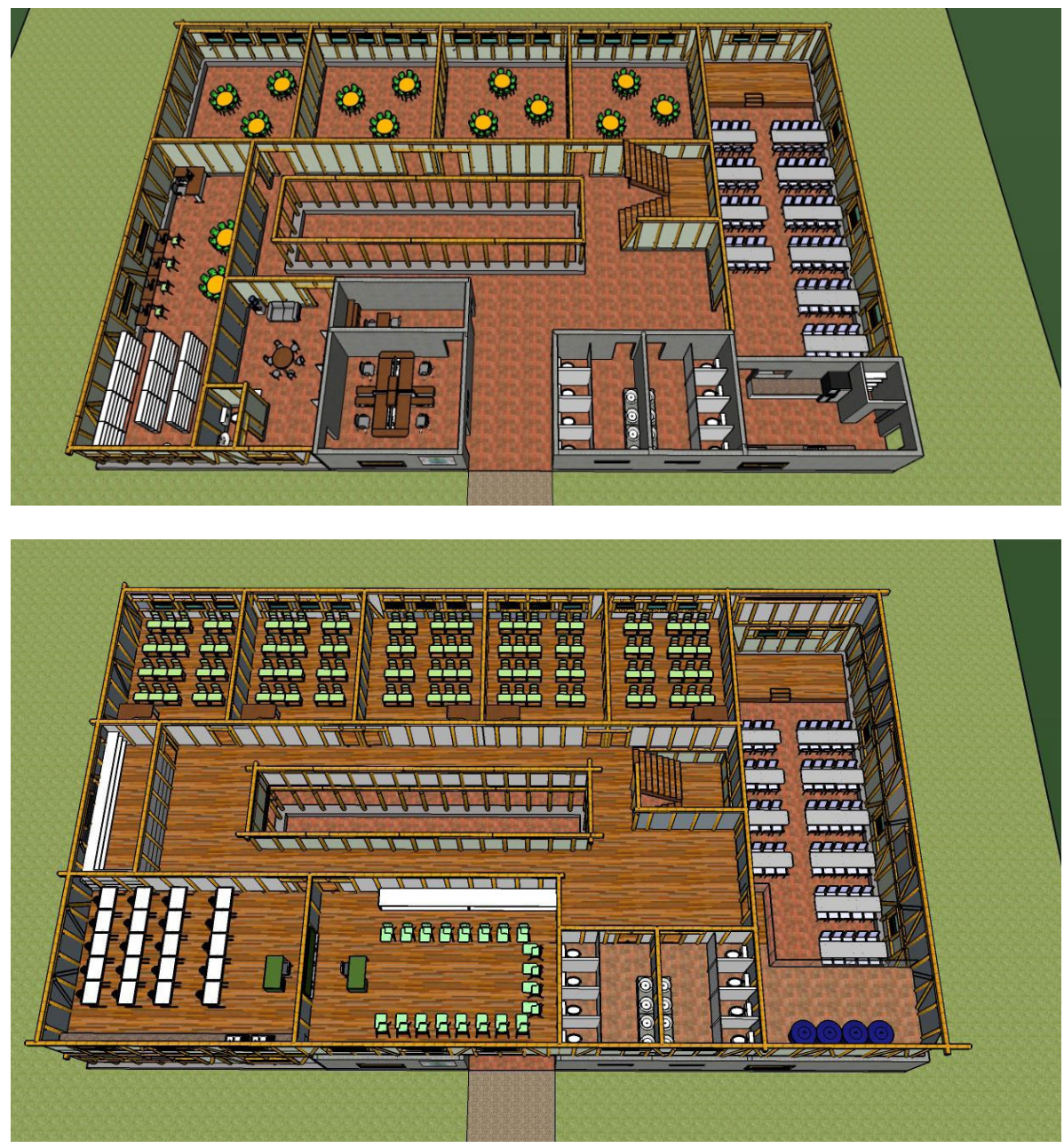

Figura 5. Vista de planta baja desde el Sur (arriba) y Vista de primera planta desde el Sur (abajo).

\subsection{Análisis de costos}

En el presente TFG se realizó una comparativa de precios unitarios de los diferentes sistemas constructivos empleados en una construcción convencional frente a los que forman parte de la propuesta constructiva basada en guadua y sistemas alternativos. El análisis de costos está basado en los datos de precios unitarios aportados por la Gobernación de Risaralda (Colombia), uno de los departamentos del país con mayor tradición en la construcción con guadua. Los resultados son, como se puede observar en la Tabla 1, favorables a la guadua. 
Tabla 1. Resumen análisis de costos.

\begin{tabular}{|c|c|c|}
\hline \multicolumn{3}{|c|}{ RESUMEN ANÁLISIS DE COSTOS } \\
\hline SISTEMA & PROPUESTA CON GUADUA & CONSTRUCCIÓN CONVENCIONAL \\
\hline Muro & $\begin{array}{l}\text { Muro tendinoso con entramado } \\
\text { de guadua }\end{array}$ & Muro de carga en bloque de cemento \\
\hline $\mathrm{m}^{2}$ & 16,16 EUR & 20,34 EUR \\
\hline $\begin{array}{l}\text { Forjado de } \\
\text { entresuelo }\end{array}$ & $\begin{array}{l}\text { Entramado de guadua y } \\
\text { entablado de madera }\end{array}$ & Losa maciza de H.A. \\
\hline $\mathrm{m}^{2}$ & 21,16 EUR & 44,15 EUR \\
\hline Cubierta & $\begin{array}{l}\text { Entramado de guadua y panel } \\
\text { sándwich }\end{array}$ & $\begin{array}{l}\text { Losa maciza de H.A. inclinada y panel } \\
\text { sándwich }\end{array}$ \\
\hline $\mathrm{m}^{2}$ & 25,24 EUR & 75,46 EUR \\
\hline
\end{tabular}

\section{Conclusiones}

Gracias a la investigación bibliográfica, la estadía en terreno y la posibilidad de adquirir conocimientos de diferentes profesionales especializados en este tipo de sistemas constructivos, se puede deducir que fomentar el uso de la guadua no solo es positivo, sino que también totalmente necesario. Tanto las múltiples ventajas que presenta para el medio ambiente como los aspectos socioeconómicos que conlleva lo convierten en un factor clave para el desarrollo sostenible de la región.

Desde su siembra y cosecha, hasta sus diferentes usos, la guadua puede aportar multitud de ventajas que a día de hoy están sin explotar. Es necesario rescatar las diferentes técnicas constructivas tradicionales, utilizando materiales autóctonos y respetuosos con el medio ambiente, y conjugarlos con los avances tecnológicos que se han producido en la sociedad actual, con el fin de conseguir soluciones sostenibles que cubran las necesidades básicas de las poblaciones locales de América Latina.

Las infraestructuras son un punto muy importante del progreso de las sociedades, y deben respetar algunos pilares básicos como la integridad del edificio, la durabilidad, la sostenibilidad ambiental y la economía que permita a los diferentes estratos sociales beneficiarse de las mismas.

A su vez, es imprescindible tener en cuenta las condiciones climáticas y del entorno a la hora de realizar los diferentes proyectos de edificación, con el fin de revertir una situación cada vez más común en los territorios sudamericanos, como es la construcción sin asesoría técnica ni previsión, que deriva en patologías y condiciones de vida insalubres. 
La mejor forma de fomentar esto y demostrar a los habitantes sus múltiples cualidades, resulta ejecutando grandes proyectos sociales y comunitarios donde puedan comprobar de primera mano las ventajas de este tipo de construcciones. Este proyecto pretende generar este impacto en la ciudadanía de Quibdó y así servir de inspiración para futuras construcciones similares en la zona.

\section{Bibliografía}

BROTO, E. 2014. Bambú: arquitectura y diseño. Barcelona, España: LinksBooks. ISBN 978-84-9054-027-5.

GIRALDO HERRERA, E., s.d. Bienes y servicios ambientales de la Guadua en Colombia [en línea] [consulta 26-02-2018]. Disponible en: http://www.sigguadua.gov.co/sites/default/files/archivos/bienes_y_ servicios_guadua.pdf

MINKE, G. 2012. Building with bamboo. Basilea, Suiza: Birkhäuser. ISBN 978-3-0346-0748-3.

OLGYAY, V. 1998. Arquitectura y clima: manual de diseño bioclimático para arquitectos y urbanistas. Barcelona, España: Gustavo Gili S.A. ISBN 84-252-1488-2.

TURÉGANO ROMERO, J.A.; VELASCO CALLAU, M.C.; MARTÍNEZ GARCÍA, A.

2009. Energías renovables. Arquitectura bioclimática y urbanismo sostenible (volumen I).

Zaragoza, España: Prensas Universitarias de Zaragoza. ISBN: 978-84-92774-23-4.

VILLEGAS GONZALEZ, F., 2005. Comparación consumo de recursos en la construcción de vivienda social: guadua vs. concreto. [tesis fin de estudios]. Jorge Humberto ARCILA LOSADA, director. Universidad Nacional de Colombia, Instituto de Estudios Ambientales IDEA. 



\title{
De la vivienda tradicional a la passive house.
}

\section{Unidades residenciales en San Vicente de Elviña}

\author{
Lucía Uña Canteli
}

\section{Resumen}

Se propone como tema de proyecto del taller un conjunto de 5 Unidades Residenciales para profesores de la UDC, investigadores de larga estancia con familia. Estas cinco Unidades Residenciales precisan por tanto espacios de vivienda y también lugares de trabajo para poder vivir con sus familias y trabajar disponiendo de todo lo necesario. El programa se completa con dos espacios de reunión comunes y un local social para reunión de los vecinos del pueblo.

Aunque son viviendas para investigaciones de larga estancia, no son para uso indefinido de los mismos habitantes y por tanto no es una vivienda que pueda ser inspirada en las necesidades de una persona o una familia en concreto, como a menudo sucede en la arquitectura. Es pues, que para proyectar únicamente se tienen dos puntos de referencia: el lugar y su historia.

El diseño de las mismas, a su vez, tendrá que tener una gran capacidad de cambio que permita adaptarse al grupo de individuos que en ese momento la habite. Se opta por una solución además de cambiante, sostenible. Unas viviendas con apenas consumo que alcancen la clasificación de passive house.

Palabras clave: Passive house, sostenible, residencia, vivienda, transformable.

\footnotetext{
*Datos para citación: Uña Canteli, Lucía (2019). “De la vivienda tradicional a la passive house. Unidades residenciales en San Vicente de Elviña". En Oficina de Medio Ambiente UDC (ed.), I Premio UDC Sustentabilidade a traballos fin de grado e mestrado 2018. A Coruña: Universidade da Coruña, 67-88. DOI de la obra: https://doi.org/10.17979/spudc.9788497497831.
} 


\section{Introducción}

\subsection{Aproximación al lugar. Actualidad y expectativas}

San Vicente de Elviña, es una pequeña población de menos de 250 habitantes situada en la ciudad de La Coruña, en una zona aislada que se ha visto rodeada por el campus universitario y la agitada Avenida de Alfonso Molina.

Un remanso de paz en la ajetreada ciudad que parece haber sido pausado en el tiempo.

Situada en el abrigo de un valle, la zona se va definiendo en la antigüedad alrededor de un río. En lo alto, aparece la iglesia con su campanario, en situación de poder. El lavadero y la asociación de vecinos concentra toda la actividad social de la zona.

Sus escasas calles avanzan entre sus antiguas casas, la mayoría de dos plantas, cuyos muros van definiendo el camino. Se adentran, salen, dan la vuelta a la esquina y van formando recovecos que forman los lugares semipúblicos del lugar.

El núcleo a su vez, se encuentra en una situación en la que necesita ser completado y cerrarse respecto a las grandes infraestructuras y construcciones de una escala completamente diferente de la zona. Ya no tiene grandes posibilidades de crecimiento, si no que necesita arroparse a sí mismo.

Por ello se elige ubicar las viviendas y los muros que componen el proyecto en la zona entre el núcleo y la vía que lo separa de la biblioteca Xoana Capdevielle, edificio de gran entidad en la zona.

El propósito del trabajo es tanto de crear unas viviendas adaptables a sus posibles y variados habitantes como el de aprovechar la ocasión para llevar a cabo una investigación y desarrollo de las mismas de manera lo más ecológica y sostenible posible.

\subsection{Ideas de proyecto y objetivos generales}

\section{Ideación}

Los muros son el elemento estructurador del núcleo. Van avanzando entre las viviendas, envolviéndolas, cuidándolas y creando espacios que evolucionan gradualmente de lo público a lo privado.

Esta concepción de los espacios recuerda de alguna forma a esa manera de crear hogar entre muros y a su vez entre los huecos que quedan entre ellos, que ya se podían apreciar en los antiguos castros (Fig. 1). 
La actuación surge de esa reflexión sobre los muros, sobre los espacios que definen y su sensación de protección, de arropamiento. De esos lugares que no son vivienda pero sí consideramos hogar. Estos muros serán el eje de la actuación, sobre los que se apoyan las viviendas (Fig. 2a).

Se genera una nueva calle que completa el núcleo y lo une desde el nuevo local social hasta el antiguo punto social, el lavadero.

Las nuevas construcciones toman de las ya existentes su tipología y orientaciones, fundiéndose ambas y siendo unas la evolución de las otras.

El pavimento va variando a lo largo del recorrido, siendo en su mayoría un pavimento continuo. Aparecen puntualmente losas de hormigón, próximas a las viviendas, y también zonas de césped y espacios reservados para vegetación. Vegetación entendida como 'jardín en movimiento', sin apenas mantenimiento y que va variando a lo largo de las estaciones.

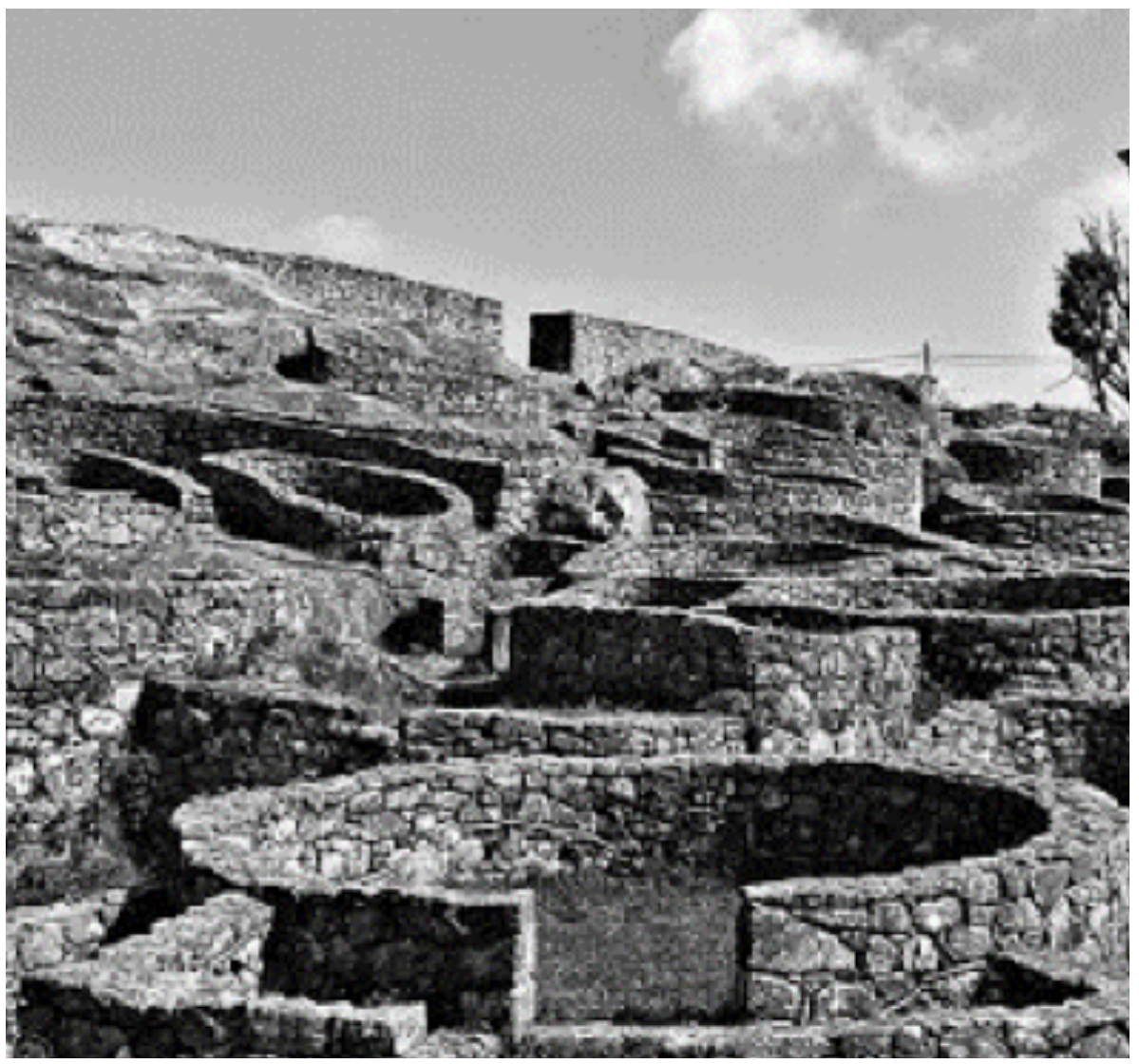

Fig. 1. Castro de Santa Tecla, Pontevedra. 

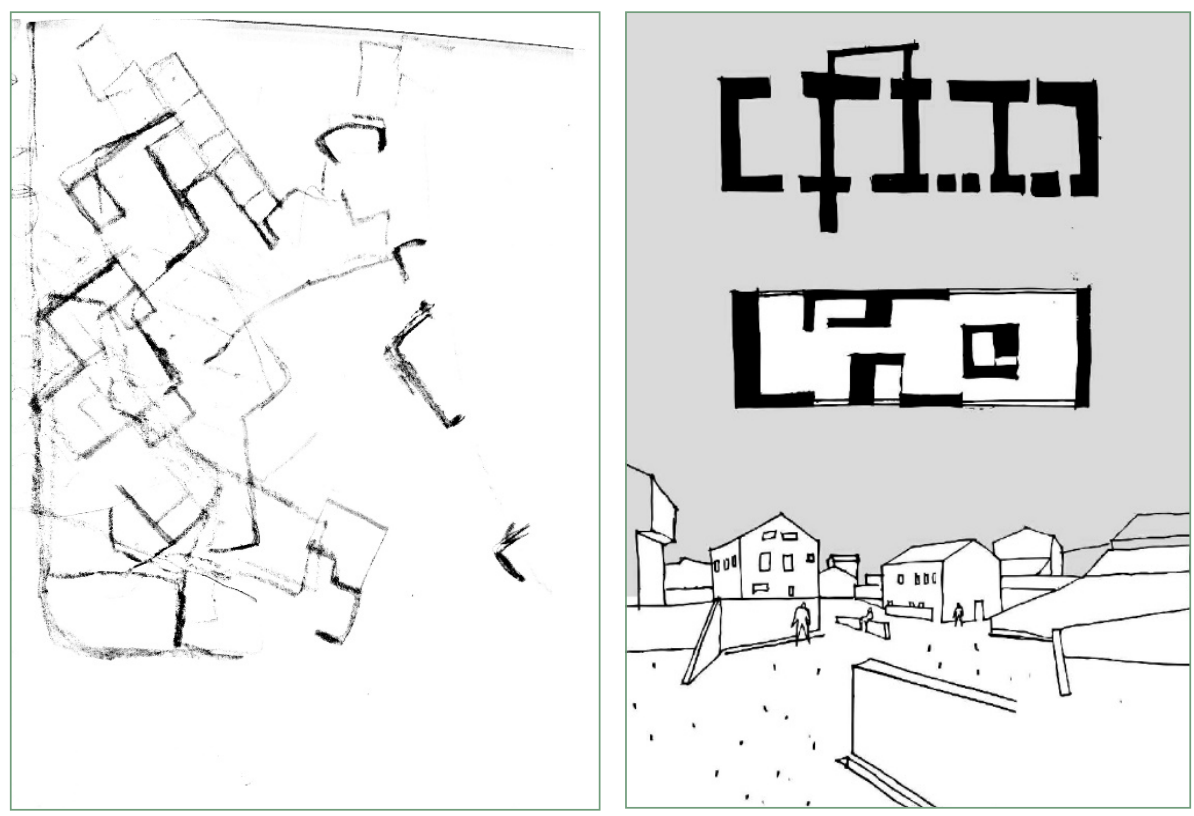

Fig. 2. Primeros bocetos de proyecto (izquierda: 2a) y comparativa tradición-adaptación (derecha: 2b).

A todo ello lo acompaña un canal que aflora a la superficie en puntos concretos, que ayuda a recoger el agua de la lluvia, conducida hasta él debido a la pendiente del propio pavimento. Un 'cauce' que rememora el antiguo arroyo que pasaba por San Vicente de Elviña años atrás. Este canal lleva las aguas recogidas a varios aljibes situados en puntos estratégicos y a los que también son conducidas las aguas de pluviales de las viviendas. Una vez ahí se aprovechará para el regadío de los jardines.

Tanto el local social como los dos espacios de reunión destinados a investigadores se sitúan conjuntamente en un edificio ya existente. El motivo de situarlos en la misma edificación es claro: ambos significan reunión. A diferencia de las viviendas, son elementos más rígidos ya que sus usuarios tienen unas necesidades constantes.

Su tipología es la misma que la de la zona, planta rectangular, muros gruesos que faciliten el confort en el interior y cubierta a dos aguas. Todo ello reinterpretado en volúmenes lo más puros posibles (Fig. 2 b).

Las cinco viviendas+estudio se sitúan completando el núcleo, en una zona conflictiva entre éste y la biblioteca (Fig. 3), dándole un nuevo piso de tierra compactada a la calle que los separa y plantando nuevos árboles que formarán una barrera vegetal que dividirá el núcleo del campus. 
En el interior, la vivienda tiende a aprovechar al máximo el espacio y aunque con distinta forma, todas cuentan con unos $60 \mathrm{~m}^{2}$ (Tabla 1) para salón, cocina, baños y dos espacios principales, el de las habitaciones y el del estudio.

Se tiende a los espacios diáfanos agrupando en compactos paquetes todos los servicios (representados en negro) que separan mediante franjas las diferentes zonas como se puede observar en catálogo de tipos. (Fig. 4).

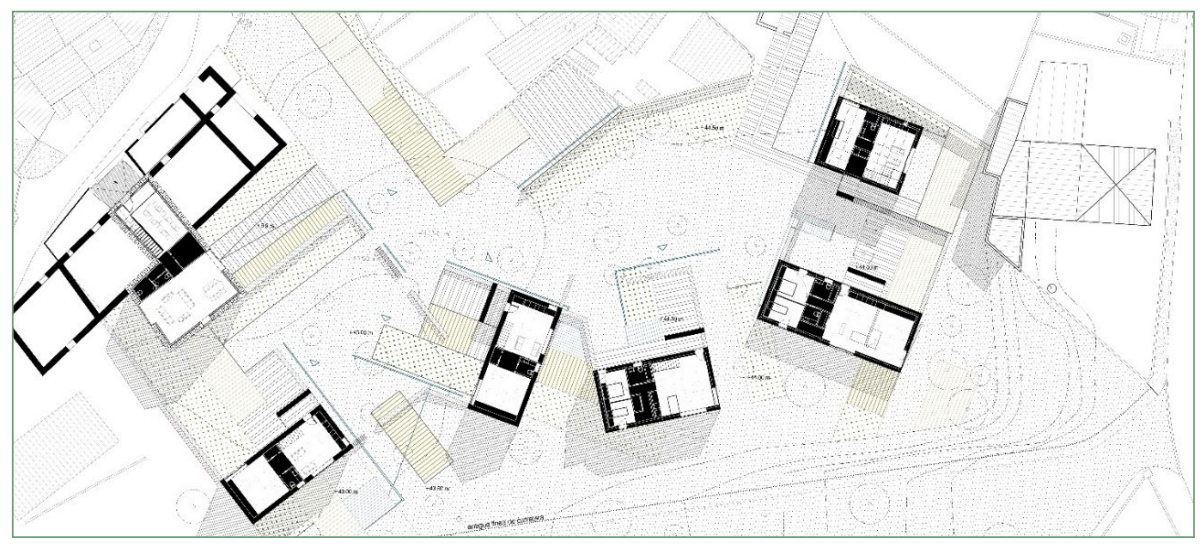

Fig. 3. Conjunto de centro de reunión (izquierda) y de las viviendas. Al sur la barrera vegetal.

En la Tabla 1 se muestran las superficies de forma comparativa de todos los tipos de vivienda (A, B, C y D).

Tabla 1. Comparativa de superficies de vivienda $\left(\mathrm{m}^{2}\right)$.

\begin{tabular}{|lllll|}
\hline Tipo de vivienda & TIPO A & TIPO B & TIPO C & TIPO D \\
\hline Distribuidores (D) & 7,82 & 5,49 & 4,86 & 10,47 \\
\hline Salón-Cocina (SC) & 24,3 & 31,53 & 28,84 & 22,68 \\
\hline Aseo (A) & 2,72 & 3,06 & 2,56 & 2,65 \\
\hline Estudio (E) & 20,23 & 18,32 & 20,74 & 18,15 \\
\hline Lavandería (L) & 1,32 & 1,3 & 1,3 & 1,21 \\
\hline Baño (B) & 4,41 & 4,25 & 4,26 & 3,94 \\
\hline Espacio Habitaciones (EH) & 16,74 & 20,23 & 19,44 & 17,85 \\
\hline Terraza & 0 & 2,21 & 0 & 0 \\
\hline Superficie Útil General & 77,54 & 86,39 & 82,00 & 76,95 \\
\hline Superficie Útil Vivienda & 57,31 & 68,07 & 61,26 & 58,8 \\
\hline Superficie Útil Estudio & 20,23 & 18,32 & 20,74 & 18,15 \\
\hline Total Superficie Construida & 111,94 & 109,99 & 96,39 & 106,91 \\
\hline
\end{tabular}




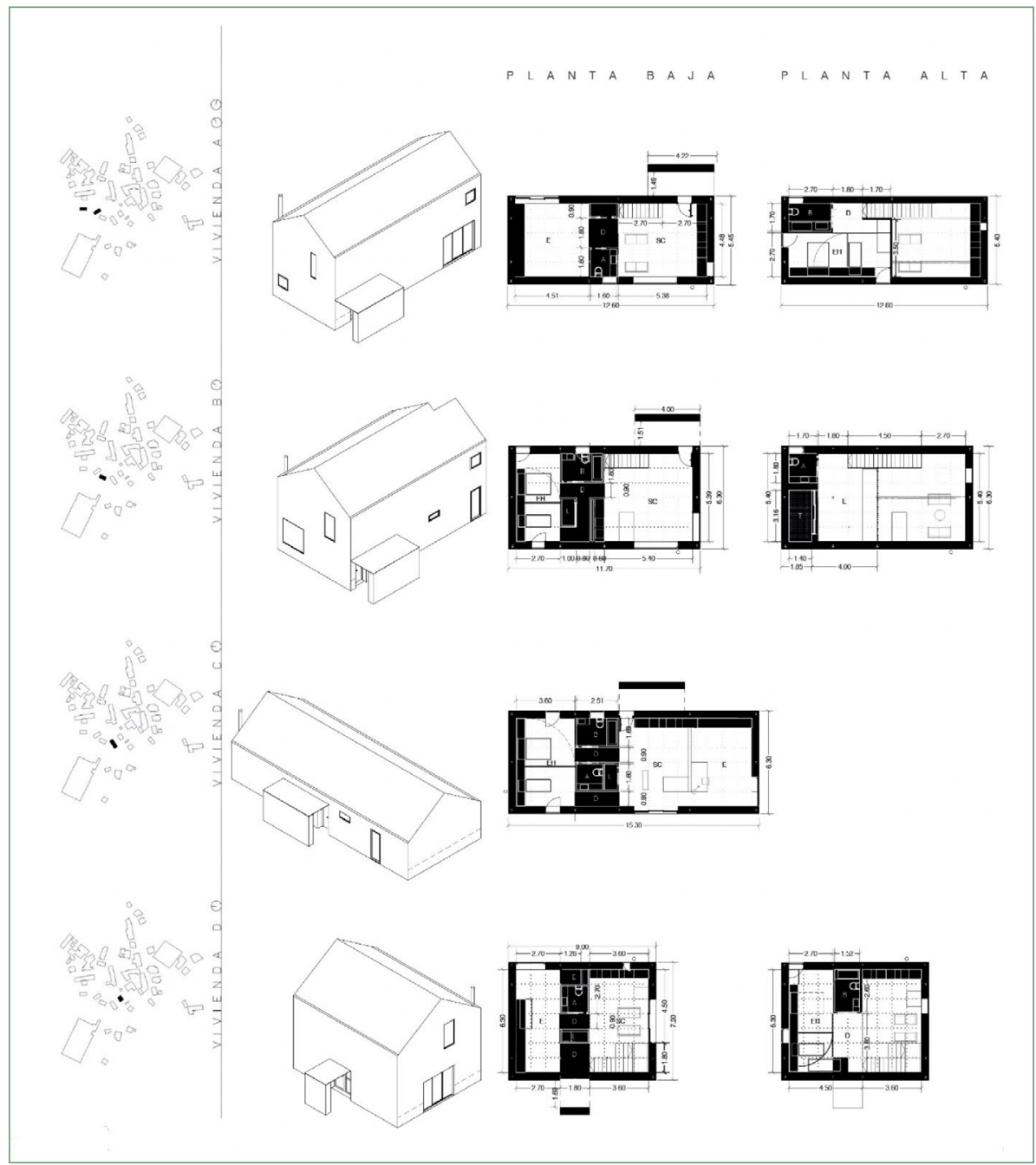

Fig. 4. Catálogo de tipos de vivienda.

\section{Técnica}

Como se explica en el anterior apartado, son unas viviendas que no pueden estar adaptadas a unas necesidades de una familia o grupo de individuos concreto, si no que únicamente podemos tomar dos referencias: el lugar y su historia. Se deben idear unas viviendas adaptables a quienes las habiten.

Está claro que realizar una vivienda $100 \%$ modificable es algo casi imposible, pero sí que se puede entender la construcción casi como una fórmula que 
comprende unas constantes y una parte variable que será la que marca la diferencia entre la forma de vivir de unos individuos y otros.

La parte constante estará comprendida por unos paquetes de estancias cerradas mientras que la parte variable serán espacios abiertos altamente modificables.

Todo ello no es posible sin una estandarización. Modular la vivienda ha sido algo fundamental a la hora tanto de realizar los tres módulos internos de la vivienda, como para facilitar y vincular constructivamente las cinco viviendas, ya que los despieces de todas son iguales. De esta manera se puede hacer una construcción con rendimientos más eficientes.

Se diseñan 3 módulos internos: el módulo-comer, módulo-dormir y módulotrabajar. Y uno externo: el módulo-instalaciones, donde se centralizan todos los contadores e instalaciones que es necesario situar en el exterior. El módulo-comer es el que contiene la cocina y alberga todas las instalaciones que se deben situar en el interior de la vivienda. En el móduloinstalaciones exterior se encuentran la parte de ellas que deben ir situadas fuera tanto por ventilación como por razones técnicas y además es el muro que articula la zona de entrada quedando protegida mediante una cubierta de vidrio. El módulo-trabajar compacta tanto almacenamiento como estudio. Finalmente, el módulo-dormir hace la vivienda extremadamente modificable: nos permite crear diferentes espacios de descanso en función de las necesidades de la familia.

De este modo, nunca hay espacios deshabitados, puesto que, de no necesitar varias habitaciones se cede todo el espacio a la habitación principal. Por otro lado, al ser una construcción de un no-particular, parece la oportunidad perfecta para investigar e inculcar nuevos avances en el presente. Es pues, que todas las viviendas son Passive House.

Por ello, dispone de gruesos muros (como en el pasado se utilizaban) pero tras una labor de investigación detrás para poderlos convertir en una nueva adaptación formada por nuevas capas que hace posible el consumo casi nulo de la vivienda.

La estructura está constituida por muros sobre los que se apoya una estructura metálica ligera. De nuevo inspirado en los castros, donde lo masivo sujetaba lo efímero. En un futuro lejano, podría incluso desaparecer la estructura ligera quedando solo el masivo hormigón y formando nuevas tipologías de castros y lugares de reunión. De esta manera pasado presente y futuro quedan vinculados.

A su vez, el concepto de la estructura viene ligado desde el primer momento a la idea de proyecto: los muros. Es decir, la propia estructura es el elemento 
vertebrador. Un gran zócalo masivo sobre el que se coloca una segunda estructura liviana y más volátil en las zonas de las viviendas.

Bajo la vivienda se encuentra un forjado sanitario al que se accede mediante una trampilla. Estará ventilado y en él se colocarán las arquetas de la red de residuales y la toma de tierra, entre otras instalaciones.

Con todo, la solución estructural pretende ser coherente tanto con la idea de proyecto como con las exigencias técnicas. Sin dejar de lado la búsqueda de que la propia estructura sea el elemento configurador del espacio arquitectónico, funcionando como un todo. (Fig. 5). También se mantendrán la mayor parte de los muros de mampostería del lugar, para su recuperación e integración en el proyecto.

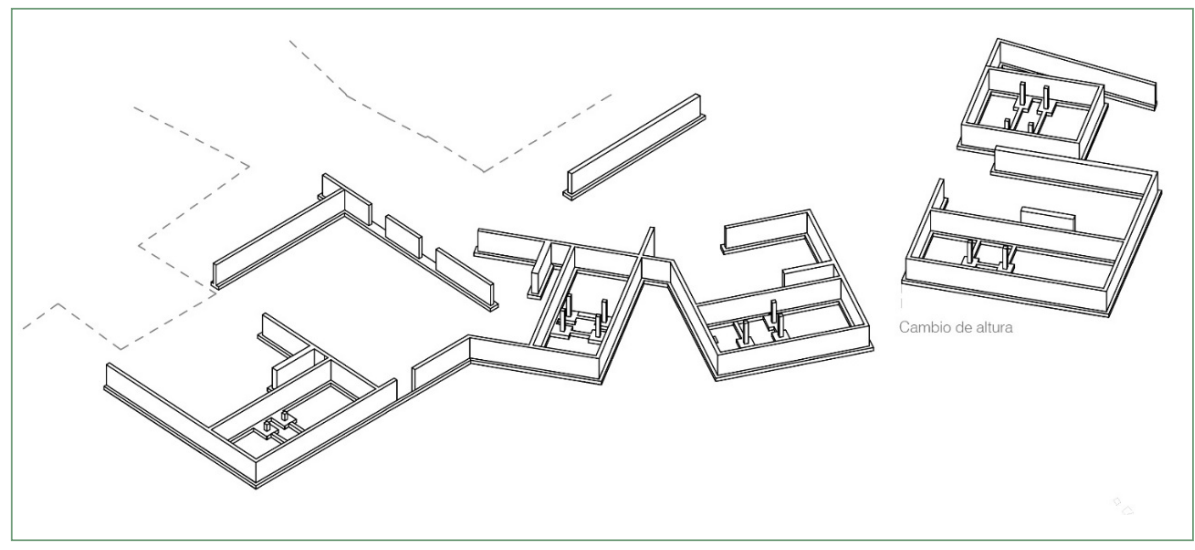

Fig. 5. Los muros como elemento estructurador de la propuesta.

\section{Materiales y métodos}

\subsection{Sistema envolvente}

La fachada está formada por un interior a base de aislamiento que se divide en tres capas: la capa exterior de $7 \mathrm{~cm}$, una capa intermedia situada entre pilares de $10 \mathrm{~cm}$, rematado por tablero estructural y otra última capa de remate interior formada por un trasdosado o tabique autoportante de $10 \mathrm{~cm}$.

Todo ello constituye una fachada ventilada cuyo acabado exterior es una lámina de zinc (que será protegida por la propia pátina que desarrolla el material aumentando su resistencia), colocada sobre tablero estructural sujetos por una subestructura dejando una cámara de aire de $4 \mathrm{~cm}$ y una lámina transpirable que protege al aislamiento del exterior. 
El zinc será con acabado natural y se colocará a junta alzada haciendo coincidir las juntas con los despieces ya previstos. La parte baja de la fachada (los primeros $60 \mathrm{~cm}$ ) está formada por los muros de hormigón armado de $30 \times 60 \mathrm{~cm}$.

Para para impedir la ascensión de humedad por capilaridad, se aplicará una impregnación hidrófuga aplicada mediante rodillo o pulverizado.

Todas las carpinterías tendrán la calidad adecuada para passive house, teniendo en estos puntos puentes térmicos muy pequeños.

La cubierta sigue teniendo la misma metodología que la fachada, siendo un recubrimiento continuo y formando un volumen lo más puro posible. El recubrimiento exterior es la continuación del zinc de la fachada sobre el mismo tipo de tablero estructural (OSB de $1.83 \times 2.53 \mathrm{~m}$ ). Estos tableros estructurales se colocan directamente sobre la estructura principal de la vivienda, de esta manera no es necesaria una subestructura.

Una primera capa de aislamiento de lana de roca de $7 \mathrm{~cm}$ se coloca sobre las propias correas de la estructura y entre éstas una segunda capa, de otros $7 \mathrm{~cm}$. A continuación, un tablero estructural remata el cerramiento y a él se ancla el falso techo de yeso.

Con esta sucesión de capas se evita tanto el paso del ruido como la existencia de puentes térmicos (Fig. 6).

\subsection{Urbanización exterior}

La urbanización exterior se hará acorde a lo establecido en las ideas iniciales de proyecto en la que se mantienen y se crean nuevos muros hormigón. Una retícula virtual vinculada a la ordenación de las viviendas ayuda a ordenar las texturas de estos espacios, creando franjas de césped, vegetación y losas de pavimento duro (hormigón), sobre una gran superficie unificada de tierra pisada.

Entre el núcleo y la biblioteca Xoana Capdevielle se encuentra actualmente la calle Rebandas, un vial que se hace desaparecer, convirtiéndose en un cinturón verde que separa el núcleo de los nuevos equipamientos universitarios. Para ello se busca la regeneración de los árboles hasta el momento existentes y se plantan nuevos ejemplares para generar ese nuevo "bosque-separador".

Las especies de arbolado se han seleccionado teniendo en cuenta el clima y la zona donde se van a plantar. Es muy importante el hecho de ser especies de tipo caduco, ya que favorece a las condiciones de passive house de las viviendas. De esta manera en verano les proporciona sombras mientras que en invierno al no tener hojas, deja pasar el sol. 
Ci2. Zapata corrida de cimentación de hormigón armado.

Es1. Muro de hormigón armado.

Es2. Pilares metálicos.

Es3. Enanos de hormigón armado.

Es4. Forjado de losa mixta.

Es5. Estructura de hormigón armado.

Ee1. Lámina de zinc c/acabado natural.

Ee2. Entablado base tablero OSB virutas orientadas.

Ee3. Subestructura metálica.

Ee4. Panel aislante de lana de roca.

Ee5. Panel aislante de lana de roca.

Ei1. Trasdosado autoportante.

Ei2. Panel de poliestireno extruido.
Ei3. Sistema de calefacción suelo radiante.

Ei4. Pavimento continuo s/superficie absorbente.

Ei5. Pavimento tarima flotante de madera.

Ei6. Falso techo.

Cu1. Lámina de Zinc acabado natural.

Cu2. Impermeabilización monocapa adherida.

Cu3. Entablado base tablero OSB de virutas orientadas.

Cu4. Canalón oculto.

Cu5. Panel aislante de lana de roca.

Cu6.Panel aislante de lana de roca.

Ec1. Zancas de escalera de acero.

Ec2. Peldaño de madera maciza.

Ec3. Barandilla panel de madera.

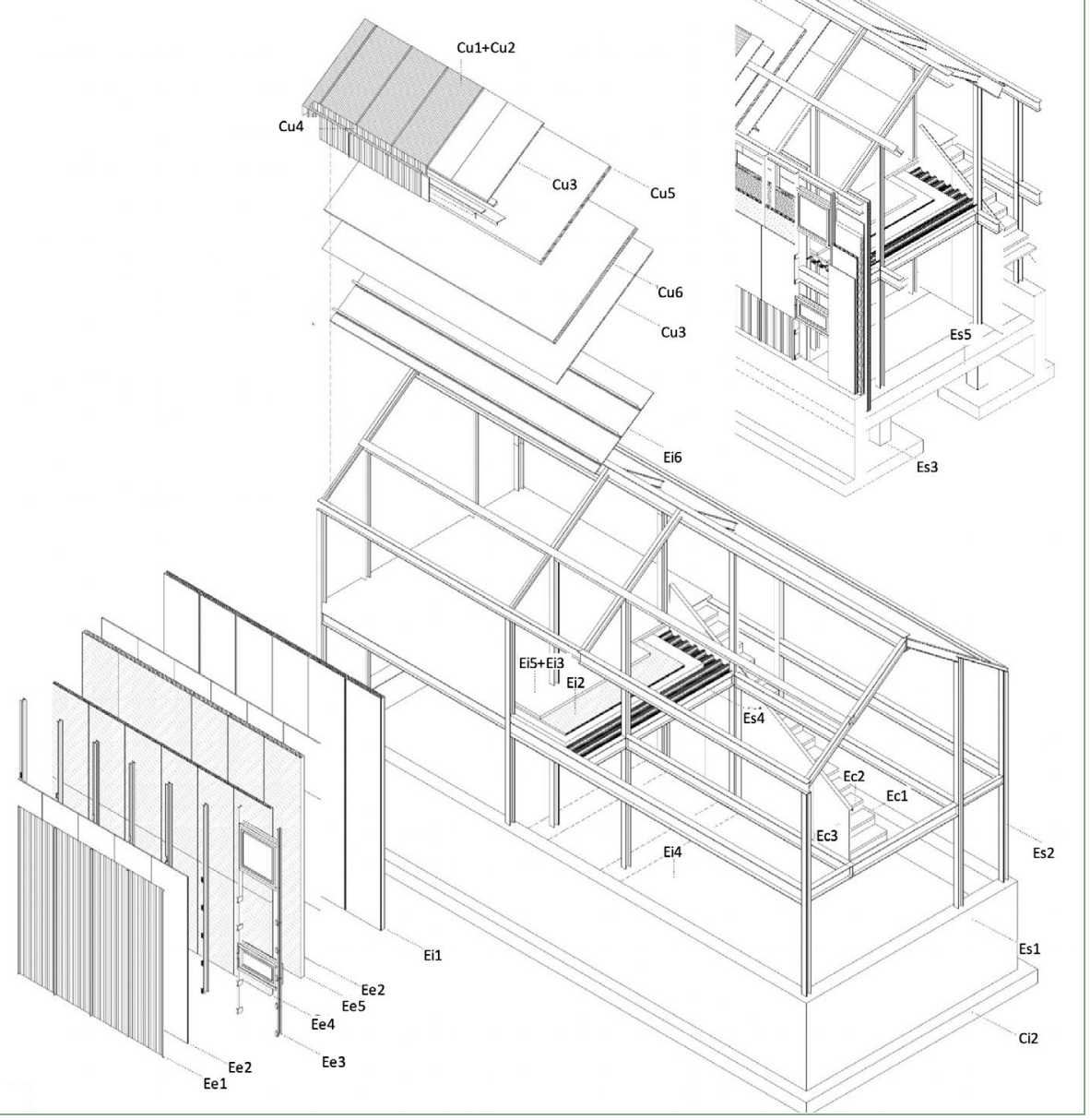

Fig. 6. Construcción de una vivienda tipo. 
En las nuevas zonas semipúblicas de las viviendas también se especifican las especies de plantas que formarán las zonas vegetales. Para su selección se han estudiado tanto sus escalas de crecimiento como su floración a lo largo de las estaciones del año.

Para las franjas vegetales se utilizarán gramíneas (Fig. 7) con poco mantenimiento inspiradas en el concepto de jardín en movimiento de Gilles Clément, variando el paisaje según la estación del año.

En cuanto a los pavimentos se busca que creen diferentes espacios de estancia potenciando la idea de graduación público-privada. El pavimento mayoritario será de tierra pisada con un tratamiento tipo Polipavement o similar.

Este tratamiento es un líquido que solidifica la tierra y se utiliza sobre suelos naturales ofreciendo una resistencia muy grande tanto a la lluvia, a vehículos pesados (como camiones de bomberos) y siendo de bajo mantenimiento y apto para sillas de ruedas.

Este pavimento conduce por su superficie la evacuación de aguas por gravedad hasta los canales de hormigón que la conducen después de unos filtros a los aljibes (Fig. 8).

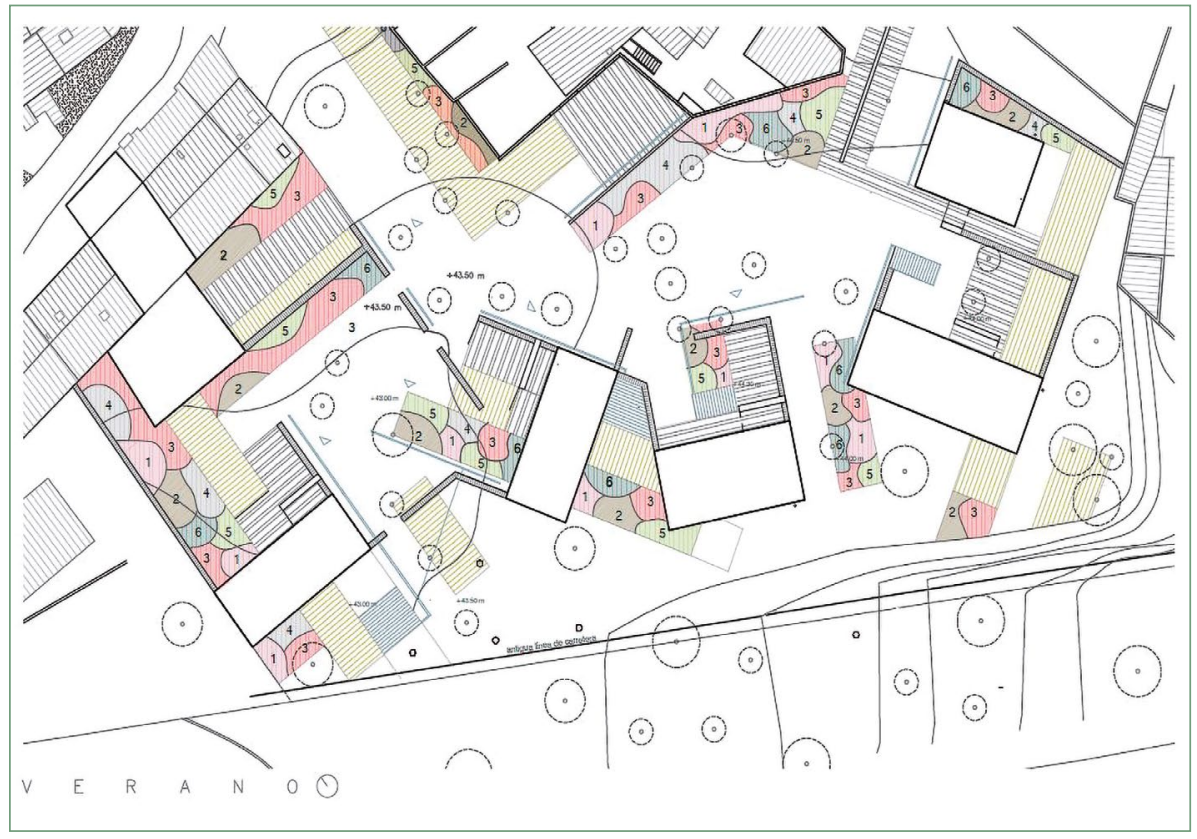

Fig. 7. Especies a utilizar en las franjas vegetales (1. Astilbe x Arendsii, 2. Stipa Gigantea, 3. Helenium, 4. Agastache Blue Fortune, 5. Anthyllis Cytisoides). Ejemplo de foración en verano. 


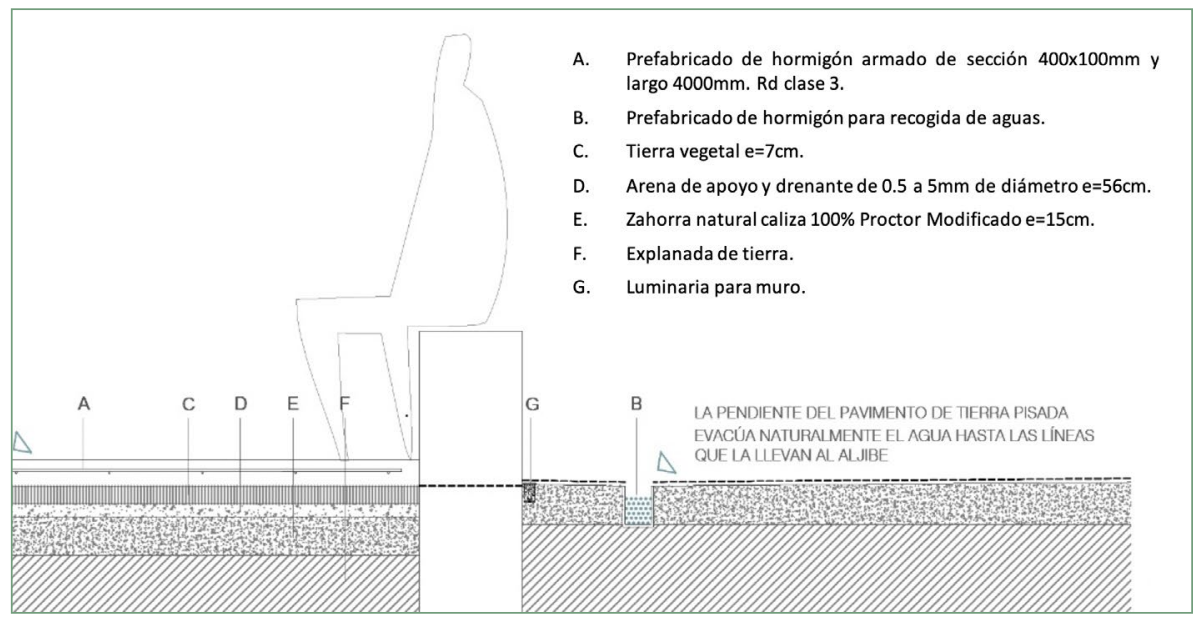

Fig. 8. Evacuación de aguas del pavimento.

Puntualmente, en los accesos a las viviendas aparecen franjas de losas de hormigón prefabricadas de dimensiones 400×100 mm de sección y longitud variable, sobre terreno natural, mezclándose con las franjas de césped donde se recomienda la especie Festuca en combinación con Ray Grass Inglés.

\subsection{Sistemas de acondicionamiento e instalaciones}

Las instalaciones se han diseñado para obtener un consumo energético mínimo:

- Se utiliza un sistema de climatización mediante renovación de aire.

- Se ha elegido una bomba de calor con un COP de 4,5 y tecnología Inverter, que mejora su rendimiento, reduciendo considerablemente el consumo eléctrico del edificio.

- La instalación eléctrica va equipada con un sistema de luminarias a base de LEDs que contribuyen al ahorro energético.

- Los electrodomésticos tendrán una clase energética A+++.

2.3.1. Instalación de fontanería. Se busca disponer de medios adecuados para suministrar al equipamiento higiénico, aportando caudales suficientes para su funcionamiento, sin alteración de las propiedades de aptitud para el consumo e impidiendo los posibles retornos que puedan contaminar la red, incorporando medios que permitan el ahorro y el control del caudal del agua. 
Los equipos de producción de agua caliente estarán dotados de sistemas de acumulación y los puntos terminales de utilización tendrán unas características tales que eviten el desarrollo de gérmenes patógenos.

El sistema de abastecimiento de agua de la red municipal comienza en la acometida de la red exterior de la canalización que discurre por el margen de la carretera, la actual Calle Rebandas.

La obtención de Agua Caliente (ACS) se produce a partir de una Bomba de Calor que se compone de una unidad exterior y una interior. La unidad exterior se encuentra en el muro de instalaciones junto con todos los contadores necesarios para la vivienda y sus acometidas (Fig. 9).

La unidad interior se encuentra alojada en la parte alta del módulocomer donde también se dispondrá de la llave de corte general.

Dada la filosofía de passive house de la vivienda, se decide instalar un panel solar que reduzca la energía no renovable utilizada. Estos paneles se prevén en la parte trasera de la vivienda situados en el suelo. A ellos está conectado un Interacumulador de intercambio simple, también alojado en el interior del módulo comer y vinculado a la unidad interior de la bomba de calor.

Se ha calculado un panel solar de $1.34 \times 1.64 \mathrm{~m}$, suficiente para la demanda de una vivienda.

2.3.2. Instalación de climatización. Para la climatización se propone un suelo radiante del tipo panel "UPONOR IBERIA".

La exigencia de calidad térmica del ambiente se considera satisfecha en el diseño y dimensionamiento de la instalación térmica. Por tanto, todos los parámetros que definen el bienestar térmico se mantienen dentro de los valores establecidos: Una temperatura de verano en las estancias de 25 o, en invierno de 21 y yna humedad relativa interior de $50 \%$.

Además, para mejorar la passive house se instalará un recuperador de calor que hará que disminuya la cantidad energía necesaria para climatizar la casa. Este recuperador será del tipo VMC de doble flujo, para viviendas unifamiliares, con intercambiadorde calor de flujos cruzados, con un rendimiento de hasta el 92\%. De esta manera se puede aprovechar parte del calor del aire que expulsamos fuera de la vivienda para renovar y calentar con él el aire nuevo que impulsamos desde el exterior. 
1. Contador de Agua fría.

2. Unidad exterior de bomba de calor.

3. Tubería que lleva el AF al interior de la vivienda.

4. Tubos de líquido refrigerante de la bomba de calor.

5. Llave de paso general de la vivienda.

6. Llave de paso de local húmedo, cocina.

7. Unidad interior de bomba de calor.

8. Distribución de AF y ACS por tuberías por forjado sanitario.

9. Llave ACS cuarto húmedo y cocina.

10. Interacumulador de intercambio simple.

11. Extracción de humos de cocina.

12. Recuperador de calor.

13. Cuadro eléctrico.

14. Colectores suelo radiante.

15. Suelo radiante.

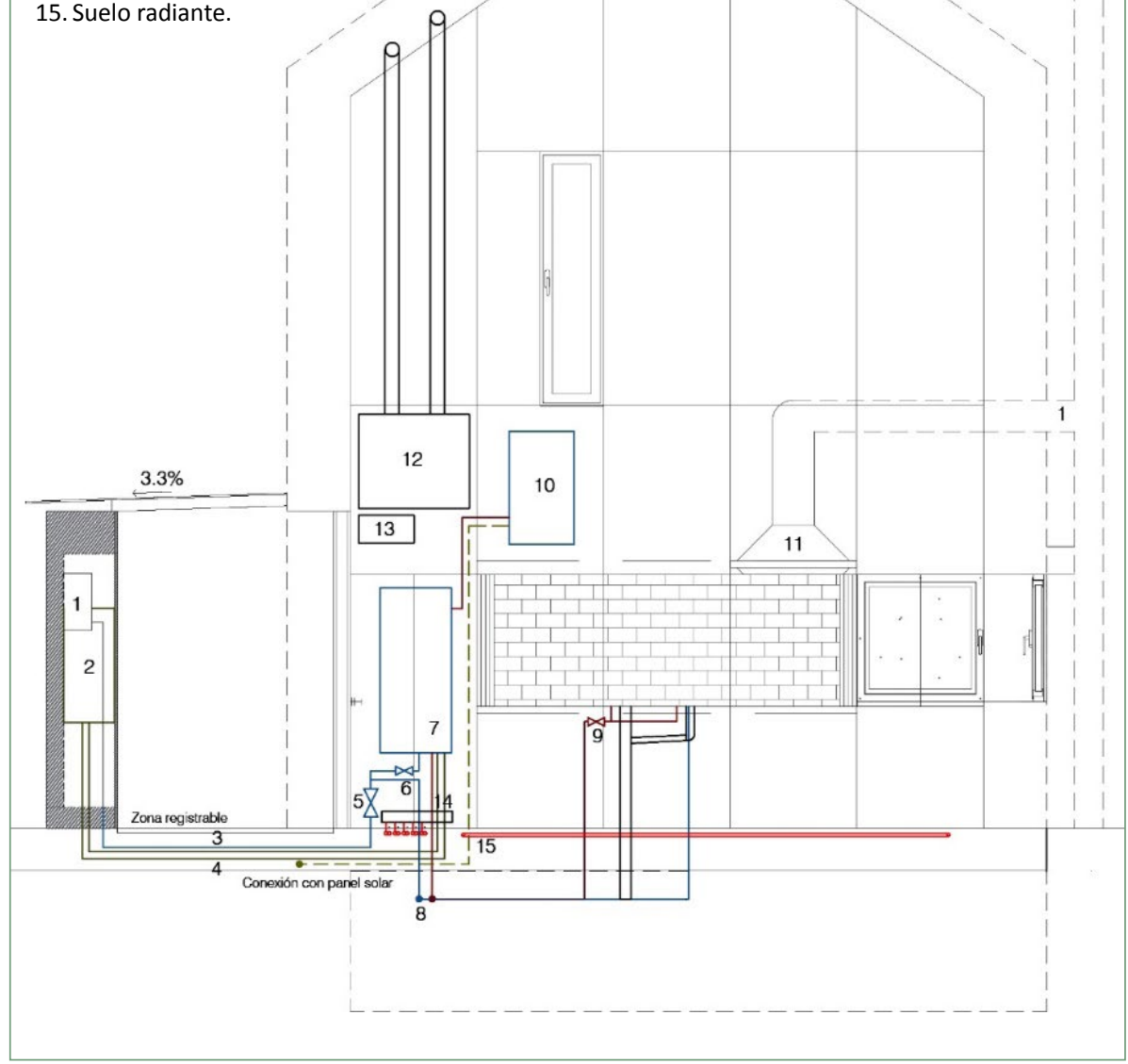

Fig.9. Sección módulo-cocina y módulo-instalaciones. 


\subsubsection{Instalación eléctrica}

Se proyecta una instalación que verifique el cumplimiento del Reglamento Electrotécnico para Baja Tensión e Instrucciones Técnicas Complementarias (ITC) BT01 a BT51.

Las necesidades de consumo de electricidad son las siguientes: iluminación y fuerza.

En este caso, como el suministro es para un único usuario, se simplifica la instalación colocando una caja de protección y medida (CPM) en lugar de una CGP. Con su correspondiente línea general de alimentación que aloja los elementos de protección de las líneas generales de alimentación y marcará el principio de la propiedad de las instalaciones de los usuarios. Se situará en una zona de acceso público: El muro de instalaciones que hay antes de entrar a la vivienda.

Las derivaciones individuales enlazan cada contador con su correspondiente cuadro general de mando y protección.

En la entrada de cada vivienda se instalará el cuadro general de mando y protección, que contará con los siguientes dispositivos de protección: Interruptor general automático, Interruptor diferencial general, Interruptor automático de corte omnipolar.

\section{Resultados y discusión}

\subsection{Resumen del cálculo de la demanda energética}

La Tabla 2 muestra un resumen de los resultados obtenidos en el cálculo de la demanda energética de calefacción y refrigeración de cada zona habitable, junto a la demanda total del edificio.

Se puede ver que los valores de demanda calculada son inferiores a los valores límites, tanto para calefacción como para refrigeración. Estos valores hacen que la vivienda entre dentro de las denominadas Passive Housse o vivienda de consumo casi nulo.

\subsection{Balance energético anual del edificio}

La gráfica de barras de la Fig.10 muestra el balance energético del edificio mes a mes, contabilizando la energía perdida o ganada por transmisión térmica al exterior a través de elementos pesados y ligeros (Qtr,op y Qtr,w, respectivamente), la energía intercambiada por ventilación (Qve), la ganancia interna sensible neta (Qint,s), la ganancia solar neta (Qsol), el calor cedido o 


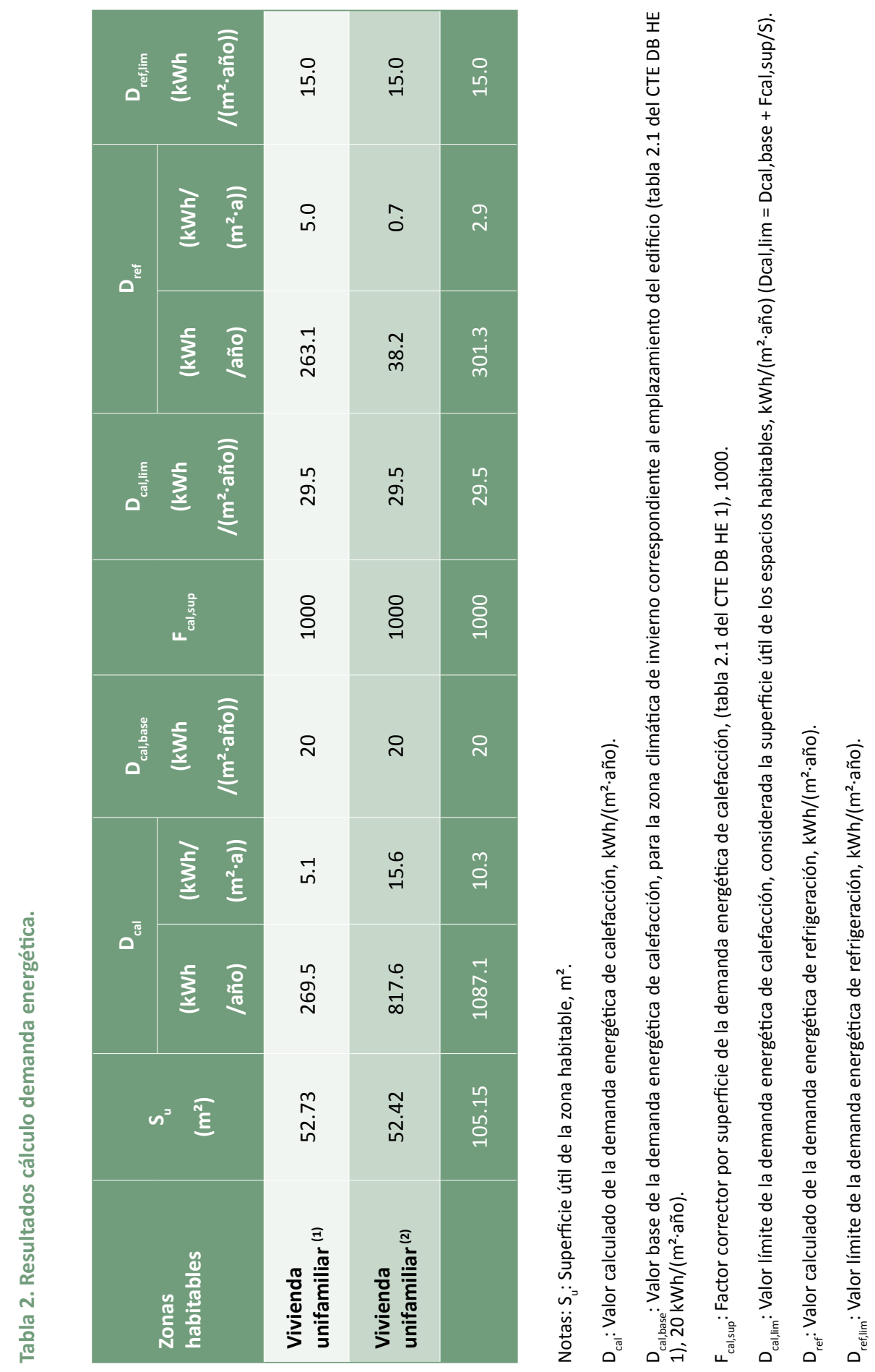


almacenado en la masa térmica del edificio (Qedif), y el aporte necesario de calefacción $(\mathrm{QH})$ y refrigeración $(\mathrm{QC})$. Estos parámetros se definen en mayor detalle a continuación:

- Qtr,op: Transferencia de calor correspondiente a la transmisión térmica a través de elementos pesados en contacto con el exterior, $\mathrm{kWh} /\left(\mathrm{m}^{2} \cdot \mathrm{año}\right)$.

- Qtr,w: Transferencia de calor correspondiente a la transmisión térmica a través de elementos ligeros en contacto con el exterior, $\mathrm{kWh} /\left(\mathrm{m}^{2} \cdot \mathrm{año}\right)$.

- Qve: Transferencia de calor correspondiente a la transmisión térmica por ventilación, $\mathrm{kWh} /\left(\mathrm{m}^{2}\right.$ ·año).

- Qint,s: Transferencia de calor correspondiente a la ganancia de calor interna sensible, $\mathrm{kWh} /\left(\mathrm{m}^{2} \cdot \mathrm{año}\right)$.

- Qsol: Transferencia de calor correspondiente a la ganancia de calor solar, $\mathrm{kWh} /\left(\mathrm{m}^{2} \cdot \mathrm{año}\right)$.

- Qedif: Transferencia de calor correspondiente al almacenamiento o cesión de calor por parte de la masa térmica del edificio, kWh/ ( $\left.m^{2} \cdot a n ̃ o\right)$.

- QH: Energía aportada de calefacción, kWh/(m²·año).

- QC: Energía aportada de refrigeración, kWh/(m².año).

- QHC: Energía aportada de calefacción y refrigeración, kWh/ $\left(m^{2} \cdot a n ̃ o\right)$.

Atendiendo únicamente a la demanda energética a cubrir por los sistemas de calefacción y refrigeración, las necesidades energéticas y de potencia útil instantánea a lo largo de la simulación anual se muestran en la Fig. 11.

Por último, en los gráficos de la Fig. 12 se muestran las potencias útiles instantáneas por superficie acondicionada de aporte de calefacción y refrigeración para cada uno de los días de la simulación en los que se necesita aporte energético para mantener las condiciones interiores impuestas, mostrando cada uno de esos días de forma superpuesta en una gráfica diaria en horario legal, junto a una curva típica obtenida mediante la ponderación de la energía aportada por día activo, para cada día de cálculo.

La información gráfica de la Fig. 12 se resume en la Tabla 3 de resultados estadísticos del aporte energético de calefacción y refrigeración. 


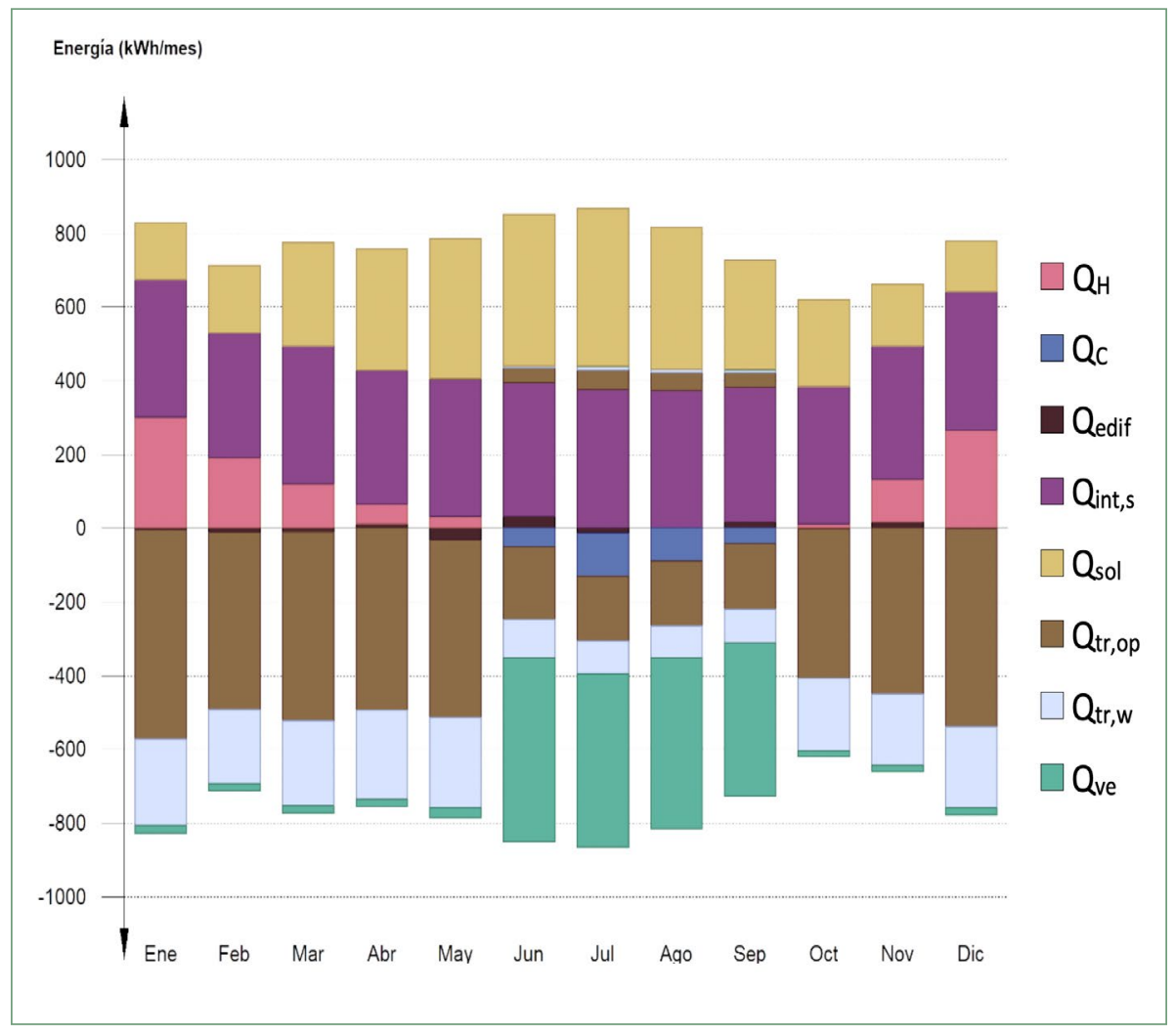

Fig. 10. Gráfica balance energético del edificio (leyendo: ver texto).

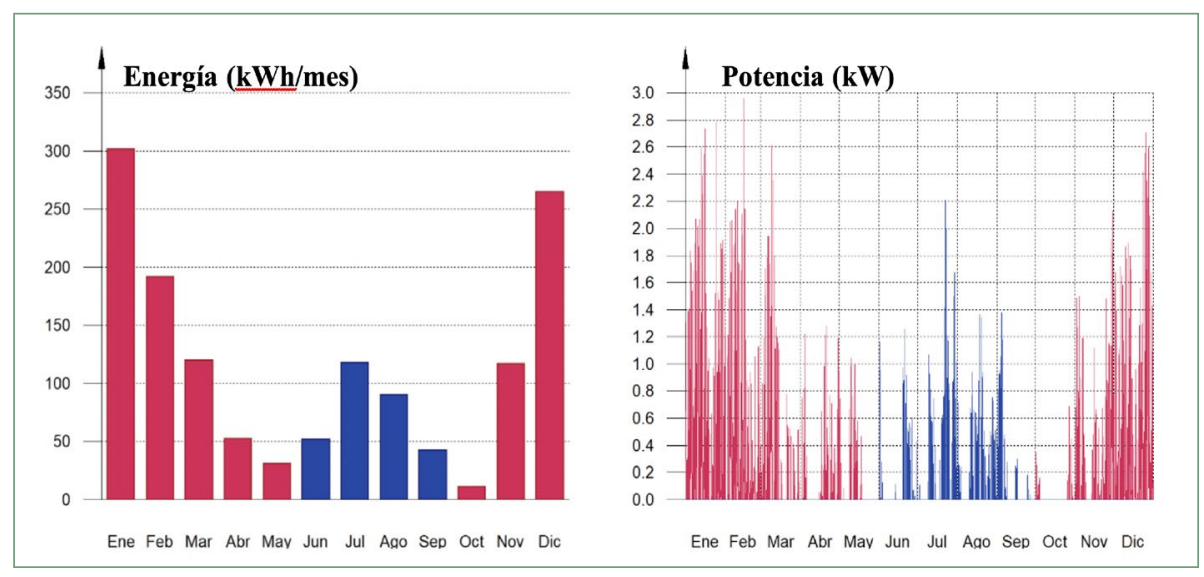

Fig. 11. Necesidades energéticas (izquierda) y de potencia (derecha). 


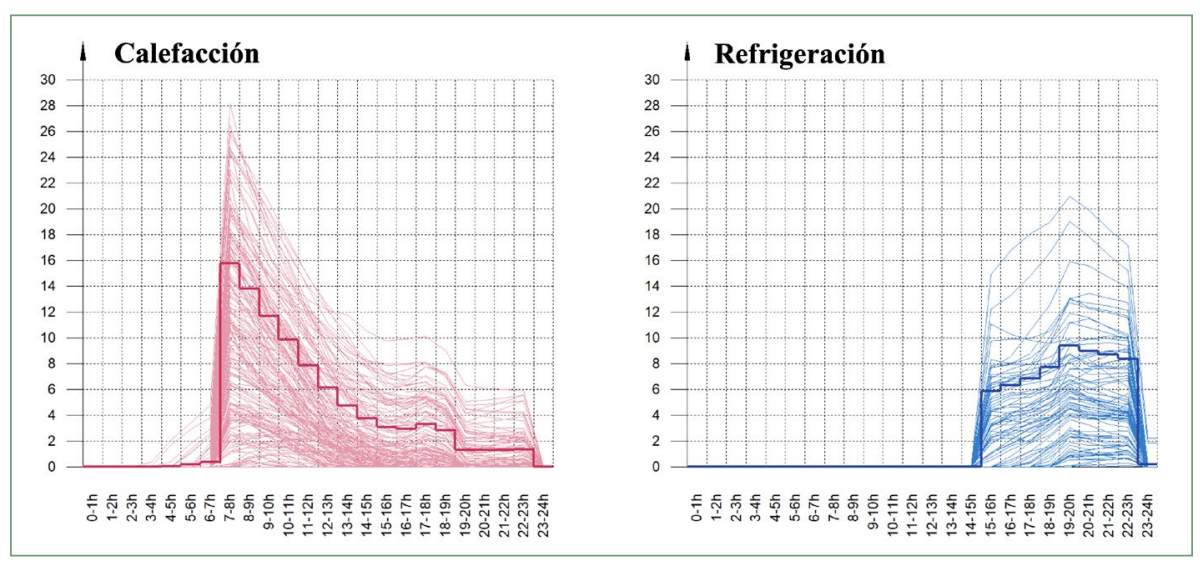

Fig. 12. Demanda diaria superpuesta de calefacción $\left(\mathrm{W} / \mathrm{m}^{2}\right)$ y demanda diaria superpuesta de refrigeración $\left(\mathrm{W} / \mathrm{m}^{2}\right)$.

Tabla 3. Resultados estadísticos de calefacción y refrigeración.

\begin{tabular}{|c|c|c|c|c|c|c|}
\hline & $\begin{array}{l}\text { Actividades } \\
\text { (N9) }\end{array}$ & $\begin{array}{l}\text { Días } \\
\text { activos } \\
\text { (d) }\end{array}$ & $\begin{array}{l}\text { Horas } \\
\text { activas } \\
\text { (h) }\end{array}$ & $\begin{array}{l}\text { Horas por } \\
\text { activ. } \\
\text { (h) }\end{array}$ & $\begin{array}{l}\text { Potencia } \\
\text { típica } \\
\left(\mathrm{W} / \mathrm{m}^{2}\right)\end{array}$ & $\begin{array}{l}\text { Demanda típica } \\
\text { por día activo } \\
\left(\mathrm{kWh} / \mathrm{m}^{2}\right)\end{array}$ \\
\hline Calefacción & 197 & 185 & 1981 & 10 & 5.22 & 0.0559 \\
\hline $\begin{array}{l}\text { Refri- } \\
\text { geración }\end{array}$ & 75 & 75 & 533 & 7 & 5.38 & 0.0382 \\
\hline
\end{tabular}

\subsection{Procedimiento de cálculo de la demanda energética}

El procedimiento de cálculo empleado consiste en la simulación anual de un modelo zonal del edificio con acoplamiento térmico entre zonas, mediante el método completo simplificado en base horaria de tipo dinámico descrito en UNE-EN ISO 13790:2011, cuya implementación ha sido validada mediante los tests descritos en la Norma EN 15265:2007 (Energy performance of buildings - Calculation of energy needs for space heating and cooling using dynamic methods - General criteria and validation procedures). Este procedimiento de cálculo utiliza un modelo equivalente de resistencia-capacitancia $(R-C)$ de tres nodos en base horaria. Este modelo hace una distinción entre la temperatura del aire interior y la temperatura media radiante de las superficies interiores (revestimiento de la zona del edificio), permitiendo su uso en comprobaciones de confort térmico, y aumentando la exactitud de la consideración de las partes radiantes y convectivas de las ganancias solares, luminosas e internas. 
La metodología cumple con los requisitos impuestos en el capítulo 5 de CTE DB HE 1, al considerar los siguientes aspectos:

- el diseño, emplazamiento y orientación del edificio;

- la evolución hora a hora en régimen transitorio de los procesos térmicos;

- el acoplamiento térmico entre zonas adyacentes del edificio a distintas temperaturas;

- las solicitaciones interiores, solicitaciones exteriores y condiciones operacionales especificadas en los apartados 4.1 y 4.2 de CTE DB HE 1 , teniendo en cuenta la posibilidad de que los espacios se comporten en oscilación libre;

- las ganancias y pérdidas de energía por conducción a través de la envolvente térmica del edificio, compuesta por los cerramientos opacos, los huecos y los puentes térmicos, con consideración de la inercia térmica de los materiales;

- las ganancias y pérdidas producidas por la radiación solar al atravesar los elementos transparentes o semitransparentes y las relacionadas con el calentamiento de elementos opacos de la envolvente térmica, considerando las propiedades de los elementos, su orientación e inclinación y las sombras propias del edificio u otros obstáculos que puedan bloquear dicha radiación;

- las ganancias y pérdidas de energía producidas por el intercambio de aire con el exterior debido a ventilación e infiltraciones teniendo en cuenta las exigencias de calidad del aire de los distintos espacios y las estrategias de control empleadas.

\subsection{Otros aspectos constructivos}

Las viviendas diseñadas además de ser energéticamente más eficientes, se plantean por módulos de rápido montaje in situ. Sus elementos y capas, son diseñados para esta propuesta, pero bien podrían extrapolarse para ser utilizados en nuevos diseños en un futuro, al igual que el sistema constructivo desarrollado. Los cerramientos se crean analizándolos desde la efectividad térmica hasta la comprobación de las condensaciones intersticiales pasando por el análisis económico, estudio de la acústica y sin olvidar la estética en ningún momento (Fig. 13). 

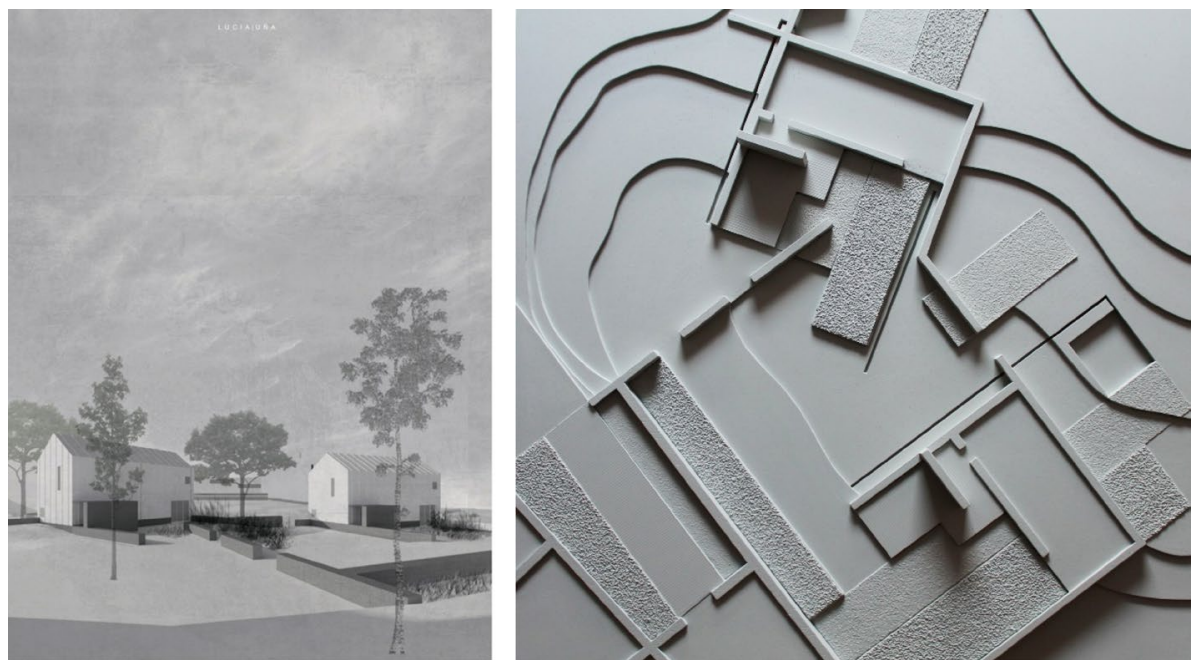

Fig. 13. Imagen de dos viviendas junto con los muros configuradores del espacio (izquierda) y maqueta conceptual de la propuesta, donde se aprecian los muros estructuradores, pavimentos, canales y aljibes (derecha).

La estructura ligera de las viviendas se asienta sobre una trama de muros pesados de hormigón que evocan a los antiguos, y bien podrían dar lugar a los castros del futuro. El edificio se posa sobre el terreno, deja su huella -pétrea-y modifica el paisaje sin atacarlo. Lo estándar no tiene por qué ser algo ajeno al lugar, estas viviendas se adaptan a la historia y tipología del sitio pero reinventándose con una nueva tecnología.

Los antiguos muros de piedra del entorno se funden con los nuevos muros de hormigón donde pasado y presente se fusionan en el conjunto de la propuesta.

\section{Conclusiones}

La passive house es algo que está más cerca de lo que pensamos. Poco a poco las viviendas van a tender a ser más eficientes energéticamente hablando. El concepto de consumo casi nulo se va inculcando poco a poco en la sociedad, la cual va modificando su manera de entenderlo.

Su intrusión en la arquitectura no tiene por qué ser algo radical. Los antiguos métodos de construcción, como los utilizados en la vivienda tradicional ya incluían gran cantidad de factores pasivos en su diseño y únicamente haría falta ir poco a poco actualizándolos con la tecnología actual. Sin embargo, 
debemos aprovechar los nuevos materiales y técnicas que posibilitan el mejor aislamiento y la estandarización.

Las nuevas edificaciones públicas, como las planteadas en el presente proyecto parecen la manera idónea de mostrar a la sociedad y generalizar este tipo de propuestas. Puesto que en el proyecto se realiza un presupuesto estimado, se ha podido comprobar que el precio de la construcción se incrementa mínimamente, además de tener muchos menos gastos a largo plazo por no tener apenas consumos.

Comparándola con una vivienda nueva construida de forma convencional, que alcanza como término medio una demanda de calefacción de unos 100 $\mathrm{kWh} / \mathrm{m}^{2} \cdot$ año, el estándar passive house consume casi siete veces menos (15 $\left.\mathrm{kWh} / \mathrm{m}^{2} \cdot a n ̃ o\right)$. El desarrollo de la vivienda planteada va más allá: $10.34 \mathrm{kWh} /$ $\mathrm{m}^{2}$.año, casi 10 veces menos que una vivienda convencional. 


\title{
Synthesis and study of new materials with barocaloric properties
}

\author{
Alba Martínez Muíño
}

\section{Summary}

More than the $20 \%$ of the world energy consumption is devoted to air conditioning and refrigeration. The most widespread technology for refrigeration is based on the mechanical compression of gases and fluids which include the use of ozone depleting chemicals (chlorofluorocarbons, CFCs, already prohibited), hazardous chemicals (ammonia, $\mathrm{NH}_{3}$ ), or greenhouse gases (hydrochlorofluorocarbons, HCFCs, and hydrofluorocarbons, HFCs) which contribute significantly to the global warming impact. Consequently, a malfunction and/or an inadequate disposal of the refrigeration machine at the end of its lifetime can result into a dangerous chemical leakage to the environment. In turn, these gases are expected to be forbidden during the next years and removed from the market.

The need of new refrigerants and coolants has led to the development of solid state materials with elastocaloric, electrocaloric, magnetocaloric and barocaloric properties. But most of them need to be submitted to big external stimuli, making difficult their introduction on the common life. Nevertheless, recent studies show that solids of the hybrid perovskite family can present giant barocaloric effects under low pressure.

This work describes the chemical synthesis, structural characterization and physical study of caloric properties of a new generation of solid-state materials

\footnotetext{
${ }^{1}$ Tutors TFM: Socorro Castro García (UDC, CICA), Jorge José López Beceiro (UDC, EPS), Alain Ponton (UPD 7, CNRS).

*Data for Citation: Martínez Muíño, Alba (2019). "Synthesis and study of new materials with barocaloric properties". In Oficina de Medio Ambiente UDC (ed.), I Premio UDC Sustentabilidade a traballos fin de grado e mestrado 2018. A Coruña: Universidade da Coruña, 89-102. Book's DOI: https://doi.org/10.17979/spudc.9788497497831.
} 
that exhibit an unprecedented potential for refrigeration technologies under the application of external stimuli such as pressure.

We have prepared the hybrid lead chloride $\mathrm{DMAPbCl}_{3}$ perovskite (being DMA the dymethylammonium cation $\left.\left(\mathrm{CH}_{3}\right)_{2} \mathrm{NH}_{2}^{+}\right)$and some $\mathrm{DMAPbCl}{ }_{3-\mathrm{Br}} \mathrm{Br}_{x}$ homologous materials, with bromide doping $x=0.1,0.2,0.3,0.4,0.5$. All samples were characterized by powder X-ray diffraction (P-XRD), Scanning Electron Microscopy-Energy Dispersive X-Ray Spectrocopy (SEM-EDX) and Thermogravimetric Analysis (TGA). Differential Scanning Calorimetry under pressure (P-DSC) studies were also carried out at room pressure and 750 p.s.i.

These studies showed barocaloric transitions in all the compounds around room temperature, and that the temperature transition can be tuned by changing the $\mathrm{Br}$ doping quantity, two conditions that make them very good candidates for use in solid state refrigeration devices.

Keywords: solid state refrigeration, barocaloric effect, hybrid perovskites.

\section{Introduction}

\subsection{The problem of the refrigerants}

Nowadays, air conditioning and refrigeration represents more than $20 \%$ of the energy world's consumption, and their demand is expected to grow in the next years. However, conventional refrigerants show low efficiency due to their liquid or gas state, which make difficult to control any scape or leak. And these escapes can damage the environment [1].

Additionally, even the most modern refrigerants, as HCFC's (hydro chlorofluorocarbons) and HFC's (hydrofluorocarbons), are going to be prohibited by the European Union in 2020 [2] due to the damage caused to the ozone layer and their contribution to the climate change.

Under normal conditions, formation and destruction of ozone occurs naturally and is in a dynamic equilibrium maintaining a constant concentration of ozone in the stratosphere. Once this reaction involves CFC's (chlorofluorocarbons), more ozone is decomposed than formed (see Figure 1). Since the mid-1970 scientists have been concerned about the harmful effects of CFC's on the ozone layer. Because these compounds are readily liquefied, inert, non-toxic, noncombustible, and volatile, they have been used as coolants in refrigerators and air conditioners. Big quantities of CFC's are also used in foam products, aerosols, and as solvents to clean newly soldered electronic circuit boards. Nearly $1.5 \mathrm{x}$ $10^{6}$ tons of CFC's can be produced in the USA per year, mostly for commercial and industrial use and with high possibilities of leaking into the atmosphere. The 
origin of the problem is that, due to their relative inertness, the CFCs diffuse to the stratosphere, where UV radiation causes their decomposition: the chlorine atoms acts as catalyst, degrading ozone into oxygen and $\mathrm{ClO}$, resulting into a decrease of the ozone layer, as represented in Figure 1.
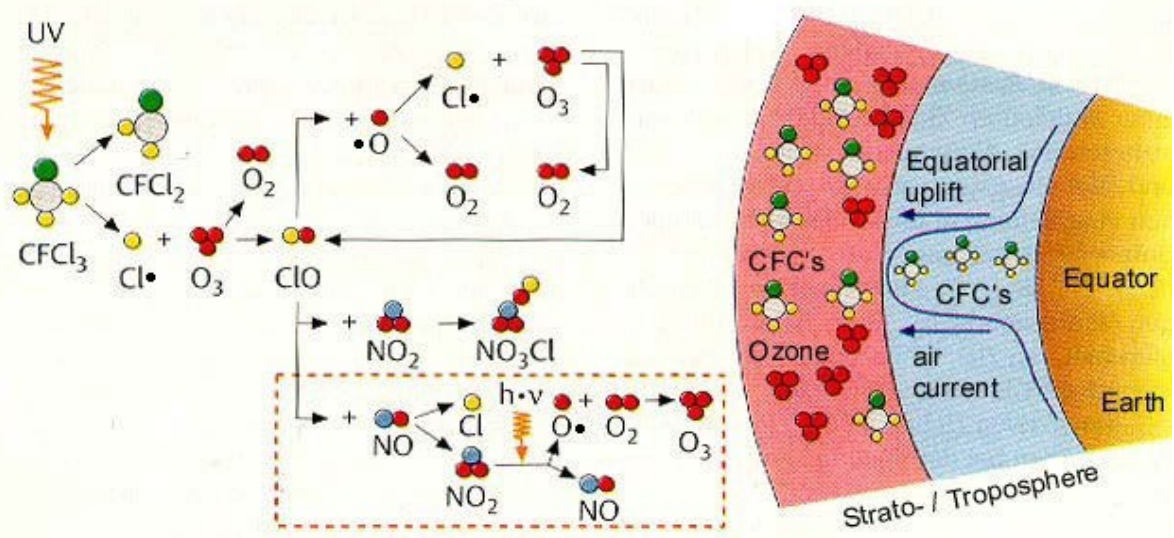

Figure 1. Ozone depletion by CFC's.

.One $\mathrm{Cl}$ atom can destroy up to $100,000 \mathrm{O}_{3}$ molecules before it is removed by some other reaction. $\mathrm{ClO}$ is an intermediate, produced in the first step and consumed in the second. The mechanism for the destruction of ozone has been supported by the detection of $\mathrm{ClO}$ in the stratosphere in recent years. So CFC's must be highly avoided in order to preserve the ozone layer, essential to live on Earth.

Coming back to old coolants or "first generation" (ammonia, carbon dioxide or sulphur dioxide, among others) [3] is not a good option: they are explosive, inflammable, toxic, etc. They can cause accidents, and they used to be on liquid or gas state. So, the leak's problem is not solved, and a new security problem is added.

Therefore, the most appropriate solution, and one of the major scientific and technological challenges, is finding more efficient and environmentally friendly cooling alternatives. One of most promising are barocaloric materials, highlighting perovskites due to their solid state and stability.

\subsection{Caloric materials}

By following this line, a good approach is developing solid-state materials with large caloric effects. This caloric effect consists on an adiabatic temperature 
change or an isothermal entropy change when the material is submitted to external stimuli. And, depending on the external stimuli they receive different name [4-6]:

- Elastocaloric effect: it is produced when the material is submitted to a mechanical stress, specifically to uniaxial strain. Then, a phase transformation is induced [6].

- Electrocaloric effect: when an electric field is applied to a dielectric material, a change in the polarization is produced. This change cause a temperature and entropy change, based on the order-disorder of the material's dipoles [7].

- Magnetocaloric effect: it occurs when a magnetic field is applied to a magnetic material and the magnetic dipoles are ordered (or disordered). If this occurs under isothermal conditions, an entropy change occurs, if it's under adiabatic conditions a temperature change is produced [8].

- Barocaloric effect: it refers to the temperature change when a material is submitted to a hydrostatic pressure.

However, most of those materials need big external stimuli to obtain a remarkable effect or rare and expensive reactants.

Recently, the ferroic organic-inorganic perovskite [TPrA][Mn(dca $\left.)_{3}\right]$ has been probed to present a giant barocaloric effect under accessible pressures, as 70 bar (reached on actual fridges) [1,9]. We can imagine a lot of applications related to this material, more than the typical refrigerant: it could be used to cool our foot while we are running (just with the foot pressure), to cool stations with the pressure made by the people walking, to regulate the temperature while we sleep on the bed, etc. [10] making a refrigeration more eco-friendly. So, a new range of applications is opened for hybrid perovskites related with this structure.

\subsection{Hybrid perovskites}

Oxidic perovskites (based on the structure of the $\mathrm{CaTiO} 3$ perovskite mineral) present $\mathrm{ABO} 3$ as general formula, being $\mathrm{A}$ a big cation (alkaline, alkaline earth or lanthanide) and $B$ a little or middle size cation (normally a transition metal). They present a typical structure based on a 3D network of BO6 octahedra connected by the corners, with each A cation on a cuboctahedral hole (and coordinated to a 12 O2-). But perovskites present a versatile structure, which admits different kind of doping and modifications [11]. Very interesting, the A metal can be changed by organic ligands [12-14] (being the most common the amines, but not the 
only ones), while the anionic oxide can be changed for a halide anion ( $\mathrm{Cl}$-, $\mathrm{Br}$ - and I-, for example), giving the ABX3 structure represented in Figure 2. Those new perovskites are the hybrid halide perovskites [18], and belong to a family of materials called Hybrid Organic-Inorganic Perovskites (HOIP) [15]. These HOIP's have been known for decades, since Mitzi et al. initiated their study in 90's [18].

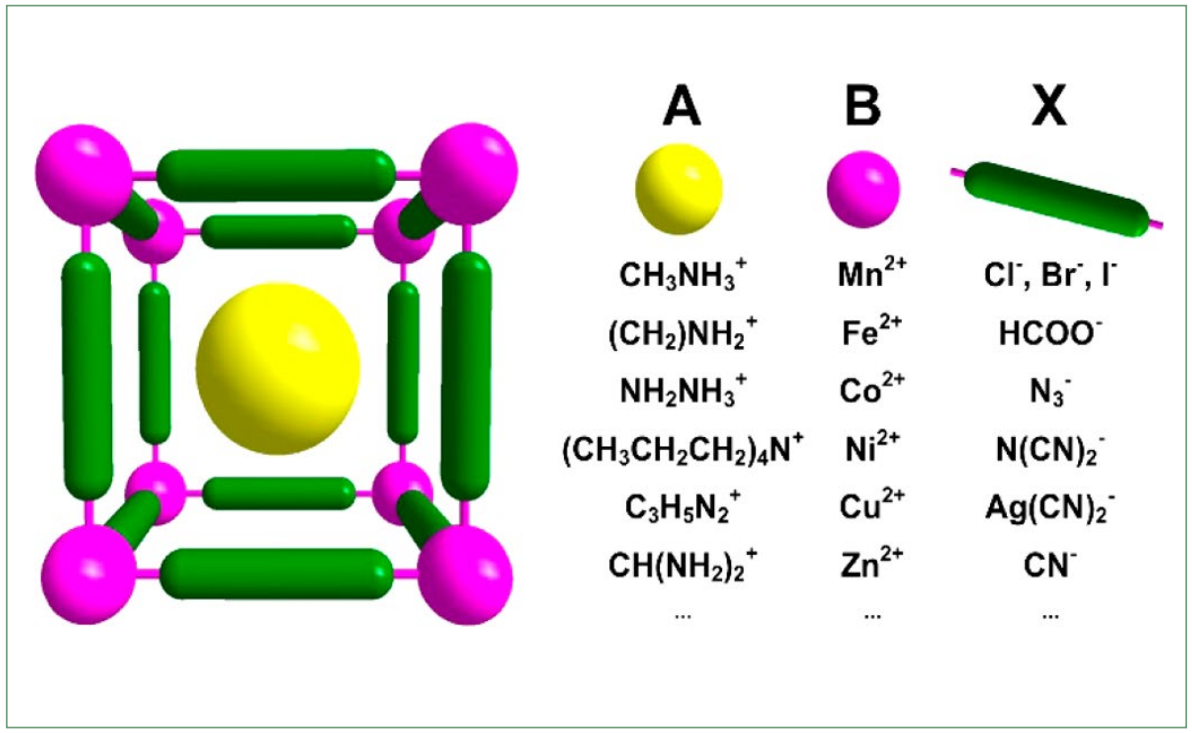

Figure 2. General ABX3 hybrid organic-inorganic perovskite structure, where A (yellow sphere) is an alkyl ammonium cation, B (pink spheres) is a transition metal cation and X (green rods) is an halide or a polyatomic bidentate-bridge ligand [19].

The presence of the organic and inorganic blocks increases the perovskite's chemical diversity, their structural richness and flexibility. These give them novel multifunctional properties, as unique electrical, magnetic, and optical properties.

Recent studies of the research group in which this work was developed, reached the synthesis and structural characterization of the $\mathrm{DMAPbX}_{3}$ $\left(\mathrm{X}=\mathrm{Cl}^{-}, \mathrm{Br}^{-}\right)$hybrid perovskites, where DMA is the dymethylammonium cation $\left(\mathrm{CH}_{3}\right)_{2} \mathrm{NH}_{2}^{+}$. Both compounds display similar structures derived from perovskite, and a structural phase transition, associated with a sharp dielectric transition, which take place near room temperature for the chloride compound. These features suggest that $\mathrm{DMAPbCl}_{3}$ is a good candidate to exhibit barocaloric effect near the room temperature. 


\subsection{Objectives}

The main objective of this work is developing new barocaloric solid-state materials as potential refrigerants and cooling substituents.

For this purpose, the next tasks were proposed:

1. Synthesis and characterization of $\mathrm{DMAPbCl}_{3}(\mathrm{DMA}=$ dimethyl ammonia).

2. Synthesis and characterization of $\mathrm{DMAPbCl}_{3-\mathrm{x}} \mathrm{Br}_{\mathrm{x}}(0<\mathrm{x}<0.5)$ doped perovskites.

3. Characterization and study of the structural transition of the synthesized materials.

4. Establishing the relationship between the temperature transition and $\mathrm{Br}$ doping quantity.

5. Study of the barocaloric properties of the synthetized materials.

\section{Experimental}

\subsection{Synthesis of synthesis of $D M A P B C L_{3-x} B_{x}$ hybrid perovskites}

All starter materials and metallic salts used are commercially available (Aldrich), and were used as received by the correspondent supplier, unless the opposite is indicated. No solvents were used on the synthesis.

Different $\mathrm{DMAPbl}_{3-\mathrm{x}} \mathrm{Br}_{\mathrm{x}}$ (DMA= dimethyl ammonia) perovskites were synthetized in the laboratory by mechanosynthesis using the quantities specified in Table I.

The mechanosynthesis seemed to be the best option, due to its simplicity, the no-need of crystallization and the little time that it requires. The efficiency of this method is close to $100 \%$ (only mass loses due to transfers are considered).

With these things in mind, the synthesis of the first complex (DMAPbCl${ }_{3}$ ) was tried. Specific quantities (see Table I) of DMACl and $\mathrm{PbCl}_{2}$ were mixed on a 1:1 proportion (Scheme 1) with a marble mortar, grinding during 5 minutes, in order to get a homogeneous powder. 
Table I. DMACl, $\mathrm{PbCl}_{2}$ and $\mathrm{PbBr}_{2}$ quantities used to obtain $1 \mathrm{~g}$ of $\mathrm{DMAPbCl}{ }_{3-\mathrm{x}} \mathrm{Br}_{x}$.

\begin{tabular}{|c|c|c|c|}
\hline $\begin{array}{c}\mathrm{PbBr}_{2} \\
\text { (dopant) }\end{array}$ & $\mathrm{PbCl}_{2}$ & DMACI & \\
\hline-- & $\begin{array}{c}0.81 \mathrm{~g} \\
(2.90 \mathrm{mmol})\end{array}$ & $\begin{array}{c}0.19 \mathrm{~g} \\
(2.90 \mathrm{mmol})\end{array}$ & $\mathrm{DMAPbCl}_{3}$ \\
\hline $\begin{array}{c}0.05 \mathrm{~g} \\
(0.14 \mathrm{mmol})\end{array}$ & $\begin{array}{c}0.77 \mathrm{~g} \\
(2.72 \mathrm{mmol})\end{array}$ & $\begin{array}{c}0.19 \mathrm{~g} \\
(2.87 \mathrm{mmol})\end{array}$ & $\mathrm{DMAPbCl}_{2.9} \mathrm{Br}_{0.1}$ \\
\hline $\begin{array}{c}0.11 \mathrm{~g} \\
(0.28 \mathrm{mmol})\end{array}$ & $\begin{array}{c}0.72 \mathrm{~g} \\
(2.55 \mathrm{mmol})\end{array}$ & $\begin{array}{c}0.19 \mathrm{~g} \\
(2.83 \mathrm{mmol})\end{array}$ & DMAPbCl$_{2.8} \mathrm{Br}_{0.2}$ \\
\hline $\begin{array}{c}0.16 \mathrm{~g} \\
(0.42 \mathrm{mmol})\end{array}$ & $\begin{array}{c}0.67 \mathrm{~g} \\
(2.38 \mathrm{mmol})\end{array}$ & $\begin{array}{c}0.19 \mathrm{~g} \\
(2.79 \mathrm{mmol})\end{array}$ & $\mathrm{DMAPbCl}_{2.7} \mathrm{Br}_{0.3}$ \\
\hline $\begin{array}{c}0.20 \mathrm{~g} \\
(0.55 \mathrm{mmol})\end{array}$ & $\begin{array}{c}0.62 \mathrm{~g} \\
(2.21 \mathrm{mmol})\end{array}$ & $\begin{array}{c}0.19 \mathrm{~g} \\
(2.73 \mathrm{mmol})\end{array}$ & DMAPbCl${ }_{2.6} \mathrm{Br}_{0.4}$ \\
\hline $\begin{array}{c}0.25 \mathrm{~g} \\
(0.68 \mathrm{mmol})\end{array}$ & $\begin{array}{c}0.57 \mathrm{~g} \\
(2.05 \mathrm{mmol})\end{array}$ & $\begin{array}{c}0.18 \mathrm{~g} \\
(2.73 \mathrm{mmol})\end{array}$ & $\mathrm{DMAPbCl}_{2.5} \mathrm{Br}_{0.5}$ \\
\hline
\end{tabular}

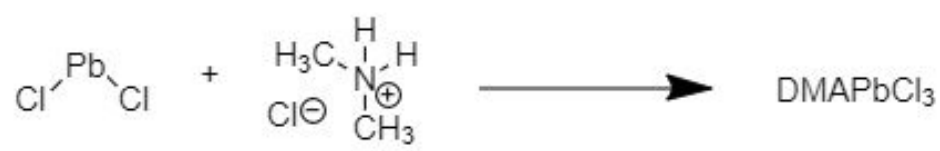

Scheme 1. Synthetic reaction of $\mathrm{DMAPbCl}_{3}$.

For the rest of the samples ( $\left.\mathrm{DMAPbCl}_{3-\mathrm{x}} \mathrm{Br}_{\mathrm{x}}\right), \mathrm{PbBr}_{2}$ was used as reactant and dopant, as can be seen on Scheme 2. This changes the DMACl: $\mathrm{PbCl}_{2}$ proportion from 1:0.95 for $x=0.1\left(\mathrm{DMAPbCl}_{2.9} \mathrm{Br}_{0.1}\right)$ to 1:0.75 for $\mathrm{x}=0.5\left(\mathrm{DMAPbCl}_{2.5} \mathrm{Br}_{0.5}\right)$.

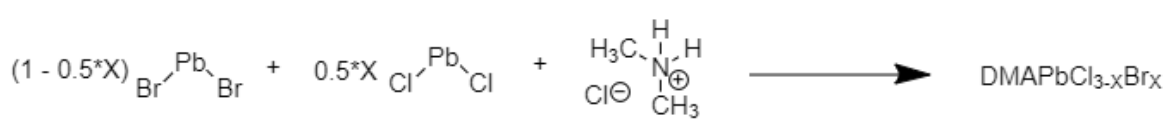

Scheme 2. Synthetic reaction of $\mathrm{DMAPbCl}{ }_{3-\mathrm{x}} \mathrm{Br}_{\mathrm{x}}$.

A white homogeneous powder was obtained from each synthesis. 


\subsection{Experimental methods of characterization}

The powder $X$-ray diffraction (P-XRD) measures were performed on a Siemens X-ray diffractometer model D5000, with a $\mathrm{Cu}\left(\mathrm{K}_{\alpha}\right)=1.5418 \AA$ as radiation source, at room temperature, and by steps of $0.05^{\circ}(2 \theta)$, with a step time of 3s. The equipment is available in the Structural Analysis Unit of the Research Support Services (SAI) of the University of Coruña (UDC).

A Jeol JSM 6400 equipment was used to make the scanning electron microscopic observations with energy dispersive $\mathrm{X}$-ray spectroscopic analysis (SEM-EDX measurements). The equipment is available in the Microscopy Unit (UM) of the Research Support Services (SAI) of the University of Coruña (UDC).

Thermal stability studies were performed with a thermogravimetric analyser (TG) in a TA Instruments 2960 SDT, in order to know the decomposition temperature of every sample. A $100 \mathrm{~mL} / \mathrm{min}$ flow of nitrogen and a sample size between $10 \mathrm{mg}$ and $15 \mathrm{mg}$ were used in all cases. The samples were placed in a platinum TGA pan with a lid and submitted to a temperature program consisting on a $10 \% \mathrm{C} / \mathrm{min}$ ramp from $\approx 40^{\circ} \mathrm{C}$ to $1000^{\circ} \mathrm{C}$; measuring mass loss data.

Differential scanning calorimetry under pressure (P-DSC) analysis, from room pressure to 750 p.s.i., were carried out in a TA Instruments Q2000 modulated DSC equipped with a pressure cell. Indium was used as standard for temperature and heat calibration of standard and pressure cells, at each pressure in the last case. For the pressure experiments, all the samples $(5-10 \mathrm{mg}$ ) were placed on a standard pan with a standard lid and a constant nitrogen gas flow of $50 \mathrm{ml} / \mathrm{min}$. Heating and cooling ramps of $10 \mathrm{~K} / \mathrm{min}$ were programmed from $293 \mathrm{~K}-298 \mathrm{~K}$ to $343 \mathrm{~K}$. Two cooling cycles and three heating cycles for every pressure and sample were performed.

\section{Results and discussion}

\section{Powder X-Ray Diffraction (P-XRD)}

The obtained experimental diffractogram of $\mathrm{DMAPbCl}_{3}$ was compared with the standard one, and no significant differences were found between them. So, it can be said that $\mathrm{DMAPbCl}{ }_{3}$ was successfully obtained. In order to check the result of the doping, a comparison between the sample's diffractogram of $\mathrm{DMAPbCl}_{2.5} \mathrm{Br}_{0.5}, \mathrm{DMAPbCl}_{2.6} \mathrm{Br}_{0.4^{\prime}} \mathrm{DMAPbCl}_{2.7} \mathrm{Br}_{0.3^{\prime}}$ DMAPbCl ${ }_{2.8} \mathrm{Br}_{0.2}, \mathrm{DMAPbCl}_{2.9} \mathrm{Br}_{0.1}$ and $\mathrm{DMAPbCl}_{3}$ was done, as can be seen in Figure 3. 


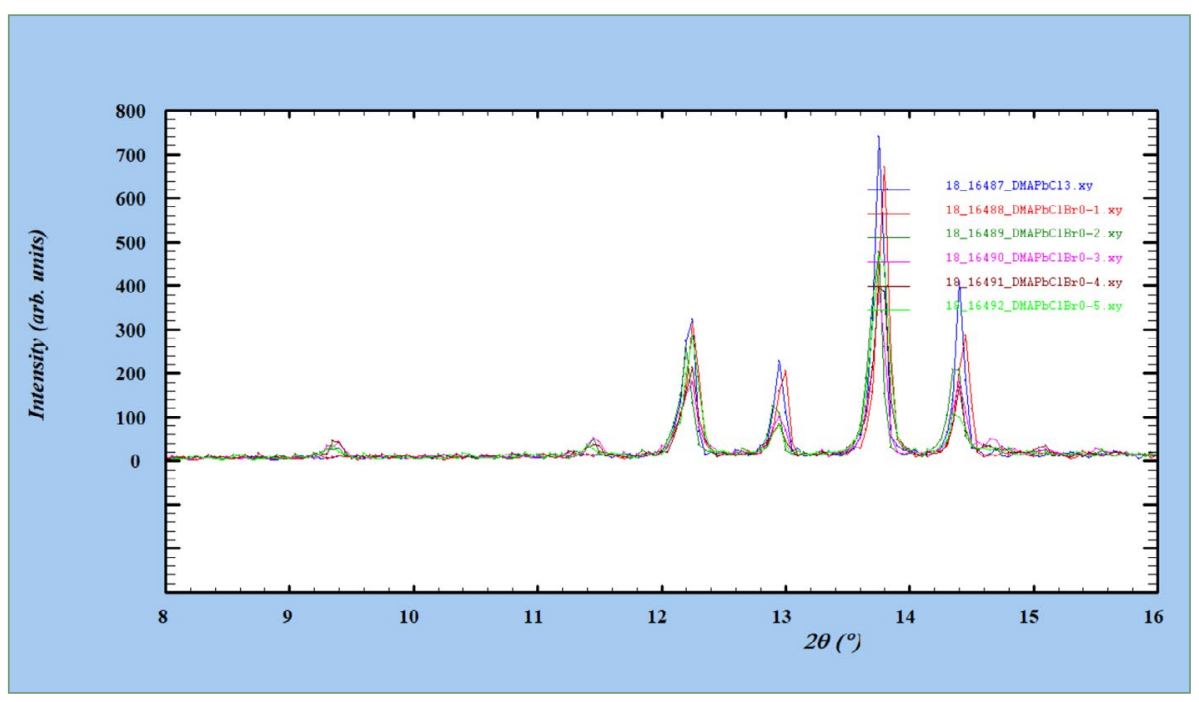

Figure 3. Comparative of the diffractogram's samples of $\mathrm{DMAPbCl}_{2.5} \mathrm{Br}_{0.5}$ (light green), DMAPbCl ${ }_{2.6} \mathrm{Br}_{0.4}$ (brown), DMAPbCl${ }_{2.7} \mathrm{Br}_{0.3}$ (fuchsia), DMAPbCl${ }_{2.8} \mathrm{Br}_{0.2}$ (dark green), $\mathrm{DMAPbCl}_{2.9}^{2.6} \mathrm{Br}_{0.1}$ (red) and $\mathrm{DMAPbCl}_{3}$ (blue), in the region of $8-160(2 \theta)$.

New peaks are observed at $02 \Theta$ around $9.3,11.5,21.1$ and 23.4, for doped samples from $\mathrm{DMAPbCl}{ }_{2.8} \mathrm{Br}_{0.2}$ to $\mathrm{DMAPbCl}_{2.5} \mathrm{Br}_{0.5}$, justified by the solid substitution solution's character of the samples. There are also some changes on the intensities of some peaks, as for example the peaks with the maxima around 25 and $12.3 \stackrel{\circ}{\circ}(2 \theta)$. However, because the position of the peaks remains unaltered, those differences doesn't mean a change on the cell of the different compounds.

\section{Scanning Electron Microscopy-Energy Dispersion X-ray Spectroscopy (SEM-EDX)}

All samples show a homogenous aspect, formed by aggregates of particles with grain sizes between $4.2 \mu \mathrm{m}$ and $6.8 \mu \mathrm{m}$, and a homogeneous distribution of all the elements. The composition was confirmed with the EDX characteristics peaks corresponding to $\mathrm{C}, \mathrm{Cl}, \mathrm{Pb}$ (for sample $\mathrm{DMAPbCl}$ ), and additionally $\mathrm{Br}$ (for samples $\mathrm{DMAPbCl}{ }_{2.5} \mathrm{Br}_{0.5}, \mathrm{DMAPbCl}_{2.6} \mathrm{Br}_{0.4^{\prime}}, \mathrm{DMAPbCl}{ }_{2.7} \mathrm{Br}_{0.33^{\prime}}$ DMAPbCl $2.8 r_{0.2}$ and DMAPbCl $2.9 \mathrm{Br}_{0.1}$ ), that appears at $1.5 \mathrm{keV}$, on the EDX spectra. An increase on the $\mathrm{Br}$ quantity can be appreciated, even went the smaller quantities were used as doping; nevertheless, the doping doesn't affect the homogeneous distribution of the elements. The stoichiometry was confirmed with the relation between the atomic percentage of $\mathrm{Cl}$ and $\mathrm{Pb}$ for $\mathrm{DMAPbCl}_{3}$ (as it is the only one with no $\mathrm{Br}$ doping), and of $\mathrm{Br} / \mathrm{Pb}$ for the others. All the ratios give expected values, from $\mathrm{DMAPbCl}_{3}$ with $3.04(\mathrm{Cl} / \mathrm{Pb})$ to $\mathrm{DMAPbCl}{ }_{2.5} \mathrm{Br}_{0.5}$ with $0.46(\mathrm{Br} / \mathrm{Pb})$. 


\section{Thermogravimetric Analysis (TGA)}

Under room conditions (air atmosphere and $25^{\circ} \mathrm{C}$ ), the samples are quite stable with time, not seeing any change during the experiments. Taking this in mind, the possible losses and contaminations due to refrigerants leakage is minimized, due to the solid character of the samples.

All samples were also tested under a nitrogen flux of $100 \mathrm{ml} / \mathrm{min}$, in order to avoid the sample's combustion, with a temperature ramp of $10 \mathrm{~K} / \mathrm{min}$. In those conditions, all samples are stable until approximately 150 ㅇ $\mathrm{C}(423 \mathrm{~K})$. At this temperature, a mass loss of approximately $18 \%$ of the weight starts, which matches with the organic part of the perovskite (DMA) (as could be expected), and with a part of $\mathrm{Cl}$ (since that element is the lightest one of the perovskite; with

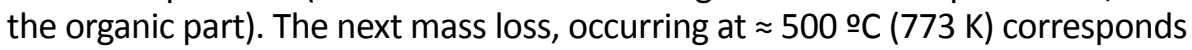
to the remaining part (80\% of the weight) and matches with $\mathrm{PbCl}_{2-\mathrm{x}} \mathrm{Br}_{x}$.

Those results prove the high stability of the compounds at room temperature, and that the $\mathrm{Br}$ doping seems not to affect their thermal stability or decomposition reactions.

\section{Pressure-Differential Scanning Calorimetry (P-DSC)}

All the samples were submitted to two experiments: one at the minimum pressure needed for a nitrogen flux of $50 \mathrm{ml} / \mathrm{min}$ (considered room pressure) and another at the maximum pressure reached by the P-DSC without noise, 750 p.s.i. (see Figure 4).

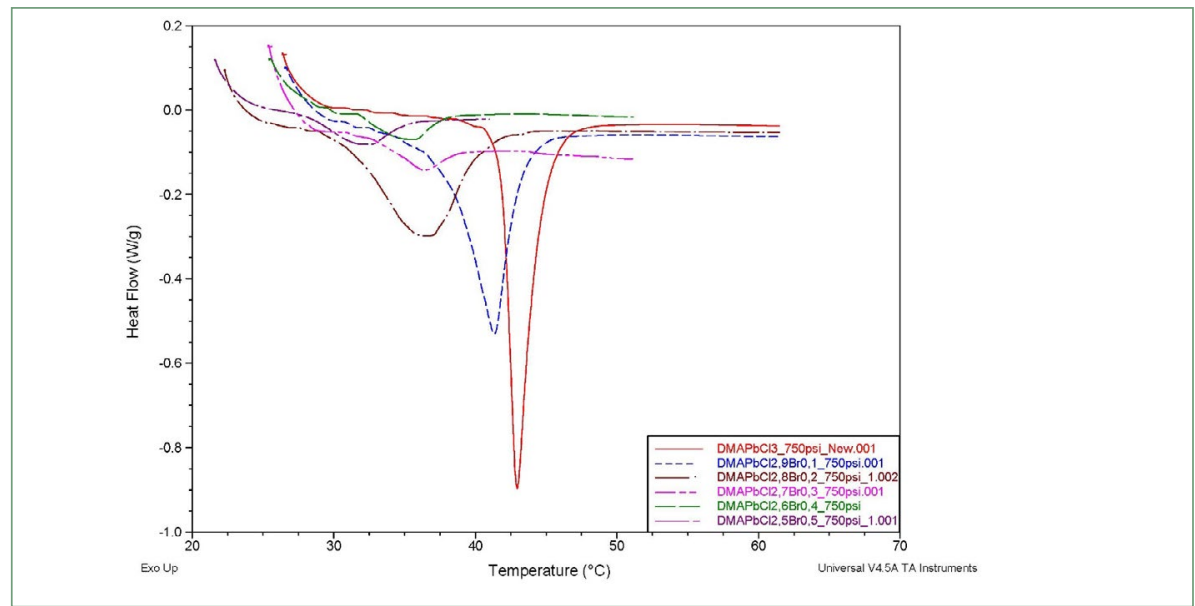

Figure 4. Heat flow vs Temperature plot of all samples at 750 p.s.i. $\mathrm{DMAPbCl}_{2.5} \mathrm{Br}_{0.5}$ (purple), DMAPbCl ${ }_{2.6} \mathrm{Br}_{0.4}$ (green), DMAPbCl ${ }_{2.7} \mathrm{Br}_{0.3}$ (fuchsia), DMAPbCl ${ }_{2.8} \mathrm{Br}_{0.2}$ (brown), $\mathrm{DMAPbCl}_{2.9} \mathrm{Br}_{0.1}$ (blue) and $\mathrm{DMAPbCl}_{3}($ red). 
An endothermic peak is observed for all samples, at room pressure and 750 p.s.i. The appearance of these peaks is related to the disorder of the DMA organic ligand. The position of the peak changes with the $\mathrm{Br}$ doping, from the highest temperature $(42.68 \stackrel{\circ}{\circ}$ or $315.83 \mathrm{~K})$ with no doping of $\mathrm{DMAPbCl}_{3}$, to the lowest one (32.16 $9 \mathrm{C}$ or $305.31 \mathrm{~K}$ ) for $\mathrm{DMAPbCl}_{2.5} \mathrm{Br}_{0.5}$ at room pressure.

The behavior is similar, and the peak movement is also seen, at a pressure of 750 p.s.i. (Figure 4), with the highest and lowest temperature also for

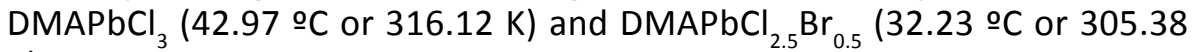
K).

A linear relationship between the doping ( $x$ value in $D M A P b C l_{3-x} B r_{x}$ ) and the temperature of the maxima of the heat flow, can be stablished for both pressures, as can be seen on Figure 5 , with a correlation value $\left(R^{2}\right)$ of 0.9 for both models. So, it can be said that the temperature of the maximum of the heat flow can be tuned with a doping agent, as $\mathrm{Br}$.

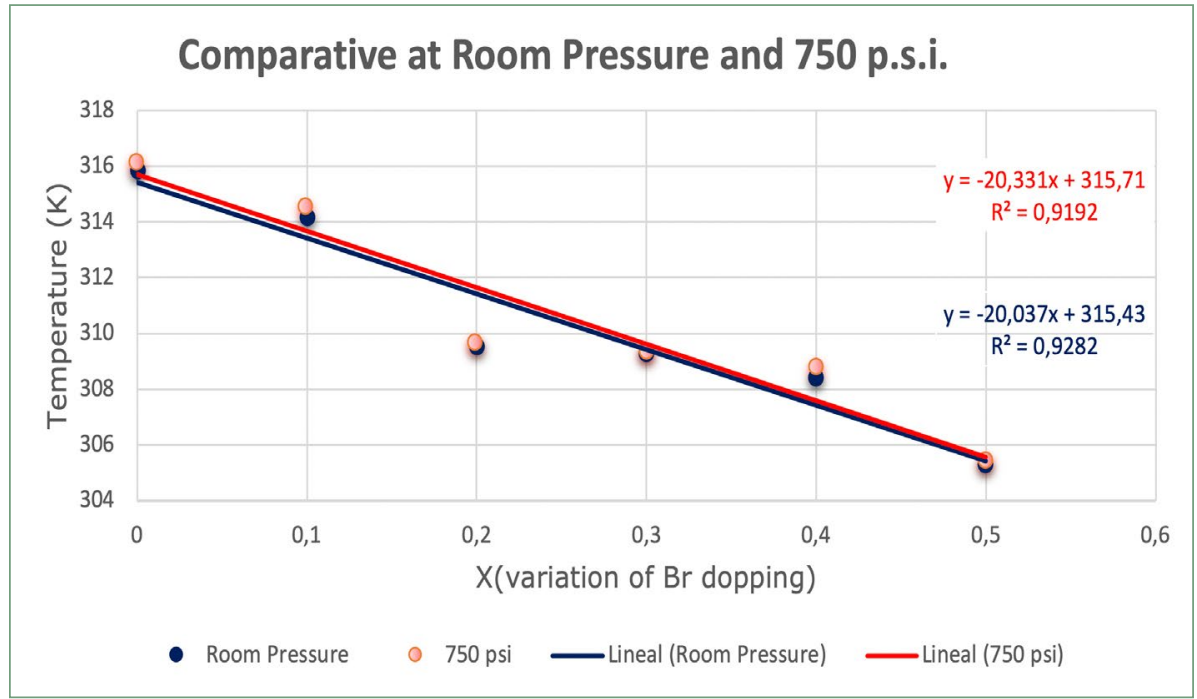

Figure 5. Peak temperature of the heat flow as a function of doping for $\mathrm{DMAPbCl}_{2.5} \mathrm{Br}_{0.5}$, DMAPbCl ${ }_{2.6} \mathrm{Br}_{0.4}, \mathrm{DMAPbCl}_{2.7} \mathrm{Br}_{0.3}, \mathrm{DMAPbCl}_{2.8} \mathrm{Br}_{0.2}, \mathrm{DMAPbCl}_{2.9} \mathrm{Br}_{0.1}$ and $\mathrm{DMAPbCl}_{3}$, at room pressure and 750 p.s.i.

Finally, the enthalpy of the structural transition is related with the heat flow absorbed by the samples when the transition occurs during the heating, and can be calculated from the peak area. We have represented the calculated values for all the samples at the two pressures in Figure 6. 


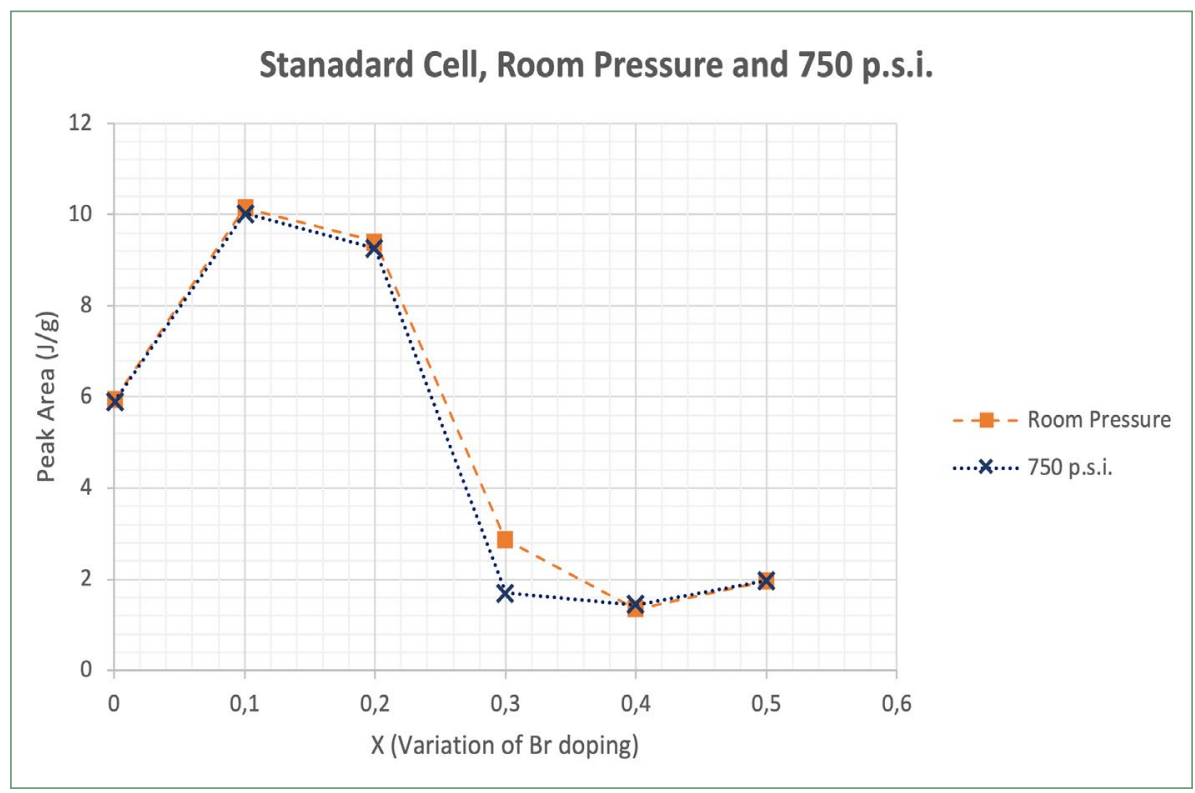

Figure 6. Peak area of the heat flow as a function of doping for DMAPbCl ${ }_{2.5} \mathrm{Br}_{0.5}$, DMAPbCl ${ }_{2.6} \mathrm{Br}_{0.4}, \mathrm{DMAPbCl}_{2.7} \mathrm{Br}_{0.3}, \mathrm{DMAPbCl}_{2.8} \mathrm{Br}_{0.2}, \mathrm{DMAPbCl}_{2.9} \mathrm{Br}_{0.1}$ and $\mathrm{DMAPbCl}$ at room pressure and 750 p.s.i.

All the samples (DMAPbCl ${ }_{3}, \mathrm{DMAPbCl}_{2.9} \mathrm{Br}_{0.1}, \mathrm{DMAPbCl}_{2.6} \mathrm{Br}_{0.4}$ and $\mathrm{DMAPbCl}{ }_{2.5} \mathrm{Br}_{0.5}$ ) present very similar enthalpy values for the experiments run at room pressure and 750 p.s.i., even if the values are slightly lower at 750 p.s.i. than at room pressure. This can be due to the limitation of the DMA vibration (which is the origin of the structural transition) by the application of the pressure.

\section{Conclusions}

The mechanosynthesis of compounds with formula DMAPbCl $3-\mathrm{Br}_{\mathrm{x}}$ and $\mathrm{x}=0$, $0.1,0.2,0.3,0.4$ and 0.5 was successfully made, obtaining in all cases $\approx 1 \mathrm{~g}$ of a white powder as product (a yield of almost 100\%).

The compounds were successfully characterized by TGA, showing that all of them are thermally stable at room temperature, and until $\approx 423 \mathrm{~K}(150 \stackrel{\circ}{\circ})$.

SEM-EDX experiments show that they are formed by aggregates of grains of sizes from $4.2 \mu \mathrm{m}$ to $6.8 \mu \mathrm{m}$, and with a homogeneous distribution of the $\mathrm{Br}$ (doping agent). 
Powder-XRD experiments revealed that $\mathrm{DMAPbCl}{ }_{2.9} \mathrm{Br}_{0.1}, \mathrm{DMAPbCl}_{2.8} \mathrm{Br}_{0.2^{\prime}}$ DMAPbCl ${ }_{2.7} \mathrm{Br}_{0.3}, \mathrm{DMAPbCl}_{2.6} \mathrm{Br}_{0.4}$ and $\mathrm{DMAPbCl}_{2.5} \mathrm{Br}_{0.5}$ are crystalline and monophasic, exhibiting all of them the same structure at room temperature.

DSC experiments under pressure revealed that all the compounds exhibit endothermic structural transitions, leading barocaloric and refrigerant properties. Even no relationship could be stablished between the magnitude of the transition and the doping agent, very interestingly, the temperature of the structural transition clearly depends on $\mathrm{Br}$ doping on a linear way.

Therefore, it can be said that the study was successfully made: the synthetized hybrid perovskites shows barocaloric properties, and the temperature of the structural transition can be modified with doping. That will be very useful in order to adapt the perovskites to the different applications' possibilities (as air conditioner coolants or home-use refrigerants, for example).

An interesting continuation of this work is to extending the $\mathrm{Br}$ doping quantities from 0.6 to 1 , showing how far the tuning effect of the $\mathrm{Br}$ can go. It is also important to deep on the study of the energy transition, in order to stablish a clear relationship with the doping, and to open new doors for the design of new solid refrigerants.

\section{References}

1. Cientifica PC, 26Ene2018. La nueva forma de enfriar que lo cambiará todo [Internet]. Cuad. Cult. Científica. 2018 [cited 2018 Jun 10]. Available from: https://culturacientifica.com/2018/01/26/la-nuevaforma-enfriar-lo-cambiara/

2. Reglamento (UE) no 517/2014 del Parlamento Europeo y del Consejo, de 16 de abril de 2014, sobre los gases fluorados de efecto invernadero y por el que se deroga el Reglamento (CE) no 842/2006Texto pertinente a efectos del EEE. :36.

3. Calm JM. The next generation of refrigerants - Historical review, considerations, and outlook. Int J Refrig. 2008;31:1123-33.

4. Mañosa L, Planes A, Acet M. Advanced materials for solid-state refrigeration. J Mater Chem A. 2013;1:4925.

5. Kitanovski A, Plaznik U, Tomc U, Poredoš A. Present and future caloric refrigeration and heat-pump technologies. Int J Refrig. 2015;57:288-98.

6. Xie Z, Sebald G, Guyomar D. Temperature dependence of the elastocaloric effect in natural rubber. Phys Lett A. 2017;381:2112-6.

7. Kutnjak Z, Rožič B, Pirc R. Electrocaloric Effect: Theory, Measurements, and Applications. Wiley Encycl Electr Electron Eng [Internet]. Hoboken, NJ, USA: John Wiley \& Sons, Inc.; 2015 [cited 2018 Jun 21]. p. 1-19. Available from: http://doi.wiley.com/10.1002/047134608X.W8244

8. Franco V, Blázquez JS, Ipus JJ, Law JY, Moreno-Ramírez LM, Conde A. Magnetocaloric effect: From materials research to refrigeration devices. Prog Mater Sci. 2018;93:112-232. 
9. Bermúdez-García JM, Sánchez-Andújar M, Castro-García S, López-Beceiro J, Artiaga R, Señarís-Rodríguez MA. Giant barocaloric effect in the ferroic organic-inorganic hybrid [TPrA][Mn(dca)3] perovskite under easily accessible pressures. Nat Commun. 2017;8:15715.

10. TEDx Talks. 2020: camino hacia el enfriamiento global | Juan Manuel Bermúdez | TEDxGalicia [Internet]. [cited 2018 Jun 10]. Available from: https://www.youtube.com/watch?v=aUJ3ysJqSpE

11. Shi T, Li G, Zhu J. Compositional design strategy for high performance ferroelectric oxides with perovskite structure. Ceram Int. 2017;43:2910-7.

12. Guo X, Burda C. Coordination engineering toward high performance organic-inorganic hybrid perovskites. Coord Chem Rev. 2016;320-321:53-65.

13. Bellitto C, Bauer EM, Righini G. Organic-inorganic hybrids: From magnetic perovskite metal(II) halides to multifunctional metal(II) phosphonates. Coord Chem Rev. 2015;289-290:123-36.

14. Yang $\mathrm{C}, \mathrm{Wu} \mathrm{Y}, \mathrm{Ma} \mathrm{Q}$, Zhang $\mathrm{W}-\mathrm{H}$. Nanocrystals of halide perovskite: Synthesis, properties, and applications. J Energy Chem. 2018;27:622-36.

15. Li J, Zhang R. Nanostructured Inorganic-Organic Hybrid Semiconductor Materials. Compr Inorg Chem II [Internet]. Elsevier; 2013 [cited 2018 May 23]. p. 375-415. Available from: http://linkinghub.elsevier.com/ retrieve/pii/B9780080977744002187

16. Frost JM, Butler KT, Brivio F, Hendon $\mathrm{CH}$, van Schilfgaarde M, Walsh A. Atomistic Origins of HighPerformance in Hybrid Halide Perovskite Solar Cells. Nano Lett. 2014;14:2584-90.

17. Motta C, El-Mellouhi F, Kais S, Tabet N, Alharbi F, Sanvito S. Revealing the role of organic cations in hybrid halide perovskite $\mathrm{CH} 3 \mathrm{NH} 3 \mathrm{Pbl3}$. Nat Commun [Internet]. 2015 [cited 2018 May 23];6. Available from: http://www.nature.com/articles/ncomms8026

18. Conducting tin halides with a layered organic-based perovski. Nat Lond. 1994;369:467.

19. Bermúdez-García JM, Sánchez-Andújar M, Señarís-Rodríguez MA. A New Playground for OrganicInorganic Hybrids: Barocaloric Materials for Pressure-Induced Solid-State Cooling. J Phys Chem Lett. 2017;8:4419-23. 


\title{
Estudo da contaminación aérea no Porto da Coruña no 2017
}

\author{
Alberto Carril Vidal ${ }^{1}$
}

\section{Resumo}

O presente traballo consiste na aproximación do cálculo das emisións provocadas polas visitas de buques mercantes e de pasaxe ao porto da Coruña durante o 2017.

Primeiro estudaranse as entradas e saídas de buques do porto, verificando os tipos de buque que pasan por esta cidade na actualidade. Realizarase un proceso de filtrado desta información para seleccionar os buques obxecto de estudo e así ter en conta as características específicas de cada tipo de buque.

Posteriormente, procederase a cuantificar as emisións de gases de combustión por sistemas de propulsión e de xeración de enerxía eléctrica, durante o ano 2017, baseándose en procesos de cálculo que permitan unha aproximación o máis certeira posible. Terase en conta para os cálculos o tipo de propulsión máis maioritario para cada tipo de buque, así como os tempos de manobra e de estadía no porto.

Os resultados finais estarán expresados tanto en cantidade total xerada, como desagregados por tipo de gas contaminante, por tipo de buque, en volume, en masa, e noutras opcións a maiores. Isto permitirá ter conciencia do verdadeiro impacto ambiental que produce esta infraestrutura na calidade do aire da cidade da Coruña.

Levarase a cabo un estudo dos resultados, coa intención de ver cal é a tendencia actual, de identificar os puntos que se poden mellorar, e de comparar as cifras obtidas coas doutros focos de contaminación atmosférica locais para coñecer así a verdadeira magnitude da contaminación aérea que produce este porto.

\footnotetext{
${ }^{1}$ Titor TFM: Ángel Martín Costa Rial.

*Datos para citación: Carril Vidal, Alberto (2019). “Estudo da contaminación aérea do Porto da Coruña no 2017". En Oficina de Medio Ambiente UDC (ed.), I Premio UDC Sustentabilidade a traballos fin de grado e mestrado 2018. A Coruña: Universidade da Coruña, 103-120. DOI da obra: https://doi.org/10.17979/ spudc. 9788497497831.
} 
Palabras chave: Emisións de buques; Buques; Impacto ambiental; Contaminación atmosférica.

\section{Introdución}

as actividades relacionadas con transporte marítimo teñen un forte impacto na cidade de A Coruña, polo que teríanse que considerar como un tema central dentro da sustentabilidade ambiental e o medio ambiente da cidade. Dentro deste tema, este traballo trata o estudo das emisións provocadas por unha das máis importantes infraestruturas civís galegas, o porto da Coruña. Isto permitirá afondar un pouco máis nun dos problemas que máis afecta á cidadanía: a contaminación atmosférica; contribuíndo dese xeito a acadar un mundo máis limpo.

O porto da Coruña está situado no noroeste de España, e permite albergar aos buques de pasaxe máis grandes do mundo. Debido á súa situación xeográfica, este porto convértese nunha escala habitual para moitas rutas de cruceiros, e é unha das máis importantes entradas de turismo da cidade chegando no ano 2016 a recibir 126735 turistas procedentes de cruceiros [1].

O porto destaca tamén pola súa terminal petrolífera controlada polo grupo Repsol, na que se xestiona o transporte de graneis líquidos. Está previsto que para o ano 2019 se leve a cabo o traslado da terminal petrolífera de Repsol ao porto exterior da Coruña (punta Langosteira). A principal actividade desta terminal é a descarga de petróleo. Este é trasegado a través do oleoduto que cruza a cidade ata a refinaría da Coruña para ser xestionado. Outras actividades desta terminal son carga e descarga de produtos refinados do petróleo, como gasóleos, gasolinas, combustible de aviación etc. así como de gases licuados derivados do petróleo (LPG), como o propano, butano, propileno etc. Conta ademais este porto con terminais para graneis sólidos e outro tipo de mercadorías de diversa índole.

Este traballo ten unha serie de semellanzas cos obxectivos de sustentabilidade das Nacións Unidas, como por exemplo:

- Saúde e benestar, debido a relación directa existente entre a calidade do aire dunha cidade e a saúde da cidadanía que a habita.

- Cidades e comunidades sostibles, debido a súa relación directa co estudo da cuantificación da contaminación do aire dunha cidade, neste caso da cidade da Coruña.

- Acción polo clima, debido a relación existente entre a contaminación aérea e problemas como o efecto invernadoiro ou o burato da capa de ozono. 
- Por outra banda, tamén se pode destacar a afinidade deste traballo cos criterios de compromiso social da UDC. Tales coma:

- Compromiso coa protección do medio ambiente, ao cuantificar a magnitude da contaminación aérea dunha das maiores infraestruturas portuarias galegas co obxectivo atopar xeitos de reducila.

- Compromiso coa promoción da saúde, pois este traballo consiste en cuantificar un dos principais focos de contaminación aérea da Coruña que afectan directamente na calidade do ar que respiran os cidadáns da bisbarra.

- Compromiso coa normalización lingüística, ao ser realizado e exposto integramente en lingua galega, e fomentando o emprego da mesma para a realización de proxectos de carácter técnico.

A contaminación aérea por mor dos buques provoca un efecto acumulativo que repercute directamente na calidade do aire de determinadas rexións do planeta, contribuíndo ao incremento de efectos negativos para o medio ambiente, tales como o efecto invernadoiro producido sobre todo polo $\mathrm{CO}_{2}$ xerado nos procesos de combustión, a redución da capa de ozono, a chuvia ácida e outras modificacións climáticas de diversa índole.

Estas alteracións provocan un aumento das temperaturas debidas a un incremento da concentración dos gases de efecto invernadoiro (GEI). O Terceiro Estudo sobre os GEI foi o último informe realizado pola Organización Marítima Internacional (OMI) no ano 2014 [2]. As principais conclusións deste estudo foi que no 2012 as emisións totais procedentes do transporte marítimo internacional estiveron preto dos 796 millóns de toneladas de $\mathrm{CO}_{2}$ e dos 816 millóns de toneladas de $\mathrm{CO}_{2 \text { eq }}$ polo que respecta aos $\mathrm{GEI}$ compostos de $\mathrm{CO}_{2}, \mathrm{CH}_{4}$ e $\mathrm{N}_{2} \mathrm{O}$. É dicir, dito informe conclúe que este tipo de transporte representada en torno o 2,2\% e o 2,1\% das emisións mundiais de $\mathrm{CO}_{2}$ e $\mathrm{CO}_{2 \text { eq }}$ das emisións de GEI. Na Táboa 1 amósase a serie completa das emisións de $\mathrm{CO}_{2}$ y $\mathrm{CO}_{2 \mathrm{eq}}$ procedentes do transporte marítimo internacional en comparación co total das emisións mundiais de $\mathrm{CO}_{2}$ y $\mathrm{CO}_{2 \mathrm{eq}} \mathrm{O}$ longo dos anos estudados. A partir destes datos podemos ver que as emisións de $\mathrm{CO}_{2 \mathrm{eq}}$ no caso do transporte marítimo son só un 2,4\% superiores ás emisións de $\mathrm{CO}_{2}$, mentres que para o total son un $10,4 \%$ superiores. Asi, a ratio de $\mathrm{CO}_{2 \mathrm{eq}} / \mathrm{CO}_{2}$ para o transporte marítimo resulta de 1,0236.

Esta contaminación é principalmente producida polos gases da combustión dos sistemas de propulsión e xeración de enerxía eléctrica de buques, pero tamén engloba outros sistemas de a bordo como incineradores, caldeiras, sistemas de xeración de gas inerte e unidades de combustión de gas. Ademais, aínda que en menor medida, están incluídas tamén dentro deste tipo de contaminación, os venteos accidentais ou forzosos de distintos gases, 
como por exemplo combustibles gasosos, produtos químicos diversos, fluídos refrixerantes, etc. Neste estudo, a atención será focalizada simplemente nos

Táboa 1. Emisións de $\mathrm{CO}_{2}$ e $\mathrm{CO}_{2 \text { eq }}$ do transporte marítimo internacional en comparación co total das emisións mundiais.

\begin{tabular}{|lcccccc}
\hline Ano & $\begin{array}{c}\mathrm{CO}_{2} \\
\text { Mundial }\end{array}$ & $\begin{array}{c}\text { Transp. } \\
\text { Marít. Intern. } \\
\left(\mathrm{M} \mathrm{t} \mathrm{CO}_{2}\right)\end{array}$ & $\begin{array}{c}\text { \% total } \\
\text { mundial } \\
\text { emitido }\end{array}$ & $\begin{array}{c}\mathrm{CO}_{2 \mathrm{eq}} \\
\text { Mundial }\end{array}$ & $\begin{array}{c}\text { Transp. Marit. } \\
\text { Intern. } \\
\left(\mathrm{M} \mathrm{t} \mathrm{CO}_{2 \mathrm{eq}}\right)\end{array}$ & $\begin{array}{c}\text { \% total } \\
\text { mundial } \\
\text { emitido }\end{array}$ \\
\hline $\mathbf{2 0 0 7}$ & 31.409 & 885 & $2,8 \%$ & 34.881 & 903 & $2,6 \%$ \\
\hline $\mathbf{2 0 0 8}$ & 32.204 & 921 & $2,9 \%$ & 35.677 & 940 & $2,6 \%$ \\
\hline $\mathbf{2 0 0 9}$ & 32.047 & 855 & $2,7 \%$ & 35.519 & 873 & $2,5 \%$ \\
\hline $\mathbf{2 0 1 0}$ & 33.612 & 771 & $2,3 \%$ & 37.085 & 790 & $2,1 \%$ \\
\hline $\mathbf{2 0 1 2}$ & 34.723 & 850 & $2,4 \%$ & 38.196 & 871 & $2,3 \%$ \\
\hline Media & 35.640 & 796 & $2,2 \%$ & 39.113 & 816 & $2,1 \%$ \\
\hline
\end{tabular}

gases de combustión provocados por sistemas de propulsión e a sistemas de xeración de enerxía eléctrica. Estes gases, son principalmente os óxidos de nitróxeno, os óxidos de xofre e o monóxido e dióxido de carbono. Tamén se terán en conta os hidrocarburos presentes en gases de escape debido a combustións incompletas, así como a materia particulada.

$\mathrm{Na}$ actualidade existe un convenio internacional para previr a contaminación por buques (MARPOL) [3], máis concretamente, no Anexo VI deste Convenio, "Regras para previr a contaminación atmosférica ocasionada polos buques", establécense as regras de obrigado cumprimento para os buques sobre as regras sobre emisións de óxidos de xofre (SOx) e materia particulada, sobre as emisións de óxidos de nitróxeno (NOx), sobre substancias que esgotan a capa de ozono, sobre compostos orgánicos volátiles (COV), etc.

Dentro destas regras existen unhas zonas de control de emisións pertencentes aos buques mercantes, determinadas como "zonas especiais", respecto as cales, por razóns técnicas en relación coas súas condicións oceanográficas e ecolóxicas e polo tráfico marítimo da zona, adóitanse procedementos especiais obrigatorios para previr a contaminación. O Convenio establece que estas zonas especiais conten cun nivel de protección superior ao doutras zonas mariñas polo que se impoñen uns controis máis rigorosos sobre as emisións. Actualmente, de xeito resumido, estas emisións están controladas no mar Báltico, o Mar do Norte e a costa dos EEUU e Canadá e, por outra banda, espérase que estas zonas sexan ampliadas nos próximos anos co mar Mediterráneo e coas zonas costeiras do Xapón, México e Noruega, entre outros. 
Estas medidas introducidas no Anexo VI de MARPOL conseguiron melloras como a redución do consumo de combustibles con alto contido en xofre a nivel mundial, un aumento da conciencia global en materia de contaminación, un avance tecnolóxico de cara ao uso de combustibles máis limpos, e tamén a procura e desenvolvemento de alternativas aos sistemas de propulsión convencionais.

Este traballo pretende cuantificar o volume de gases de combustión emitidos por buques mercantes no porto da Coruña durante un período de tempo que abrangue dende o 1 de xaneiro do 2017 até o 31 de decembro de 2017. Para levar isto a cabo realizouse unha tarefa de investigación de tódolos buques que entraron no porto no 2017, e tendo en conta as especificidades de cada tipo de barco, proceder a cuantificar as emisións producidas por cada un. Con esta información, e tendo en conta o tempo medio de estadía de cada tipo de buque en porto, pódese coñecer unha aproximación da cantidade total de gases emitidos á atmosfera na Coruña por mor de buques mercantes cunha marxe de erro reducida. Alén disto, outros obxectivos desta investigación son coñecer a proporción de gases contaminantes que producen os buques con respecto doutras fontes de contaminación da cidade, contrastar a información coa que nos proporcionan os informes de calidade do aire municipais, entre outros.

\section{Materiais e métodos}

No presente apartado procederase a explicar tanto a información de partida, así como os procedementos de cálculo ata acadar os obxectivos deste traballo.

\subsection{Materiais}

En primeiro lugar, a investigación comezou por recadar unha serie de información na capitanía marítima da Coruña, esta información consiste basicamente en recoller as entradas de buques no porto durante o ano 2017 [4]. A información facilitada consiste nunha listaxe de 1177 entradas de barcos acompañadas dos seguintes datos:

- Nome do buque

- Código identificativo de chamada

- Porto de orixe

- Horas estimada e rexistrada de chegada

- Carga de saída do porto (só dispoñible nalgúns buques) 
Posto que a información sobre a carga dos buques non se podía considerar como criterio de identificación do tipo de buque, procedeuse a identificar tódolos barcos desta listaxe e a clasificalos por tipo de buque. Esta información é pública e pódese acceder a ela a través de diferentes bases de datos, como a de Marine Traffic [5] mediante o nome ou o código identificativo de chamada.

É común que a este porto acuda un mesmo buque en diferentes ocasión ao longo do ano, polo que se contabilizaron a maiores o número de chegadas de cada buque, co obxecto de simplificar ao máximo a base de datos.

Tras un estudo da listaxe facilitada pola torre de control, os buques seleccionados para este estudo son os mencionados a continuación, e representan o $96,4 \%$ das chegadas anuais ao porto de buques non pesqueiros:

- Asfalteiros, petroleiros e quimiqueiros.

- Gaseiros LPG.

- Cruceiros.

- Graneleiros e cargueiros.

Debido a que o estudo se centra en buques mercantes e de pasaxe no porto da Coruña fican fóra do alcance deste traballo os seguintes ítems:

- A cuantificación dos gases emitidos no porto exterior da Coruña.

- A cuantificación dos gases emitidos por venteo de gas inerte dos tanques de carga, por incineradores ou por caldeiras de todos os buques.

- A cuantificación das emisións provocadas por:

- Barcos de pesca.

- Embarcacións de recreo, deportivas e iates.

- Remolcadores, gardacostas e de salvamento.

- Buques militares, de aduanas e patrulleiras.

- Buques off-shore, de control de polución e dragas.

- Oceanográficos, portacontenedores e buques escola.

- Servizo de prácticos.

\subsection{Metodoloxía de cálculo de potencias}

Unha vez identificados tódolos buques obxecto de estudo, o seguinte paso consiste na identificación dos seus sistemas de propulsión e de xeración de 
enerxía eléctrica, pois nestas instalacións é onde se xeran as combustións que producen as emisións que se pretenden contabilizar neste traballo.

Esta información foi imposible de conseguir para todos os barcos. Isto é habitual debido aos criterios de confidencialidade das empresas navieiras, ou simplemente ao carácter moi específico da información. Só foi posible conseguir información completa dalgúns poucos buques. Dalgúns só se puido coñecer o seu tipo de propulsión; doutros, só a potencia dos motores auxiliares, e na maioría dos casos non hai información dispoñible.

Tras realizar diferentes pesquisas infrutuosas, detalladas no estudo da contaminación aérea no porto da Coruña no 2017 [4], xurdiu a necesidade de deseñar un sistema para aproximar a potencia propulsora e auxiliar dos buques en función da información dispoñible, ou doutra información existente publicamente. Polo tanto optouse por ampliar a base de datos coa información de tonelaxe de peso morto e de tonelaxe de arqueo bruto, dispoñible tamén de forma gratuíta na base de datos de Marine Traffic [5]. Con isto quedaría completada a base de datos de información dos buques obxecto de estudo, ficando dispoñible no Anexo I da versión íntegra.

A información necesaria e non dispoñible ata o de agora para este apartado é, para cada buque estudado, a seguinte:

- Tipo de propulsión e potencia propulsora total

- Número de motores auxiliares e potencia auxiliar total

Para obter esta información procedeuse a deseñar un sistema para aproximar do xeito máis preciso posible o valor das potencias propulsora e auxiliar, en función do tipo de buque e do tipo de propulsión.

Realizouse unha investigación para cada tipo de buque, intentando conseguir datos de buques reais de características similares en canto a tonelaxe de peso morto e de arqueo bruto respecto dos que concirnen a este estudo, contrastando a escasa información dispoñible de buques das seguintes maneiras:

- TFG e TFM dispoñibles no repositorio da Universidade da Coruña [6] así como doutras universidades [7][8].

- Traballos para a obtención da tarxeta profesional de oficial de máquinas da mariña mercante dispoñibles na biblioteca da Escola Técnica Superior de Náutica e Máquinas da Coruña.

- Conversas con alumnos, oficiais e xefes de máquinas da mariña mercante, que navegasen en buques de similares características, así como con outros profesionais do sector e profesores de diferentes ámbitos de especialidade. 
- Visitas ao porto da Coruña e á capitanía marítima e intercambio de correos electrónicos co portal de información da autoridade portuaria da Coruña.

Tras consultar estas fontes e contrastar esta información con datos reais, púidose definir unha planta propulsora e auxiliar medio para cada tipo de barco, quedando definidas tal e como se recolle na Táboa 2.

Táboa 2. Tipo de sistemas propulsores e auxiliares medios dos buques.

\begin{tabular}{lcc}
\hline TIPO DE BUQUE & $\begin{array}{c}\text { PROPULSIÓN MÁIS } \\
\text { UTILIZADA }\end{array}$ & $\begin{array}{c}\text { PROMEDIO DE MOTORES } \\
\text { AUXILIARES }\end{array}$ \\
\hline ASFALTAEIROS & DIÉSEL 4T & 3 \\
\hline PETROLEIROS & DIÉSEL 2T & 3 \\
\hline QUIMIQUEIROS & DIÉSEL 2T & 3 \\
\hline GASEIROS LPG & DIÉSEL 4T & 3 \\
\hline GRANELEIROS & DIÉSEL 2T & 3 \\
\hline CARGUEIROS & DIÉSEL 4T & 3 \\
PASAXE (GT < 30.000) & DIÉSEL 2T & 6 \\
PASAXE (GT > 30.000) & DIÉSEL-ELÉCTRICA & 6 \\
\hline
\end{tabular}

Débese ter en conta que tódolos motores auxiliares serán motores de catro tempos (4T), mentres que os motores propulsores poderán ser de dous tempos (2T) ou de catro. Considéranse ademais tódalas plantas propulsoras e auxiliares de motores, descartando sistemas de propulsión a turbina de vapor ou turbina de gas debido a que o seu uso non está apenas implementado neste tipo de buques.

Partindo desta base, intentouse utilizar un método que relacionase o arqueo bruto (GT) ou o peso morto (DWT) de cada buque coa súa potencia propulsora (PP), para deste xeito, poder aproximar a súa potencia, posto que esta é a única información dispoñible aplicable para este propósito.

Aplicáronse diferentes fórmulas matemáticas que relacionan a tonelaxe de peso morto coa potencia propulsora de distintos artigos, mencionadas na versión íntegra do traballo, sendo estes intentos infrutuosos.

Por conseguinte, procedeuse a calcular uns ratios que relacionasen a tonelaxe de peso morto coa potencia propulsora, para cada tipo de buque, baseadas nos datos dispoñibles de buques reais. Posteriormente, estimouse a potencia máxima dos motores auxiliares mediante outros ratios diferentes, que relacionan a potencia propulsora máxima dun buque coa potencia auxiliar 
máxima. Pódense apreciar as fórmulas utilizadas para aproximar as potencias na Táboa 3.

Táboa 3. Ratios para o cálculo das potencias dos barcos.

\begin{tabular}{|c|c|c|}
\hline TIPO DE BUQUE & $\begin{array}{c}\text { POTENCIA PROPULSORA } \\
\text { MÁXIMA (kW) }\end{array}$ & $\begin{array}{l}\text { POTENCIA AUXILIAR } \\
\text { MÁXIMA (kW) }\end{array}$ \\
\hline ASFALTAEIROS & $\mathrm{PP}=\mathrm{DWT} * 0,3387$ & PAux $=P P * 0,37$ \\
\hline PETROLEIROS & $\mathrm{PP}=\mathrm{DWT} * 0,2021$ & PAux $=P P * 0,17$ \\
\hline QUIMIQUEIROS & $\mathrm{PP}=\mathrm{DWT} * 0,3387$ & PAux $=P P * 0,37$ \\
\hline GASEIROS LPG & $\mathrm{PP}=\mathrm{DWT} * 0,7912$ & PAux $=P P * 0,38$ \\
\hline GRANELEIROS & $\mathrm{PP}=\mathrm{DWT} * 0,3031$ & PAux $=$ PP $* 0,22$ \\
\hline CARGUEIROS & $\mathrm{PP}=\mathrm{DWT} * 0,4412$ & PAux $=P P * 0,25$ \\
\hline PASAXE $($ GT < 30.000) & $\mathrm{PP}=\mathrm{GT} * 0,3970$ & PAux $=P P * 0,91$ \\
\hline PASAXE (GT > 30.000) & - & PAux $=\mathrm{GT} * 0,49$ \\
\hline
\end{tabular}

O uso das ratios de proporción é o seguinte:

- A primeira ratio relaciona a tonelaxe de peso morto do buque coa potencia propulsora do mesmo.

- A segunda ratio relaciona a potencia propulsora do buque coa potencia auxiliar.

Para os buques de pasaxe usouse como referencia a tonelaxe de arqueo bruto (GT), debido a que a tonelaxe de peso morto (DWT) destes buques non é proporcional á envergadura real do barco, xa que nos barcos de pasaxe non existen adegas ou espazos para o transporte de cargamento alén dos tanques de combustible, de aceite e de auga.

Os grandes buques de pasaxe de máis de 30.000 toneladas de arqueo bruto, consideráronse de propulsión diésel-eléctrica, debido a que tras as pescudas realizadas, a propulsión máis utilizada neste tipo de buques a partir desa tonelaxe acostuma ser con motores eléctricos acimutais. Estes propulsores permiten unha maior seguridade e manobrabilidade, e son amplamente usados nos buques de pasaxe de maior tamaño.

Cabe destacar que neste último tipo de buque, a potencia auxiliar é maior que a potencia propulsora, debido a que os motores auxiliares deben subministrar enerxía eléctrica aos propulsores e tamén a todos os potentes consumidores eléctricos destes buques (iluminación, aire acondicionado, sistemas frigoríficos para a alimentación, sistemas de entretemento, etc). 
É por isto que os cálculos para este tipo concreto de buque se realizan directamente coa relación entre o arqueo bruto e a potencia dos motores auxiliares. A potencia propulsora do buque non é necesaria pois, como son motores eléctricos, non emiten ningún tipo de contaminación aérea.

En canto aos buques de pasaxe de menos de $30.000 \mathrm{GT}$, a contaminación calcúlase, ao igual que no subgrupo anterior, mediante a arqueo bruto. Porén, o cálculo das potencias propulsoras e auxiliares realízase mediante o mesmo método que para os demais buques deste estudo

\subsection{Metodoloxía de cálculo de emisións}

Para efectuar os cálculos de emisións de todos estes barcos, débense de ter en conta ademais de todos os datos que se posúen ata este momento, os seguintes factores para cada tipo de buque:

- Duración media da manobra

- Porcentaxe da potencia propulsora e auxiliar usadas na manobra

- Duración media da estadía en porto e porcentaxe da potencia auxiliar usada en porto

- Porcentaxe de buques que se conectan a corrente do porto

- Combustible usado en porto

Un correo da autoridade portuaria da Coruña confirma que non existe neste porto servizo de subministro de enerxía eléctrica aos buques mercantes ou de pasaxe, polo que o $100 \%$ dos buques estudados deben ter a súa planta auxiliar en funcionamento durante toda a súa estadía no porto.

O resto da información dos puntos que se acaban de mencionar púidose obter, ao igual que nalgúns puntos do apartado anterior, dos seguintes xeitos:

- TFG e TFM dispoñibles no repositorio da Universidade da Coruña [6] así como doutras universidades [7][8].

- Traballos para a obtención da tarxeta profesional de oficial de máquinas da mariña mercante dispoñibles na biblioteca da Escola Técnica Superior de Náutica e Máquinas da Coruña.

- Conversas con alumnos, oficiais e xefes de máquinas da mariña mercante, que navegasen en buques de similares características, así como con outros profesionais do sector e profesores de diferentes ámbitos de especialidade.

Os datos obtidos necesarios para o traballo son os que amosa a Táboa 4. 
Táboa 4. Datos necesarios para cálculo de emisións.

\begin{tabular}{|c|c|c|c|c|c|c|}
\hline TIPO DE BUQUE & $\begin{array}{c}\text { Tempo } \\
\text { medio } \\
\text { manobra (h) }\end{array}$ & $\begin{array}{c}\% \text { PP } \\
\text { manobra }\end{array}$ & $\begin{array}{l}\% \text { PAux } \\
\text { manobra }\end{array}$ & $\begin{array}{c}\text { Tempo } \\
\text { medio } \\
\text { estadía (h) }\end{array}$ & $\begin{array}{l}\% \text { PAux } \\
\text { porto }\end{array}$ & Comb. \\
\hline ASFALTAEIROS & 1,5 & $20 \%$ & $66 \%$ & 20 & $33 \%$ & LSMGO \\
\hline PETROLEIROS & 2 & $20 \%$ & $66 \%$ & 24 & $66 \%$ & LSMGO \\
\hline QUIMIQUEIROS & 1,5 & $20 \%$ & $66 \%$ & 20 & $33 \%$ & LSMGO \\
\hline GASEIROS LPG & 1,5 & $20 \%$ & $66 \%$ & 18 & $33 \%$ & LSMGO \\
\hline GRANELEIROS & 1,5 & $20 \%$ & $66 \%$ & 48 & $33 \%$ & LSMGO \\
\hline CARGUEIROS & 1,5 & $20 \%$ & $66 \%$ & 48 & $33 \%$ & LSMGO \\
\hline $\begin{array}{l}\text { PASAXE } \\
(\text { GT }<30.000)\end{array}$ & 1,5 & $20 \%$ & $66 \%$ & 8 & $33 \%$ & LSMGO \\
\hline $\begin{array}{l}\text { PASAXE } \\
(\text { GT > 30.000) }\end{array}$ & 1,5 & $20 \%$ & $80 \%$ & 8 & $10 \%$ & LSMGO \\
\hline
\end{tabular}

Segundo a normativa anticontaminación vixente [9] en portos españois está prohibido consumir combustibles de máis dun 0,10\% en masa de xofre cando a estadía é superior a 2 horas, involucrando polo tanto a todos os buques obxecto deste estudo. As opcións de combustibles coas que contan legalmente son pois:

- LSMGO (Low Sulfur Marine Gas-Oil).

- ULSIFO (Ultra Low Sulfur Intermediate Fuel Oil).

- LNG (Liquified Natural Gas).

Debido a que o uso de LNG como combustible está moi pouco estendido polo de agora (á marxe dos buques gaseiros LNG, que non acoden a esta cidade), a inmensa maioría dos buques estudados só teñen as instalacións propulsoras e auxiliares aptas para consumir combustibles convencionais, polo que se procede a descartar a terceira opción. Tras consultar con profesionais do sector, procédese a seleccionar o combustible LSMGO como estándar para todos os buques estudados. Isto débese a motivos como limitacións para a segregación de combustibles en tanques, ordes da navieira ou motivos doutra índole.

Os factores de emisións para o combustible LSMGO en g/kWh [10] para cada substancia a analizar son os que nos amosa a Táboa 5 . 
Táboa 5. Factores de emisión (g/kWh).

\begin{tabular}{lccccccc} 
Tipo de motor & $\mathrm{CO}_{2}$ & $\mathrm{CO}$ & $\mathrm{SO}_{x}$ & $\mathrm{NO}_{x}$ & $\mathrm{PM}_{10}$ & $\mathrm{PM}_{25}$ & $\mathrm{HC}$ \\
\hline DIÉSEL 2T & 545 & 0,35 & 0,36 & 13,6 & 0,25 & 0,35 & 0,50 \\
\hline DIÉSEL 4T & 609 & 0,50 & 0,40 & 9,60 & 0,25 & 0,35 & 0,50
\end{tabular}

Para as cuantificacións das emisións de cada buque teranse en conta dúas situacións específicas:

Manobra: Contabilizaranse nesta situación as emisións dos motores auxiliares en modo manobra (mínimo dous motores auxiliares arrancados) e tamén as emisións dos motores propulsores durante toda a manobra de entrada no porto dende que o buque encara a ría da Coruña. A manobra dáse por comezada cando sobe o práctico a bordo e dáse por terminada cando o buque está amarrado no seu peirao correspondente. Estímase para todo o tempo que dura a manobra un uso da potencia propulsora do $20 \%$ para tódolos buques como promedio. A estimación realízase así para que deste xeito se poida reflectir tamén en certo modo a contaminación que provocan os remolcadores que realizan a manobra acompañando o buque mercante. As emisións da manobra de saída tamén serán contabilizadas do mesmo xeito, para cada buque.

Estadía en porto: Contabilizaranse as emisións dos motores auxiliares en modo porto, tendo en conta o tipo buque, pois, por exemplo, para os petroleiros a demanda eléctrica é maior que para outros tipos de buque, como os cargueiros, xa que teñen que usar as bombas no propio buque para descargar, supoñendo isto unha maior demanda eléctrica que para un buque que é descargado mediante grúas do porto, cazos ou outros sistemas.

Con esta información xa se poden levar a cabo os cálculos do seguinte xeito para cada barco de cada tipo de buque:

Emisións en porto: Para cada substancia, as emisións de cada buque serán o produto do factor de emisión correspondente $(f)$, polas horas de estancia en porto $\left(h_{p}\right)$, pola potencia auxiliar do buque (PAux), polo índice de potencia usada en porto $\left(\% P A u x_{p}\right)$ :

$$
\text { Emisións porto }=\left(f \cdot h_{p} \cdot P A u x \cdot \% P A u x_{p}\right)
$$

Emisións en manobra: Para cada substancia, as emisións de cada buque serán a suma das emisións dos motores principais máis a dos auxiliares. Á súa vez, estas son respectivamente: 
- O produto do factor de emisión correspondente (f), polas horas de manobra $\left(h_{M}\right)$, pola potencia propulsora do buque $(P P)$, polo índice de potencia propulsora usada en manobra $\left(\% P P_{M}\right)$.

- O produto do factor de emisión correspondente $(f)$, polas horas de manobra $\left(h_{M}\right)$, pola potencia auxiliar do buque (PAux), polo índice de potencia auxiliar usada en manobra (\%PAux $\left.x_{M}\right)$.

Emisións manobra $=\left(f \cdot h_{M} \cdot P P \cdot \% P P_{M}\right)+\left(f \cdot h_{M} \cdot P A u x \cdot \% P A u x_{M}\right)$

Emisións totais para un tipo de buque: Serán a suma das emisións en porto máis das emisións en manobra, para cada substancia, de tódolos buques dun mesmo tipo de buque.

Deste xeito pódense obter as emisións anuais para cada tipo de buque durante o ano 2017 así como as emisións anuais totais de cada substancia en todo o porto.

\section{Resultados e discusión}

\subsection{Emisións totais do porto}

Os resultados de emisións no porto da Coruña no ano 2017, amosadas en toneladas de cada substancia e por tipo de buque, están recollidas na Táboa 6. No referido ao $\mathrm{CO}_{2}$, as emisións directas acadaron as 22724 t en 2017. Considerando a ratio media para o transporte marítimo internacional de $1,0236 \mathrm{t} \mathrm{CO}_{2 \mathrm{eq}} / \mathrm{t} \mathrm{CO}_{2}$ (Táboa 1), podemos estimar unhas emisións equivalentes de $23322 \mathrm{t} \mathrm{CO}_{2 \mathrm{eq}}^{2 \mathrm{eq}}$.

Táboa 6. Emisións totais no porto da Coruña no 2017 procedentes dos sistemas de propulsión e xeración eléctrica dos buques.

\begin{tabular}{lcccccccc} 
Tipo de buque & NN visitas & $\mathrm{CO}_{2}$ & $\mathrm{CO}$ & $\mathrm{SO}_{x}$ & $\mathrm{NO}_{x}$ & $\mathrm{PM}_{10}$ & $\mathrm{PM}_{25}$ & $\mathrm{HC}$ \\
\hline Asfaltaeiros & 33 & 155,91 & 0,13 & 0,10 & 2,46 & 0,06 & 0,09 & 0,13 \\
\hline Petroleiros & 74 & $4.346,74$ & 3,42 & 2,86 & 75,93 & 1,82 & 2,55 & 3,65 \\
\hline Quimiqueiros & 224 & $4.006,34$ & 3,19 & 2,63 & 68,48 & 1,67 & 2,34 & 3,35 \\
\hline Gaseiros LPG & 82 & 843,89 & 0,69 & 0,55 & 13,30 & 0,35 & 0,48 & 0,69 \\
\hline Pasaxe & 124 & $7.740,76$ & 6,34 & 5,08 & 122,58 & 3,18 & 4,45 & 6,36 \\
\hline Graneleiros & 56 & $2.815,59$ & 2,25 & 1,85 & 47,49 & 1,17 & 1,64 & 2,34 \\
\hline Cargueiros & 345 & $2.815,59$ & 2,31 & 1,85 & 44,38 & 1,16 & 1,62 & 2,31 \\
\hline TOTAL (t) & & $22.723,94$ & 18,34 & 14,93 & 374,62 & 9,41 & 13,18 & 18,83 \\
\hline $\begin{array}{l}\text { TOTAL } \\
\text { (m }{ }^{3} \text { a 25-C) }\end{array}$ & & $12.336,56$ & 16.085 & 5.677 & 237.103 & - & - & - \\
\hline
\end{tabular}




\subsection{Medias de emisións}

Na Táboa 7 represéntanse os datos das emisións totais e medias en todo o conxunto portuario por tipo de substancia durante todo o 2017.

Táboa 7. Emisións medias por unidade de tempo.

\begin{tabular}{lcccccccc} 
Emisións & Unidades & $\mathrm{CO}_{2}$ & $\mathrm{CO}$ & $\mathrm{SO}_{x}$ & $\mathrm{NO}_{x}$ & $\mathrm{PM}_{10}$ & $\mathrm{PM}_{25}$ & $\mathrm{HC}$ \\
$\begin{array}{l}\text { Por } \\
\text { visita }\end{array}$ & $\mathrm{t}$ & 24,23 & 0,0195 & 0,0159 & 0,3994 & 0,0100 & 0,0141 & 0,0201 \\
\hline Mensual & $\mathrm{t}$ & $1.893,66$ & 1,5281 & 1,2443 & 31,2186 & 0,7845 & 1,0984 & 1,5691 \\
\hline Diaria & $\mathrm{t}$ & 62,26 & 0,0502 & 0,0409 & 1,0264 & 0,0258 & 0,0361 & 0,0516 \\
\hline Por hora & $\mathrm{kg}$ & $2.594,06$ & 2,0933 & 1,7046 & 42,7652 & 1,0747 & 1,5046 & 2,1494 \\
\hline Por min. & $\mathrm{kg}$ & 43,23 & 0,0349 & 0,0284 & 0,7128 & 0,0179 & 0,0251 & 0,0358 \\
\hline Por seg. & $\mathrm{g}$ & 720,57 & 0,5815 & 0,4735 & 11,8792 & 0,2985 & 0,4179 & 0,5971 \\
\hline Por seg. & $\mathrm{m}^{3} \mathrm{a} 25 \circ \mathrm{C}$ & 0,39 & 0,0005 & 0,0002 & 0,0075 & - & - & - \\
\hline TOTAL & $\mathrm{t}$ & $22.723,94$ & 18,34 & 14,93 & 374,62 & 9,41 & 13,18 & 18,83 \\
\hline $\begin{array}{l}\text { Volume } \\
\text { total }\end{array}$ & $\mathrm{m}^{3}$ a $25 \circ \mathrm{C}$ & $12.336,56$ & 16.085 & 5.677 & 237.103 & - & - & - \\
\hline & & & & & & & &
\end{tabular}

\subsection{Repercusións do traslado da terminal petrolífera}

Está previsto que para inicios do ano 2019 se leve a cabo o traslado da terminal petrolífera de Repsol [11] ao porto exterior da Coruña (punta Langosteira). Na Táboa 8 pódese apreciar como repercutirá isto no volume de gases xerados no porto interior e, por conseguinte, na área metropolitana da Coruña.

Pola contra, o volume de gases que se seguirá emitindo no porto interior tras o traslado da terminal de Repsol será o que amosa a Táboa 9.

Táboa 8. Emisións provocados polos buques que acoden a terminal petrolífera.

\begin{tabular}{|lllllllll|}
\hline Tipo de buque & $N$ No visitas & $\mathrm{CO}_{2}$ & $\mathrm{CO}$ & $\mathrm{SO}_{x}$ & $\mathrm{NO}_{x}$ & $\mathrm{PM}_{10}$ & $\mathrm{PM}_{25}$ & $\mathrm{HC}$ \\
\hline Asfaltaeiros & 33 & 155,91 & 0,13 & 0,10 & 2,46 & 0,06 & 0,09 & 0,13 \\
\hline Petroleiros & 74 & $4.346,74$ & 3,42 & 2,86 & 75,93 & 1,82 & 2,55 & 3,65 \\
\hline Quimiqueiros & 224 & $4.006,34$ & 3,19 & 2,63 & 68,48 & 1,67 & 2,34 & 3,35 \\
\hline Gaseiros LPG & 82 & 843,89 & 0,69 & 0,55 & 13,30 & 0,35 & 0,48 & 0,69 \\
\hline TOTAL (t) & 413 & $9.352,88$ & 7,43 & 6,14 & 160,17 & 3,90 & 5,46 & 7,82 \\
\hline TOTAL (\%) & $44,0 \%$ & $41,2 \%$ & $40,5 \%$ & $41,1 \%$ & $42,8 \%$ & $41,4 \%$ & $41,4 \%$ & $41,5 \%$ \\
\hline
\end{tabular}


Táboa 9. Emisións que permanecerán no porto interior tras o traslado da terminal petrolífera.

\begin{tabular}{lcccccccc}
$\begin{array}{l}\text { Tipo de } \\
\text { buque }\end{array}$ & No visitas & $\mathrm{CO}_{2}$ & $\mathrm{CO}$ & $\mathrm{SO}_{x}$ & $\mathrm{NO}_{x}$ & $\mathrm{PM}_{10}$ & $\mathrm{PM}_{25}$ & $\mathrm{HC}$ \\
\hline $\begin{array}{l}\text { Pasaxe } \\
\text { Graneleiros }\end{array}$ & 124 & $7.740,76$ & 6,34 & 5,08 & 122,58 & 3,18 & 4,45 & 6,36 \\
\hline Cargueiros & 345 & $2.815,59$ & 2,25 & 1,85 & 47,49 & 1,17 & 1,64 & 2,34 \\
\hline TOTAL (t) & 525 & $13.371,06$ & 10,90 & 8,78 & 214,45 & 5,51 & 7,71 & 11,01 \\
\hline TOTAL (\%) & $56,0 \%$ & $58,8 \%$ & $59,4 \%$ & $58,8 \%$ & $57,2 \%$ & $58,6 \%$ & $58,5 \%$ & $58,5 \%$ \\
\hline
\end{tabular}

\subsection{Discusión dos resultados}

Segundo o estudo do Observatorio da Sustentabilidade (RENADE) do 2015 [12] sobre ás emisións de GEl de grandes empresas, Galicia é a terceira comunidade autónoma que máis cantidade de gases de efecto invernadoiro emite á atmosfera, o que supón un 11,2\% das emisións de toda España, só superada po Asturias (16,3\%) e Andalucía (18,9\%). Estes datos contrastan cos emitidos polo sistema español de inventario (SEI) [13], onde mostra a Galicia como quinta comunidade máis emisora de GEl, co $8,7 \%$ das emisións totais do estado para o mesmo ano. No mesmo informe, no ano 2017 sitúase en cuarta posición co 8,9\% do total.

A continuación representaranse os datos en comparativa con outros focos de emisión galegos [14]. Para poder realizar esta comparación, débense converter as emisións deste estudo en emisións equivalentes de $\mathrm{CO}_{2}\left(\mathrm{CO}_{2 e q}\right)$, por ser esta unidade na que se adoitan publicar os datos de emisións anuais no sector industrial. Estas contabilizan a totalidade das emisións de gases de efecto invernadoiro, expresadas na cantidade equivalente de dióxido de carbono que provocaría un dano similar na atmosfera.

Os resultados comparados con outros focos de emisións a nivel Galicia [14], están representados na Táboa 10.

Na Táboa 10 pódense apreciar as fontes emisoras de contaminación aérea de Galicia con máis de $100.000 \mathrm{t}$ de $\mathrm{CO}_{2}$ equivalente. Os datos máis actualizados dispoñibles son do ano 2015. Cabe facer mención ademais aos datos de contaminación por transporte marítimo do Instituto Nacional de Estatística [15], para ter unha visión máis global da magnitude das cifras.

Por comparación cos datos da Táboa 10, o porto da Coruña, con 23322 t CO ${ }_{2 \mathrm{eq}}$ ' estaría moi lonxe dos principais focos emisores galegos de gases de efecto invernadoiro. Sen embargo, queda pendente a valoración dos efectos da emisión doutros contaminantes que si poden ter unha forte incidencia na saúde, como son as 18,34 t CO, 14,93 t SOx, 374,62 t NOx, as 9,41 t PM10 ou as 18,83 t HC. 
Táboa 10. Principais emisores de gases de efecto invernadoiro de Galicia.

\begin{tabular}{|lllll|}
\hline $\begin{array}{l}\text { INSTALACIÓN } \\
\text { EMISORA }\end{array}$ & EMPRESA & UBICACIÓN & EMISIÓNS (t CO ${ }_{2 \mathrm{eq}}$ ) \\
\hline Central térmica & ENDESA & As Pontes & 7.542 .286 & $52,24 \%$ \\
\hline Central térmica & Gas Natural & Meirama & 3.016 .683 & $20,90 \%$ \\
\hline Refinaría & Repsol & A Coruña & 1.157 .267 & $8,02 \%$ \\
\hline Planta de alúmina & Alcoa & San Cibrao & 651.978 & $4,52 \%$ \\
\hline Fábrica de aluminio & Alcoa & San Cibrao & 471.241 & $3,26 \%$ \\
\hline Planta produción H $_{2}$ & Air Liquide Ibérica & Meicende & 192.977 & $1,34 \%$ \\
\hline Produción metalúrxica & Ferroatlántica & Dumbría & 181.701 & $1,26 \%$ \\
\hline Produción metalúrxica & Ferroatlántica & Cee & 155.707 & $1,08 \%$ \\
\hline Produción metalúrxica & Ferroatlántica & Arteixo & 149.980 & $1,04 \%$ \\
\hline Fábrica de aluminio & Alcoa & A Coruña & 147.892 & $1,02 \%$ \\
\hline Planta de coxeneración & Bioetanol Galicia & Curtis & 136.947 & $0,95 \%$ \\
\hline Planta de coxeneración & Forestal del Atlántico & Mugardos & 132.014 & $0,91 \%$ \\
\hline Planta de coxeneración & Intasa & S. Sadurniño & 131.572 & $0,91 \%$ \\
\hline Planta de coxeneración & Bionersa & Boiro & 129.601 & $0,90 \%$ \\
\hline Explotación mineira & Magnesitas de Rubián & Lugo & 120.939 & $0,84 \%$ \\
\hline Planta de coxeneración & Finsa & Santiago & 117.665 & $0,82 \%$ \\
\hline Emisións totais Galicia & & & 14436450 & $100,00 \%$ \\
\hline
\end{tabular}

\section{Conclusións}

A Coruña é unha cidade costeira e, polo tanto, o seu porto é unha entrada importante de comercio que fai medrar a economía da cidade. Esta infraestrutura é unha gran conexión con Europa e co mundo, tanto para o turismo como para o tráfico de mercadorías, e é por iso que o crecemento desta cidade en concreto vai ir sempre ligado ao crecemento do seu porto. Sen embargo, o feito de ser unha cidade costeira con porto de mar ten tamén algunha desvantaxe, como que as emisións debidas á actividade industrial e ao comercio marítimo repercuten na calidade do aire que todos respiramos.

Como primeira conclusión, tras observar o apartado de resultados deste traballo, pódese corroborar que as emisións debidas ao tráfico marítimo de mercadorías e pasaxeiros non é a principal fonte de emisións de GEI da cidade da Coruña. A área metropolitana da Coruña conta con porto marítimo interior e exterior, aeroporto, refinaría, importantes fábricas, coxeneracións, central térmica e diversos focos menores debidos á actividade industrial, que xunto coa intensidade do tráfico de vehículos, fan que esta zona presente 
unha das peores calidades de aire de toda Galicia. Máis preocupante que - $\mathrm{CO}_{2}$ emitido polos buques podería ser a emisión de gases nocivos para a saúde, aspecto que require de máis estudo.

A información que aporta este traballo permite afirmar que a calidade do aire non pode ser óptima. Aínda que este estudo non entrega datos de concentración dos diferentes gases no aire, si permite ver a grande magnitude das emisións que se están realizando cada día á atmosfera, non só polo porto, senón tamén por mor de toda a industria e tráfico local. É imposible que nas zonas máis industrializadas de Galicia a calidade do aire sexa boa, cando as emisións son da orde de millóns de toneladas equivalentes de $\mathrm{CO}_{2}$ anuais en zonas tan reducidas.

\section{Referencias}

1. Autoridade portuaria da Coruña (2018) O porto e os seus servizos. Recuperado de http://www. puertocoruna.com/-[10/05/2018]

2. Marine Environment Protection Committee (MEPC) 67th sessión (2014). Reduction of GHG Emissions from Ships. Third IMO GHG Study 2014 -Final Report.

3. Convenio internacional para prevenir la contaminación por los buques, (MARPOL), enmendado por los Protocolos de 1978 y 1997. Organización Marítima Internacional.

4. Carril, A. (2018) Estudo da contaminación aérea no Porto da Coruña no 2017. TFM/MEM/07-18 Recuperado de : https://ruc.udc.es/dspace/ [05/07/2019]

5. Marine Traffic (2018) Base de datos de buques. Recuperado de : https://www.marinetraffic.com/ [10/04/2018]

6. Universidade da Coruña (2018) Repositorio oficial da Universidade da Coruña. Recuperado de: https:// ruc.udc.es/dspace/ - [18/05/2018]

7. Universidad de Oviedo (2018) Repositorio oficial de la Universidad de Oviedo. Recuperado de: http:// digibuo.uniovi.es/dspace/ - [18/05/2018]

8. Universitat de Barcelona (2018) Centre de Recursos per a I'Aprenentatge i la Investigació. Recuperado de: http://crai.ub.edu/es/recursos-de-informacion/repositorios-digitales - [18/05/2018]

9. Boletín Oficial del Estado (2015) Real Decreto 290/2015 polo que se modifica o Real Decreto 61/2006, polo que se regula o uso de determinados biocarburantes e o contido de xofre dos combustibles para o uso marítimo - [01/02/2018]

10. Kristenen, H.O. (2015) Energy demand and exhaust gas emissions of marine engines. Technical University of Denmark (DTU) - [05/04/2018]

11. La opinión A Coruña (2018) Noticias de A Coruña. Xornal do día 08/02/2018. Recuperado de: https:// www.laopinioncoruna.es/coruna/2018/02/08/puerto-admite-repsol-retrasara-traslado/1261280.html $[22 / 05 / 2018]$

12. RENADE [Registro Nacional de Derechos de Emisión de Gases de Efecto Invernadero] (2018) - Informe de responsabilidad de las grandes empresas. Recuperado de: http://www.renade.es/esp/Home.aspx $[27 / 05 / 2018]$ 
13. Ministerio para la Transición Ecológica (2018). Emisiones de GEI por comunidades autónomas a partir del inventario español-serie 1990-2017. Recuperado de: https://www.miteco.gob.es/es/calidad-yevaluacion-ambiental/temas/sistema-espanol-de-inventario-sei-/emisionesgeiporccaaserie1990-2017_ tcm30-488206.pdf - [22/07/2019]

14. INEGA [Instituto enerxético de Galicia] (2018) - Emisións do Plan Nacional de Asignación dende 2012. Recuperado de: http://www.inega.gal/enerxiagalicia.html - [20/05/2018]

15. INE [Instituto Nacional de Estadística] (2015) Cuentas de emisiones a la atmósfera por transporte marítimo y vías navegables interiores. Recuperado de: http://www.ine.es - [20/05/2018] 


\title{
Sistema domótico de eficiencia
}

\section{energética en el hogar con interfaz de realidad aumentada}

\author{
Óscar Blanco Novoa ${ }^{1}$
}

\section{Resumen}

En las próximas décadas los mayores problemas que tendrá que afrontar el sector energético serán el control de las emisiones de gases de efecto invernadero y la escasez de combustibles fósiles. Además de encontrar nuevas formas de energía renovables, es necesario desarrollar tecnologías que permitan un consumo sostenible y más eficiente.

En 2014 entró en vigor un nuevo sistema de tarificación conocido como PVPC (Precio variable para el pequeño consumidor), mediante esta tarifa el precio se fija por franjas horarias y se factura por la energía consumida en cada una de ellas haciendo uso de contadores inteligentes. Su objetivo es reducir los picos de demanda y estabilizar la curva de consumo de manera que las centrales eléctricas puedan utilizar de forma más eficiente los recursos. Esto permite maximizar el uso de fuentes de generación renovables y reducir la quema de combustibles fósiles, mientras que los consumidores se benefician reduciendo su coste en la factura eléctrica.

En este proyecto se ha desarrollado un sistema domótico modular y de fácil implantación basado en una serie de enchufes inteligentes que son capaces de obtener el coste de la energía en tiempo real y tomar decisiones con el objetivo de determinar el momento óptimo para encender cada aparato de forma automatizada.

El sistema, además de interfaces tradicionales de móvil y escritorio, presenta un novedoso e intuitivo modo de interacción con el sistema basado en una

\footnotetext{
${ }^{1}$ Tutores/as TFM: Tiago M. Fernández Caramés y Paula Fraga Lamas.

*Datos para citación: Blanco Novoa, Óscar (2019). "Sistema domótico de eficiencia energética en el hogar con interfaz de realidad aumentada". En Oficina de Medio Ambiente UDC (ed.), I Premio UDC Sustentabilidade a traballos fin de grado e mestrado 2018. A Coruña: Universidade da Coruña, 121-137. DOI de la obra: https://doi.org/10.17979/spudc.9788497497831.
} 
aplicación de realidad mixta desarrollada para las gafas Microsoft HoloLens que hace el sistema más accesible a cualquier usuario.

Palabras clave: Domótica, Realidad Aumentada, Internet of Things (IoT), Energía, Eficiencia energética.

\section{Introducción}

\subsection{Descripción del problema}

Los estudios relacionados con el uso más eficiente de la energía han ido creciendo en los últimos años al mismo tiempo que términos como las smart homes o la Red eléctrica inteligente (Smart grid) [1] se han ido asentando en la sociedad.

En Estados Unidos, la producción energética es la mayor fuente de gases de efecto invernadero con un $28 \%$ del total de las emisiones [2]. En España, en 2017, el $21 \%$ de las emisiones se produjeron en procesos de generación de electricidad, solo superadas por el transporte con un $26 \%$, ambas por encima del sector industrial, el cual supuso un $19 \%$ del total de las emisiones [3]. Estos datos ponen de manifiesto que el control y el consumo sostenible son tan importantes como la producción de energía.

La ONU, en su último informe sobre sostenibilidad [4] destaca que la energía es el factor que contribuye principalmente al cambio climático y representa alrededor del $60 \%$ de todas las emisiones mundiales de gases de efecto invernadero.

1.1.1 Educación y concienciación ambiental. Una de los puntos destacados por la ONU en materia de sostenibilidad ambiental consiste en la educación y la sensibilización respecto de la mitigación del cambio climático, la adaptación a él, la reducción de sus efectos y la alerta temprana [4]. Y una de las claves en la concienciación sobre eficiencia energética es ser conscientes de lo que consumimos a diario, algo que no es nada fácil en la actualidad.

La mayor parte de la gente es muy consciente del consumo de su teléfono móvil y desactiva los recursos innecesarios como el GPS o el Bluetooth cuando no los está usando. A nadie se le ocurriría, por ejemplo, ir con la linterna del móvil encendida todo el día, porque sabemos que nos quedaríamos sin batería en pocas horas. Sin embargo, lo mismo no ocurre al pulsar el interruptor de la luz o subir la calefacción, porque la electricidad es aparentemente ilimitada y no es fácil ser consciente de lo que está consumiendo cada aparato en casa o en el trabajo.

En este aspecto sería de gran utilidad tener una herramienta que nos mantuviese informados de cuánto están consumiendo los aparatos que 
usamos en tiempo real y nos alerte cuando se están produciendo consumos innecesarios para poder tomar medidas correctivas y generar consciencia hacia un consumo sostenible.

1.1.2. Economía sostenible. A mayor escala, existe una problemática relacionada con la variabilidad de la demanda energética a lo largo del día. Esto se produce porque la mayor parte de la gente sigue unos hábitos similares: nos duchamos, cocinamos o ponemos la lavadora más o menos a las mismas horas. Esto provoca que se produzcan picos de consumo todos los días en las mismas franjas horarias.

Si los picos de demanda son muy elevados, se pueden producir sobrecargas, inestabilidad en la red e incluso apagones. Además, las centrales eléctricas son más eficientes si la curva de consumo se mantiene estable a lo largo del día y, por el contrario, la generación energética es muy ineficiente cuanto mayor es el grado de variabilidad. Las tarifas de discriminación horaria son un ejemplo para intentar estabilizar la curva de demanda energética, incentivando el consumo a ciertas horas del día.

En 2014 se aprobó una nueva normativa que establece una tarifa llamada PVPC (precio voluntario para el pequeño consumidor) [5]. Este sistema no marca dos zonas de tarificación como las anteriores tarifas de discriminación horaria, sino que el precio varía cada hora de forma dinámica. Dicho coste se publica a diario en la página de Red Eléctrica Española [5] y se factura haciendo uso de los contadores inteligentes recientemente instalados en toda España.

Con este método, no solo se pretende reducir los picos de demanda energética para estabilizar la curva de consumo, sino que también permite incentivar el consumo en los momentos en los que están disponibles fuentes de generación renovables (e.g., eólica o solar). De esta manera los usuarios pueden ahorrar costes a la vez que se mejora la eficiencia energética y se reduce la quema de combustibles fósiles. Sin embargo, el éxito de estas tarifas ha sido limitado debido al inconveniente que supone tener que planificar cuándo encender cada aparato para aprovechar dicha tarifa.

1.1.3. Campus sostenible. Una de las problemáticas a nivel energético que se produce en la mayoría de espacios compartidos como empresas, asociaciones o en las instalaciones del campus, consiste en la dificultad para gestionar adecuadamente los recursos cuando éstos son utilizados por muchas personas.

Por ejemplo, es relativamente común que proyectores, ordenadores y equipos de laboratorio queden encendidos tras su uso. Esto no solo provoca un elevado gasto innecesario, sino que reduce la vida útil de los aparatos (debido a la llamada obsolescencia programada), quedando encendidos largas horas, lo cual aumenta también el riesgo de fallos o incluso de incendios. 
Por otro lado, tener un historial detallado de consumo, permitiría obtener estadísticas y gráficas que serían de gran utilidad como herramienta de concienciación y con el objetivo de detectar y resolver problemas.

\subsection{Objetivo del trabajo}

El trabajo desarrollado en este proyecto consiste en el diseño y construcción de una serie de enchufes inteligentes conectados a internet que presenta una solución novedosa y sencilla a todos los problemas mencionados anteriormente.

Los enchufes inteligentes desarrollados son capaces de obtener a través de internet el coste de la energía en tiempo real y permiten monitorizar el consumo de los aparatos conectados a ellos y a su vez planificar el encendido y apagado en base a algoritmos inteligentes que tienen en cuenta las preferencias del usuario y el coste de la energía.

Es una solución integral que incluye el hardware, los servicios de red y las interfaces de usuario necesarias para controlar el sistema de forma sencilla e intuitiva.

Dispone de una aplicación web y otra de realidad aumentada pensadas para abstraer completamente toda la complejidad del sistema al usuario final, permitiéndole monitorizar el estado y consumo de cada enchufe de forma sencilla, así como encenderlos y apagarlos remotamente y configurar preferencias para que se realicen acciones automáticamente. Además, todos los componentes han sido desarrollados de modo que pueden ser instalados y configurados de forma sencilla directamente por el usuario.

\subsection{Potenciales beneficios y aplicaciones}

1.3.1. Concienciación energética. El sistema permite al usuario ver desde el teléfono móvil qué aparatos están encendidos y cuánto están consumiendo en tiempo real, lo cual nos proporciona una manera sencilla de cuantificar el consumo que estamos realizando cada vez que enchufamos algo, haciendo al usuario más consciente e incentivando el ahorro energético.

Además, los datos de consumo de cada aparato se almacenan a lo largo del tiempo de forma independiente, pudiendo realizar comparaciones entre ellos para ofrecer al usuario datos que le permiten conocer el porcentaje del consumo total y el coste que supone cada aparato, lo que facilita la aplicación de medidas correctivas y de ahorro energético.

Tener cuantificados los datos de consumo abre la posibilidad de realizar estadísticas muy útiles, tanto en el contexto doméstico como en el industrial. Tras la finalización del primer prototipo, se tomaron medidas del suministro eléctrico 
de una vivienda durante un año y se cotejaron los datos el coste de la energía en cada período de facturación horario para calcular empíricamente el coste que habría tenido dicha vivienda con cada una de las tarifas disponibles en el mercado, dando como resultado una oportunidad de ahorro de un 20,8 \%. Cabe destacar que la tarifa idónea depende totalmente de los hábitos de consumo, por lo que es necesario hacer mediciones personalizadas y no es posible extrapolar los datos.

Por otro lado, con un simple gesto en su teléfono móvil, el usuario puede encender o apagar aparatos de forma remota, lo cual permite al usuario controlar la mayor parte de aparatos más cómodamente.

1.3.2. Sostenibilidad económica. Algunos aparatos tienen cierta flexibilidad respecto a la hora a la que deben funcionar. Por ejemplo, a la mayor parte de la gente le dará igual a qué hora encienda la lavadora mientras la ropa esté lista antes de una hora límite. Del mismo modo, los calentadores de agua eléctricos calientan un volumen importante de agua y luego mantienen el calor durante horas, por lo que da igual cuando se activen mientras el agua esté caliente a la hora de ducharnos. Por su parte, muchos sistemas de calefacción calientan acumuladores que luego desprenden calor durante varias horas.

Casualmente, los aparatos que tienen flexibilidad horaria coinciden en gran medida con aquellos que tienen un mayor consumo de potencia. Por este motivo, sería muy conveniente alinear su funcionamiento con las franjas de tiempo en que la energía es más barata en la medida de lo posible.

Como se ha comentado anteriormente, consumiendo en estos periodos de bajo coste, no solo estamos reduciendo nuestra factura eléctrica, sino que además estamos colaborando con una generación más eficiente y un mejor aprovechamiento de las fuentes renovables.

El sistema de enchufes inteligentes está pensado para permitir la planificación inteligente de este tipo de aparatos en base a preferencias. Por ejemplo, un usuario podría establecer que quiere poner la lavadora entre las 10 y las 14 horas y cargar el móvil o el coche eléctrico durante la noche y el sistema se encargaría de encender el enchufe de forma automática en el momento en que el coste fuese mínimo dependiendo de la tarificación aplicable ese día.

Con la proliferación de coches eléctricos, un sistema como el desarrollado se volverá prácticamente imprescindible ya que, debido a la gran demanda energética que estos producen, la infraestructura actual no soportaría que todos se pusiesen a cargar al mismo tiempo. Un sistema de enchufes inteligentes es necesario para distribuir la carga de cada vehículo y aprovechar de una manera más eficiente los recursos.

1.3.3. Aplicación práctica al campus. Como comentábamos anteriormente, en las instalaciones del campus es relativamente común que proyectores, 
ordenadores y equipos de laboratorio queden encendidos tras su uso debido a despistes. Este sistema permite detectar y apagar de forma autónoma todos esos aparatos a las horas en que no están siendo usados y activarlos de nuevo automáticamente por la mañana.

Asimismo, permite llevar un control del consumo y gasto de cada uno de los elementos conectados a la red con el objetivo de poder cuantificar su consumo de forma independiente para poder tomar medidas correctivas e identificar que aparatos podrían ser sustituidos por otros más eficientes recuperando la inversión a medio plazo.

Por otro lado, el sistema puede detectar consumos residuales de los aparatos basándonos en el consumo instantáneo del mismo y apagarlos de forma automática cuando se detecta que se encuentran en estado de stand by.

El sistema también es capaz de detectar en tiempo real anomalías en la red monitorizando el consumo, localizar aparatos que han dejado de funcionar o aquellos con un consumo inusual pudiendo identificar cortocircuitos y cortar la corriente antes de que puedan producirse incendios.

1.3.4. Accesibilidad. La interacción con algunos sistemas e interfaces, puede resultar un problema para algunas personas. La interfaz de realidad aumentada desarrollada, permite visualizar toda la información del sistema directamente superpuesta sobre los elementos reales del entorno.

Tras un minucioso análisis del estado actual de las soluciones comerciales y académicas de realidad aumentada $[6,7]$, se llegó a la conclusión de que el dispositivo más adecuado para demostrar las capacidades de esta tecnología e impulsar el desarrollo de interfaces más accesibles eran las gafas Microsoft HoloLens. El principal motivo es que técnicamente se encuentran un paso por delante sus competidores debido al impulso económico de Microsoft.

Las gafas HoloLens 1 actualmente tienen un coste de 3.000 dólares y funcionan con un sistema operativo equivalente a Windows 10 . Sin embargo, varias grandes empresas están apostando por esta tecnología y está previsto que en los próximos años tanto Microsoft como sus competidores pongan a la venta dispositivos de este tipo, lo que hará que mejore la tecnología y se abaraten costes.

A través de estas gafas de realidad aumentada el usuario puede visualizar los datos sobre los propios electrodomésticos e interactuar con el sistema domótico mediante gestos en el aire sin necesidad de acercarse y manipular físicamente ningún elemento.

1.3.5. Otras aplicaciones. El sistema de planificación del sistema de enchufes inteligentes permite establecer una secuencia de encendido y apagado de luces y aparatos de forma periódica. De esta manera, se permite automatizar 
su funcionamiento e incluso simular presencia (e.g., simular su uso con el objetivo de disuadir a ladrones).

Añadiendo más sensores podrían realizarse mediciones de otras variables como agua o gas, para ofrecer una visión global del consumo energético de un espacio (e.g., vivienda, establecimiento, campus), así como datos ecológicos y de emisiones.

\subsection{Antecedentes}

En los últimos años han surgido numerosos desarrollos relacionados con la domótica doméstica (e.g., luces inteligentes, básculas, enchufes). La mayoría de estos desarrollos son sistemas ad hoc creados con unos objetivos concretos y con difícil integración con terceros.

Debido a esto, surge la idea de desarrollar un sistema modular que haga uso de tecnologías abiertas y que a su vez aporte valor a este ecosistema de tecnologías, favoreciendo la interacción entre diferentes componentes de terceros, haciendo uso de protocolos y APIs (Interfaces de Programación de Aplicaciones) estándar.

Este proyecto tiene un amplio recorrido. Comenzó en 2016 con un primer prototipo de enchufe inteligente que se presentó como Trabajo Fin de Grado (TFG) del mismo autor. En él se desarrolló una primera versión del hardware del enchufe que ofrecía las funcionalidades básicas y mostraba los datos a través de una aplicación web. Este TFG obtuvo matrícula de honor, ganó el segundo premio al mejor proyecto de grado y máster de software libre de Galicia y quedó finalista como mejor proyecto aplicado de la facultad de informática.

A pesar de la gran innovación existente en tecnologías Internet of Things (IoT) en los últimos años, las interfaces gráficas existentes no han sufrido grandes cambios. Por este motivo, este proyecto presenta una aplicación de Realidad Aumentada (RA) que permite explorar nuevas formas de interacción. Dicha interfaz permite visualizar información sobre elementos del propio entorno de una forma intuitiva y se integra con el resto de tecnologías del sistema para complementar la funcionalidad ofrecida por una interfaz tradicional basada en web.

El trabajo realizado durante este tiempo dio lugar a la publicación de tres artículos científicos en revistas de alto impacto y una publicación en un congreso internacional que se citan a lo largo de este documento.

\section{Diseño y evaluación del sistema}

En este apartado se detalla la arquitectura del sistema implementado y las interfaces de comunicación entre los diferentes componentes. Debido a la 
extensión de esta memoria no será posible mostrar el diseño completo de cada componente ni su justificación, para lo cual deberá remitirse a la memoria oficial del proyecto.

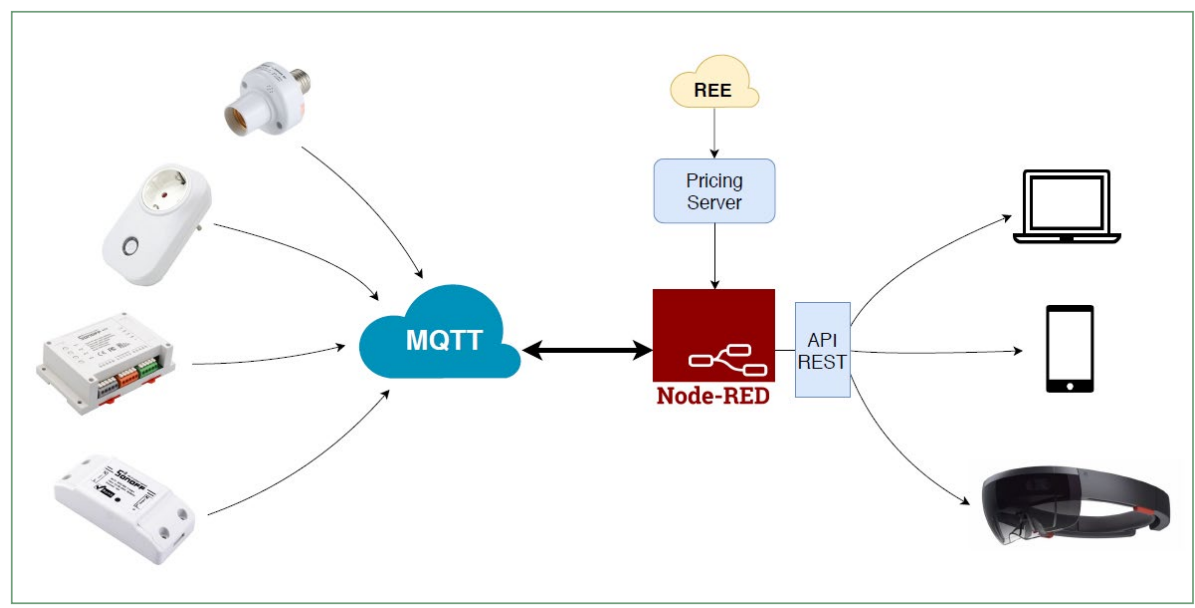

Figura 1. Esquema general del sistema.

En el diagrama de la Figura 1 puede verse el esquema general de la arquitectura del sistema, así como la forma en que interactúan entre sí los diferentes componentes.

Es necesario un mecanismo de comunicación que permita realizar peticiones desde cualquier punto de internet hacia los enchufes, para lo cual se ha implementado un protocolo de comunicación con Message Queue Telemetry Transport (MQTT) que permite realizar peticiones a gran velocidad siendo a su vez un protocolo de comunicación estándar y ampliamente utilizando en domótica en la actualidad.

Para la comunicación con las interfaces de realidad aumentada se utiliza el protocolo HTTP mediante una serie de APIs REST debido a ser la tecnología más extendida para estetipo deaplicación. Laconversión ytraducción entrelos diferentes protocolos se realiza mediante la herramienta de control de flujos de IBM Node-Red.

\subsection{Sistema domótico}

El enchufe inteligente es un dispositivo hardware conectado a la red eléctrica que dispone de un pequeño microcontrolador, un relé y un sensor de corriente. Por medio de los cuales tiene la posibilidad de controlar el paso de corriente a través de un enchufe estándar y puede monitorizar la intensidad que circula 
por dicho enchufe y por lo tanto obtener la potencia y la energía consumida a lo largo del tiempo.

2.1.1. Versión 1.0. La primera versión del enchufe consiste en el prototipo que se puede ver en la Figura 2. Está compuesto por una regleta de 5 enchufes a la que se le habían eliminado 2 de ellos para introducir en el espacio disponible los elementos necesarios para hacerlo inteligente.

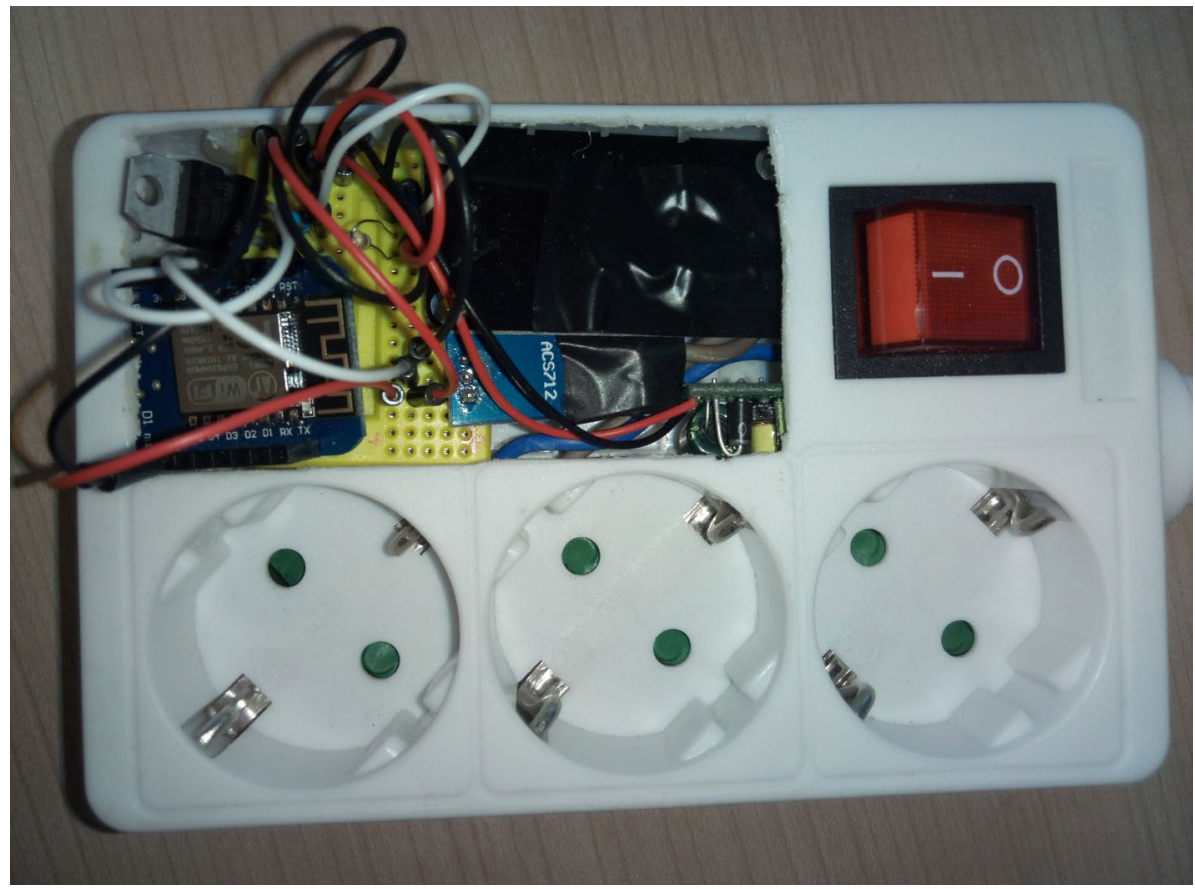

Figura 2. Versión 1.0 del enchufe inteligente.

Con esta versión se llevaron a cabo las primeras pruebas y fueron realizadas una serie de análisis de rendimiento que dieron lugar a una publicación en la revista Sensors [8] (revista indexada en el JCR con un factor de impacto en 2016 de 2,677 y clasificada como Q1/T1 en el campo Instruments and Instrumentation).

2.1.2. Version 1.2 Aalborg. Investigadores de la universidad de Aalborg en Dinamarca disponen de un laboratorio de eficiencia energética pionero [9]. Trasla publicación sobre el enchufe inteligente, los investigadores de Aalborg se pusieron en contacto para intercambiar opiniones, que resultaron finalmente en un acuerdo para mandarles una nueva versión del enchufe inteligente con una serie de modificaciones que sugirieron para el mismo [10]. 
A mayores, ya que era necesario construir un nuevo enchufe, se realizó un nuevo diseño hardware y, además, por seguridad, se diseñó una tapa con una impresora 3D que permitía tapar todos los componentes del enchufe para evitar que hubiese terminales de alto voltaje expuestos hacia el exterior el mismo. En la Figura 3 puede verse el enchufe que actualmente se encuentra en Aalborg.

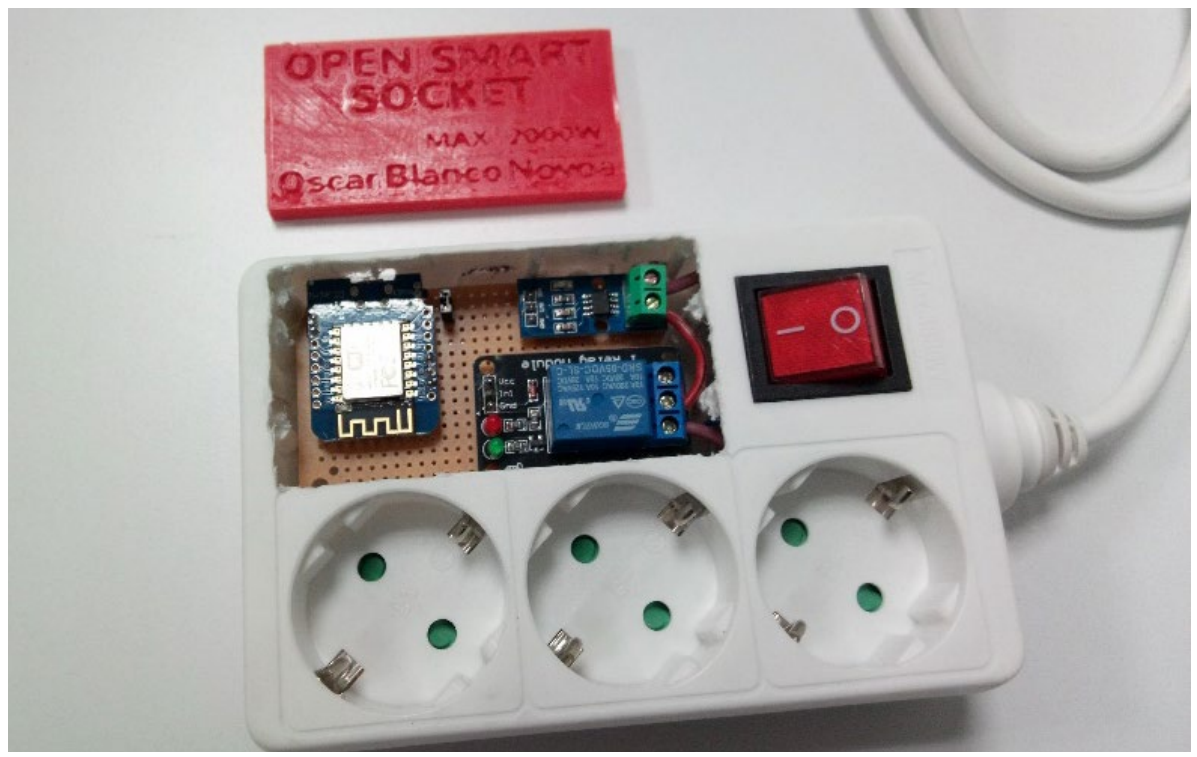

Figura 3. Versión 1.2 del enchufe inteligente enviada a Aalborg.

2.1.3. Versión 2.0. Durante el desarrollo de las primeras versiones del prototipo había comenzado a popularizarse dentro de la comunidad open source los desarrollos de la empresa Itead Studio que ofrecía un módulo de control energético que únicamente permitía encender y apagar remotamente electrodomésticos a través de una aplicación móvil. El módulo se llama SonOff y puede verse en la Figura 4.

La clave del éxito de esta empresa es que sus módulos integraban un microcontrolador ESP8266, muy popular en la comunidad open source y el mismo que se había escogido en los prototipos anteriores del enchufe.

Tras analizar el mercado se llegó a la conclusión de que era muy complicado competir contra un hardware comercial de un precio tan económico $(9,04$ e) y que ya dispone de las certificaciones de industria necesarias para ser comercializado en Europa. Porotrolado, se identificaron una serie de carencias en el mismo, pues la única funcionalidad existente consiste en el encendido 
y apagado remoto. Por tanto, se optó por la opción de utilizar el hardware de SonOFF como base, modificarlo y diseñar un nuevo módulo software para poder ofrecer todas las funcionalidades planteadas en este proyecto.

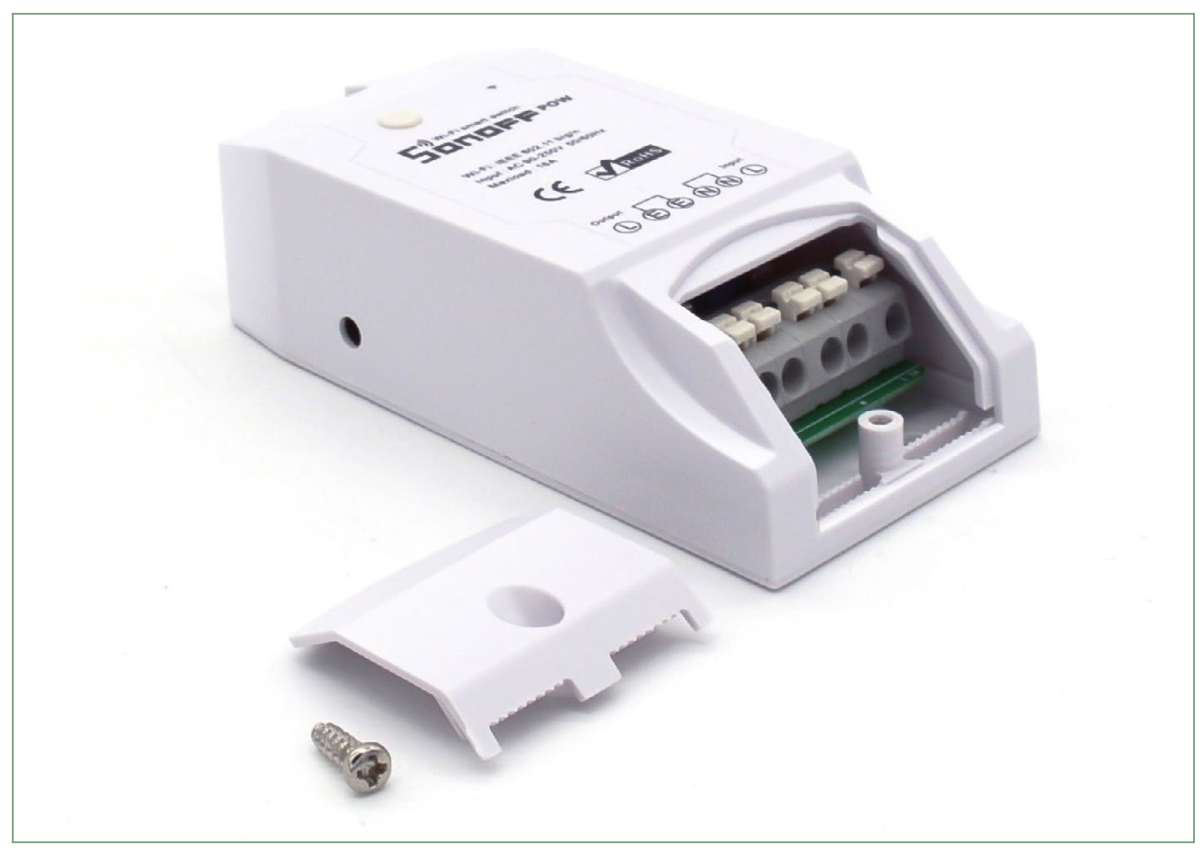

Figura 4. Módulo SonOff Pow de la empresa Itead Studio.

\subsection{Servicios de comunicación}

Se han denominado como servicios de comunicación una serie de servidores y procesos que se encuentran en un servidor en la nube y que dan soporte al funcionamiento del resto de módulos del sistema, actuando como proveedores de información y como canal de comunicación.

Los servicios de red están compuestos de tres elementos principales: el servidor de precios concachéqueseencarga defacilitarlos precios dela energíahaciendo de intermediario entre el sistema y Red Eléctrica Española, el servidor MQTT que da soporte a las comunicaciones a través de este canal y Node-RED, que encamina los flujos de datos hacia los módulos correspondientes en cada situación.

En el diagrama de la Figura 5 pueden verse los bloques generales del subsistema de servicios de red y la manera en que interaccionan entre ellos. $A$ continuación, se describe el diseño e implementación de cada uno de ellos. 


\subsection{Interfaz web}

La aplicación web es una interfaz gráfica que permite al usuario visualizar el historial de consumo y el estado del enchufe, así como solicitar el encendido y apagado remoto del mismo.

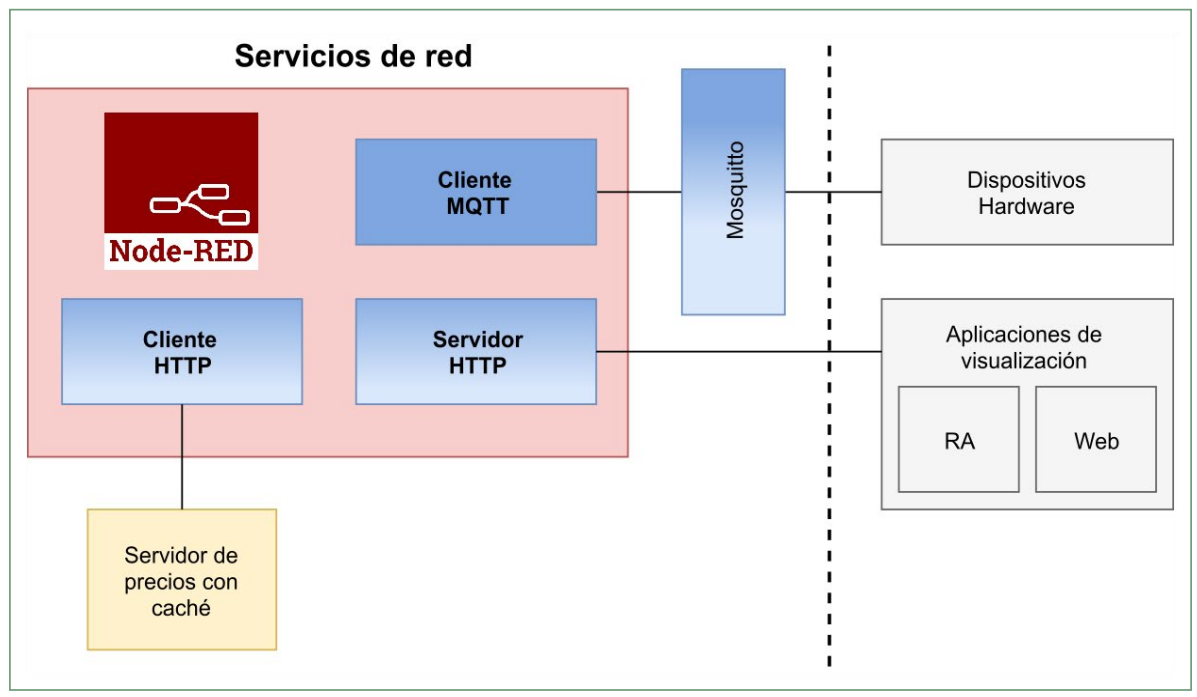

Figura 5. Diagrama de los servicios de red.

La aplicación web proporciona una manera visual e intuitiva de interactuar con el sistema abstrayendo toda la complejidad subyacente. Además, la aplicación web complementa a la aplicación de realidad aumentada permitiendo realizar en ella acciones más complejas como la programación de intervalos de funcionamiento.

El sistema desarrollado está compuesto por los siguientes elementos:

- El historial de consumo.

- La lista diaria de precios de la energía.

- El estado del enchufe.

- Los intervalos de funcionamiento programados.

En la Figura 6 puede verse el resultado final de la aplicación.

\subsection{Interfaz de realidad aumentada}

La aplicación de realidad aumentada fue uno de los desarrollos de este proyecto con más complejidad debido a la inmadurez de las tecnologías. 
Además, debido a la novedad, existen muy pocos o ningún proyecto de referencia que realice tareas similares a las que se van a desarrollar. Debido a ello, se realizó un análisis de las soluciones de realidad aumentada existentes en el mercado [6] y una evaluación del rendimiento de cada una de ellas [7] para determinar cuáles eran las más adecuadas.

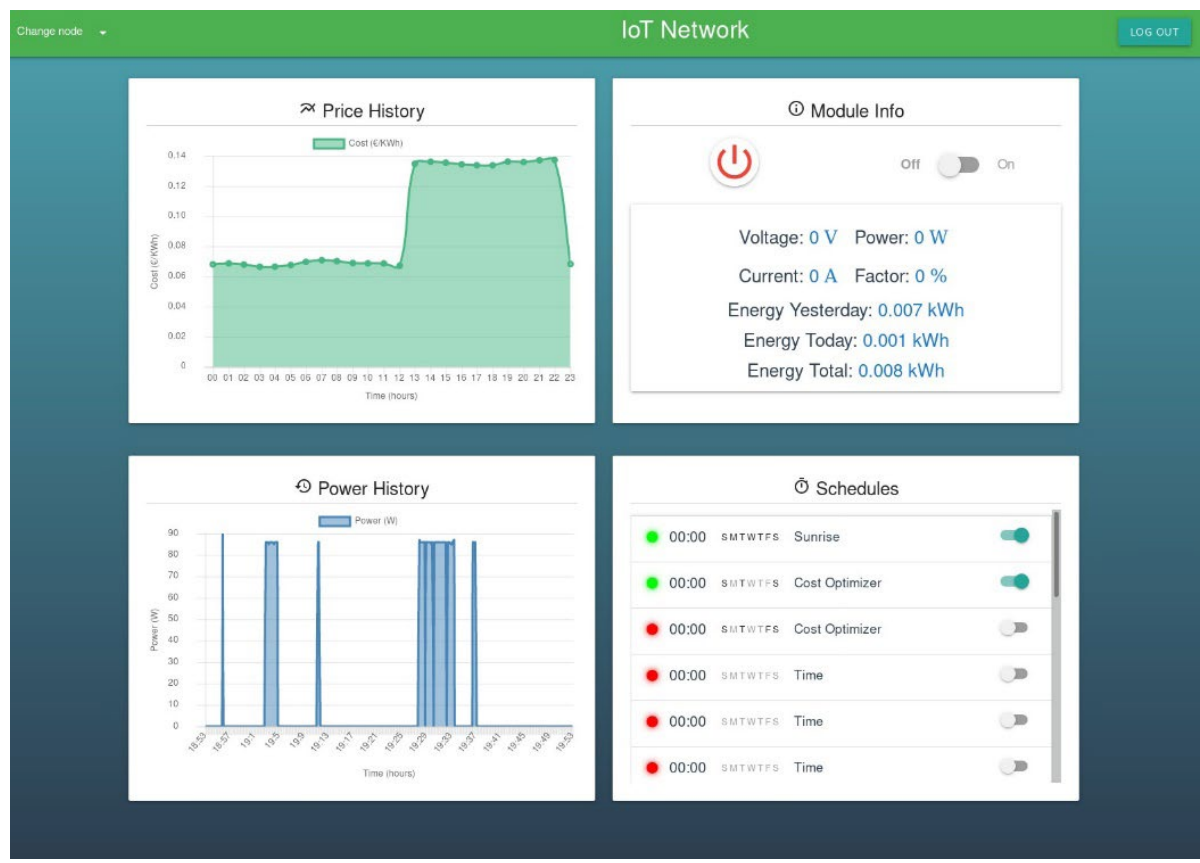

Figura 6. Captura del resultado final de la aplicación web.

Cabe destacar que esta parte del proyecto es la más novedosa, ya que se utilizan tecnologías que todavía no están asentadas en el mercado y que por lo tanto su disponibilidad y coste no es accesible para todo el mundo. Sin embargo, estos sistemas se están popularizando a un ritmo muy elevado en los últimos años y han demostrado ofrecer características muy interesantes. Esta parte del proyecto explora y demuestra las capacidades de estas tecnologías dando un paso más hacia su adopción en diferentes entornos.

En un futuro próximo es previsible que tanto el coste como el formato de los dispositivos de realidad aumentada mejore notablemente, integrándose en el día a día de la gente de la misma manera en que hoy se utilizan los teléfonos móviles. Este proyecto se adelanta a dicha evolución tecnológica, contribuyendo a construir las bases para hacerla posible. 
A través de las gafas HoloLens la experiencia de usuario es completamente inmersiva ya que los elementos se proyectan directamente delante de los ojos del usuario. Por el momento no existen muchos artículos que estudien las buenas prácticas relacionadas con el desarrollo de interfaces en este tipo de dispositivos. Un ejemplo representativo sería [11] donde los autores estudian la interacción de 100 estudiantes con una aplicación de realidad aumentada. En [12] los autores estudian la experiencia de usuario en función de la luminosidad.
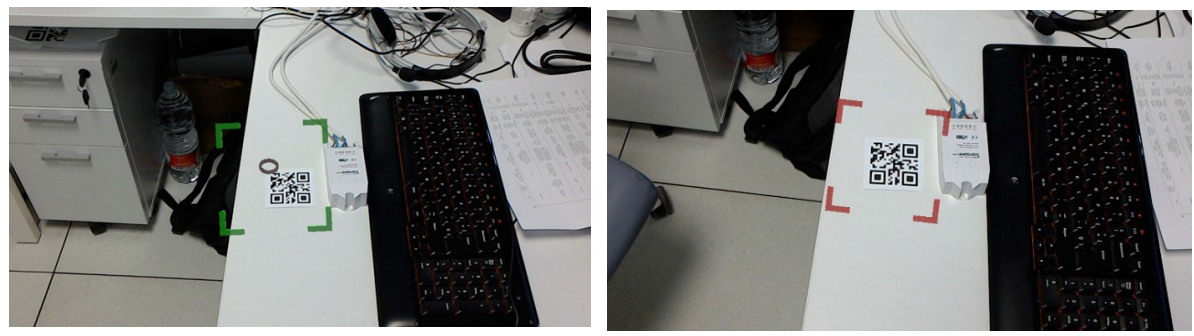

Figura 7. Marcador de reconocimiento de códigos QR mientras está escaneando (rojo) y una vez ha detectado un código (verde).

Teniendo en cuenta estas directrices, se ha prestado atención especial a que todos los elementos del entorno sean objetos 3D posicionables en un punto del entorno real (por ejemplo, encima de una mesa). De la misma manera todos los elementos deben ser conscientes del entorno y responder acorde al mismo.

La primera vez que añadimos un enchufe nuevo al sistema de realidad aumentada el usuario debe escanear un código QR para vincular el nuevo enchufe al sistema. Dicho código QR podría venir en la caja del enchufe al comprarlo. Para llevar a cabo esta tarea se ha implementado un sistema de reconocimiento de códigos QR (Figura 7).

Una vez detectado el código QR se despliega el panel de control, el cual aparece flotando en el aire y se mueve siguiendo los movimientos de cabeza del usuario. Durante esta fase se muestra también una malla con aspecto de tela de araña sobre el mapeo realizado del entorno (Figura 8), y el usuario puede posicionar el panel sobre una superficie física y éste se ajustará a ella sin atravesarla. Cuando el usuario esté conforme con la solución deberá realizar un gesto con la mano para fijar las coordenadas.

El panel de control es una superficie con botones y displays que permite monitorizar el estado del enchufe y realizar acciones sobre él, tiene como objetivo emular un elemento físico que permite controlar el estado de un enchufe. En concreto permite encender y apagar el dispositivo mediante un 
gesto con la mano en el aire, visualizar su estado y consultar los valores de potencia consumida y factor de potencia en tiempo real.

Con el objetivo de mejorar la experiencia de usuario, se han implementado animaciones para todas las acciones de manera que los botones se mueven al pulsarlos simulando el comportamiento de un elemento físico. Además, para indicar el estado del enchufe, se ilumina el botón que se encuentra activo en cada momento.

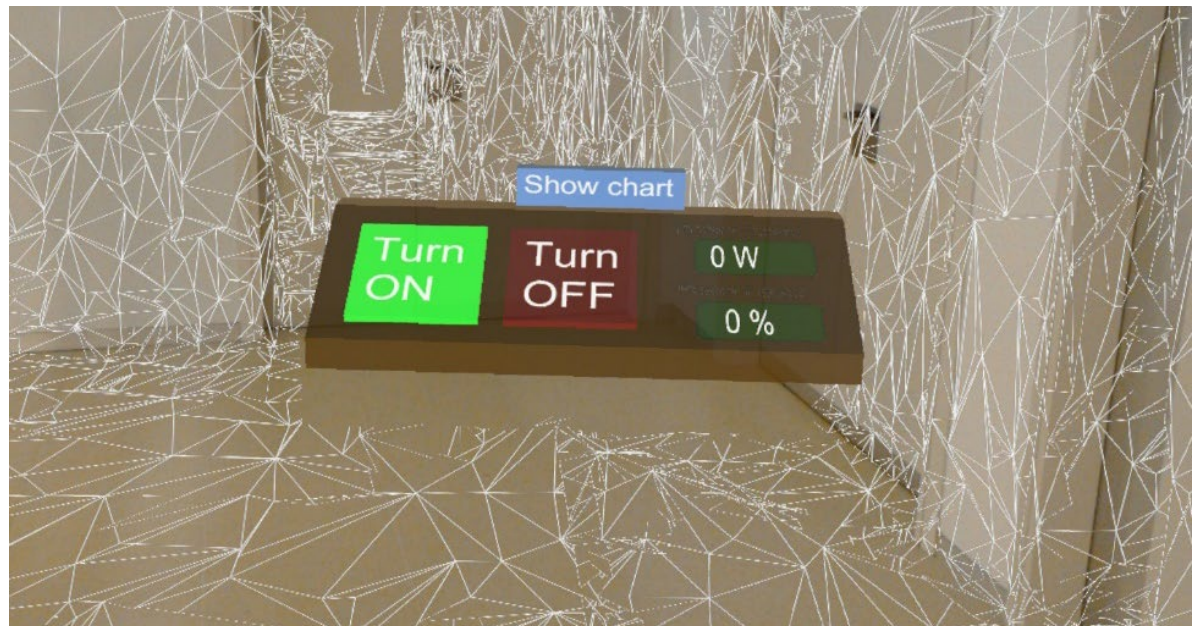

Figura 8. Panel de control virtual en fase de posicionado con las mallas del entorno visibles.

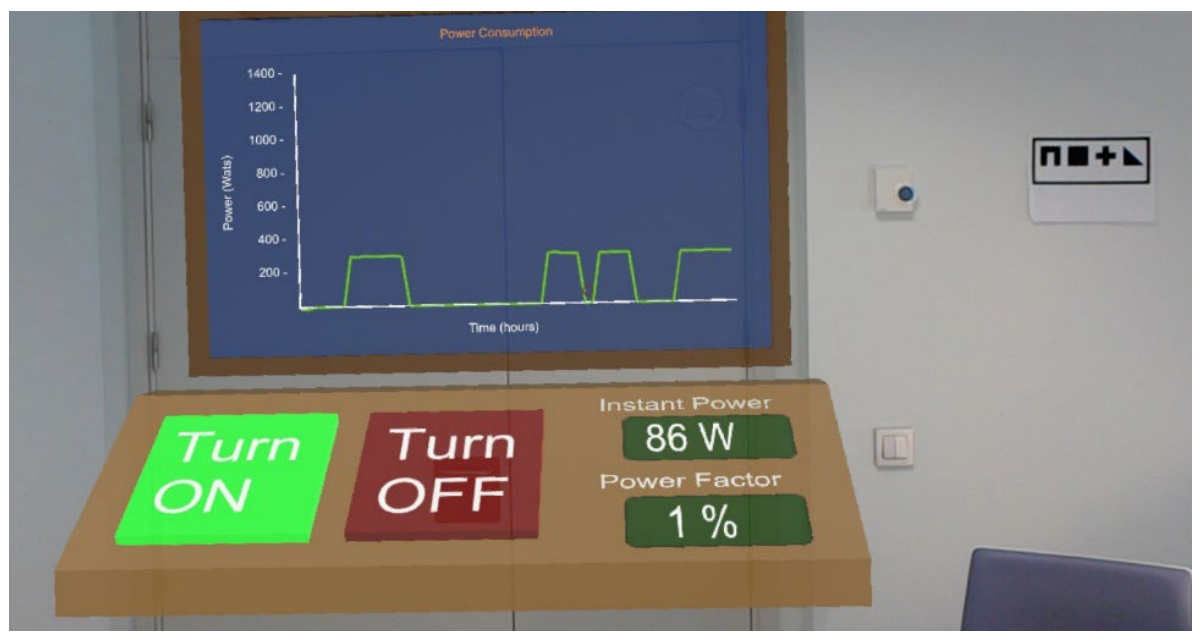

Figura 9. Panel de control virtual con la gráfica desplegada. 
Accionando el botón Show Chart en la parte superior del panel de control se activa el módulo de la gráfica. Dicho módulo muestra la potencia consumida por el enchufe en un periodo de tiempo. En la Figura 9 puede verse el panel de control con la gráfica desplegada.

\section{Conclusiones}

Este proyecto aborda el tema de la sostenibilidad desde diferentes puntos. Por un lado, el sistema de enchufes inteligentes nos permite ser conscientes de la energía consumida tanto en casa como en el trabajo y favorece la concienciación sobre la eficiencia y el consumo energético. Al mismo tiempo, los datos históricos de consumo nos permiten tomar decisiones informadas para mejorar la eficiencia.

La aplicación de realidad aumentada no es imprescindible para el funcionamiento del sistema, ya que la aplicación web dispone de toda la funcionalidad necesaria. Sin embargo, esta interfaz ofrece la visión más innovadora del proyecto y nos acerca un paso más hacia las posibilidades que nos brindan estas tecnologías. Debido a las limitaciones de la tecnología actual, solo se ha realizado la implementación para las gafas HoloLens, pero con los avances que se están realizando en este campo es previsible que muy pronto aparezcan otras soluciones similares y comiencen a abaratarse costes. Esta parte del proyecto ha supuesto todo un reto, debido a la novedad de las tecnologías utilizadas. Propone nuevos modos de interacción accesibles e intuitivos que hasta ahora no habían sido vistos en la literatura. Permite visualizar la información directamente proyectada sobre el entorno a través de las gafas Microsoft HoloLens e interactuar con el sistema utilizando gestos en el aire sin necesidad de acercarse $y$ manipular elementos físicos.

Por otro lado, un sistema como el propuesto resulta imprescindible para la transición hacia una economía energéticamente sostenible en el contexto de las Smart Cities y el Smart Grid. Debido a la creciente demanda de energía producida por nuevos actores de la sociedad moderna, como los vehículos eléctricos, se hace necesario un sistema que favorezca la estabilidad de la red y permita un mejor aprovechamiento de las energías renovables premiando a los usuarios que hacen un mejor uso de las mismas mediante una reducción del coste. El campus no es una excepción y para ser completamente sostenible debe contar con elementos inteligentes que le permitan gestionar su funcionamiento de forma óptima. 


\section{Referencias}

1. Rosslin John Robles and Tai hoon Kim. Applications, Systems and Methods in Smart Home Technology: A Review. Vol. 15. International Journal of Advanced Science and Technology, Febrero 2010.

2. United States Environmental Protection Agency. Sources of greenhouse gas emissions. https://www3.epa. gov/climatechange/ghgemissions/sources.html. Diciembre 2018.

3. Ministerio de Agricultura, Alimentación y Medio Ambiente. Sistema español de inventario. http://www. magrama.gob.es/es/calidad-y-evaluacion-ambiental/temas/ sistema-espanol-de-inventario-sei-/. Diciembre 2018.

4. ONU. Objetivos de desarrollo sostenible. https://www.un.org/ sustainabledevelopment/es/. Diciembre 2018.

5. Red Eléctrica de España. Precio voluntario para el pequeño consumidor (pvpc). http://www.ree.es/es/ actividades/operacion-del-sistema-electrico/ precio-voluntario-pequeno-consumidor-pvpc. Diciembre 2018.

6. Paula Fraga-Lamas, Tiago M Fernández-Caramés, Óscar Blanco-Novoa, and Miguel A Vilar-Montesinos. A review on industrial augmented reality systems for the industry 4.0 shipyard. IEEE Access, 6:1335813375, 2018.

7. Oscar Blanco-Novoa, Tiago M Fernández-Caramés, Paula Fraga-Lamas, and Miguel A Vilar-Montesinos. A practical evaluation of commercial industrial augmented reality systems in an industry 4.0 shipyard. IEEE Access, 6:8201-8218, 2018.

8. Óscar Blanco-Novoa, Tiago M. Fernández-Caramés, Paula Fraga-Lamas, and Luis Castedo. An electricity price-aware open-source smart socket for the internet of energy. Sensors, 17(3), 2017.

\section{Bibliografía}

Intelligent dc microgrid living lab. http://www.et.aau.dk/research-programmes/ microgrids/activities/intelligentdc-microgrid-living-lab/. 2018.

Óscar Blanco-Novoa, Tiago M Fernández-Caramés, Paula Fraga-Lamas, and Luis Castedo. An open-source iot power outlet system for scheduling appliance operation intervals based on real-time electricity cost. In 2017 IEEE International Conference on Internet of Things (iThings) and IEEE Green Computing and Communications (GreenCom) and IEEE Cyber, Physical and Social Computing (CPSCom) and IEEE Smart Data (SmartData), pages 917-924. IEEE, 2017.

Hannes Kaufmann and Andreas Dünser. Summary of usability evaluations of an educational augmented reality application. In Randall Shumaker, editor, Virtual Reality, pages 660-669, Berlin, Heidelberg, 2007. Springer Berlin Heidelberg.

George Drettakis, Luc Robert, and Sylvain Bougnoux. Interactive common illumination for computer augmented reality. In Julie Dorsey and Philipp Slusallek, editors, Rendering Techniques '97, pages 45-56, Vienna, 1997. Springer Vienna. 



\title{
I premio UDC sustentabilidade a traballos fin de grao e mestrado 2018
}

\author{
BASES do «I Premio UDC SUSTENTABILIDADE» aos traballos fin de \\ grao (TFG) e fin de mestrado (TFM) que mellor integraron as dimen- \\ sións da sustentabilidade nos seus proxectos
}

\section{Obxectivos}

A Universidade da Coruña vén desenvolvendo nos últimos anos un programa de mellora continuada para a sustentabilidade no marco da Guía para a sustentabilidade na UDC (2011) e no Plan estratéxico da UDC 2013-2020. Este obxectivo incluíu a creación de comités ambientais nos centros (Programa Green Campus), a elaboración de plans sectoriais en Mobilidade e espazo público, Eficiencia enerxética, Uso sustentable da auga, Xestión de residuos e Ambientalización curricular. No marco destes plans desenvólvense iniciativas tales como a mellora da recollida selectiva de residuos, a compostaxe de residuos orgánicos, a introdución de equipamentos e prácticas de aforro e uso eficiente da enerxía e da auga, instalacións de produción de enerxía renovable, o préstamo de bicicletas e outras accións de fomento da mobilidade sustentable, a conservación e mellora da biodiversidade nos espazos fluviais e forestais do campus universitario, a introdución de recomendacións e contidos relativos a sustentabilidade nas guías docentes, a promoción da saúde e dos hábitos de vida saudables, ou o programa de sensibilización e voluntariado ambiental. O recoñecemento coas bandeiras Green Campus para 5 centros no período 2015- 2017, e o resultado da avaliación internacional GreenMetric da sustentabilidade nas universidades (posición 86 a nivel mundial de 619 universidades participantes) son indicadores dos resultados acadados con estes programas.

As avaliacións externas da CRUE-Sustentabilidade en 2011 e GreenMetrics en 2016 coincidiron en pór de manifesto a elevada puntuación da UDC nos eidos de ensino e investigación. Consciente desta significativa achega 
á sustentabilidade ambiental na UDC, a Vicerreitoría de Economía, Infraestruturas e Sustentabilidade, a través da Oficina de Medio Ambiente (OMA-UDC), quere contribuír ao seu recoñecemento e a potenciar aqueles estudos e traballos que contribúen a un mellor coñecemento e á adopción de medidas e prácticas de sustentabilidade no ámbito do campus e os centros universitarios, en particular, e ao desenvolvemento sustentable no ámbito galego ou ao coñecemento e sensibilización dos problemas ecolóxicos globais e a educación ambiental.

A dotación total destinada aos premios será de dous mil catrocentos euros $(2400 €)$ con cargo á partida orzamentaria 0200 422D 480.02. Quedan excluídos desta cantidade os posibles gastos administrativos relacionados co concurso, coa súa difusión ou coa publicación das obrasseleccionadas.

\section{Modalidades e dotación}

Os premios UDC SUSTENTABILIDADE presentan dúas modalidades:

a) Premio aos traballos fin de grao da UDC que mellor integraren as dimensións da sustentabilidade nos seus proxectos

b) Premio aos mellores traballos fin de mestrado da UDC que mellor integraren as dimensións da sustentabilidade nos seusproxectos.

En cada modalidade concederanse dous premios, I e II premio, e dous accésits, segundo se indica a continuación:

- Cada traballo premiado e os accésits recibirá un diploma acreditativo e a publicación nunha colección da UDC.

- O I premio en cada modalidade recibirá ademais 800 euros (sobre o que se aplicará a retención do IRPF quecorresponda).

- O II premio en cada modalidade recibirá ademais 400 euros (sobre o que se aplicará a retención do IRPF quecorresponda).

\section{Avaliación}

A avaliación para asignar os premios e accésits terá en conta os seguintes criterios:

- A afinidade coa temática da sustentabilidade ambiental, que se considerará como criterio imprescindible. 
- A orixinalidade do tema e a súa achega a un ou varios dos obxectivos de sustentabilidade da ONU e do compromiso social (ambiental, igualdade, normalización lingüística, cooperación, promoción da saúde...) da UDC.

- Os resultados obtidos e/ou a súa aplicabilidade práctica á mellora da sustentabilidade nos campus e centros da UDC.

- A adecuación á totalidade das presentes bases.

\section{Requisitos}

Poden ser candidatos/as nesta convocatoria os/as estudantes da UDC que defenderon os TFG e TFM nos anos 2017 e 2018. Os/as candidatos/as, polo feito de se presentaren, outorgan permiso á OMA-UDC para publicar o traballo.

\section{SOLICITUDE, PRAZO E FORMA DE PRESENTACIÓN}

Os/as candidatos/as deben cubrir e imprimir o formulario de inscrición que se achega xunto con esta convocatoria.

Este formulario de solicitude dirixirase ao Vicerreitor de Economía, Infraestruturas e Sustentabilidade e presentarase preferentemente no Rexistro Electrónico da UDC, no Rexistro Xeral da Universidade da Coruña (Maestranza, no 9, 15001, A Coruña) ou nos rexistros auxiliares do campus da Coruña (provisoriamente na Facultade de Ciencias na Zapateira) ou do campus de Ferrol (Edificio de usos administrativos, rúa Dr. Vázquez Cabrera s/n, Esteiro, 15403, Ferrol). Asemade, poderán presentarse por calquera dos procedementos previstos no Artigo 16.4 da Lei 39/2015 de 1 de outubro de Procedemento Administrativo Común das Administracións Públicas.

O prazo para a presentación de solicitudes comezará a contar o dia seguinte á publicación desta convocatoria no taboleiro electrónico da UDC, e rematará ás 14:00 h do día 31 de decembro de 2018.

Dentro do mesmo prazo indicado no parágrafo anterior, farán chegar á Oficina de Medio Ambiente a seguinte documentación:

a) Memoria publicable do traballo (TFG ou TFM): Memoria resumo, até un máximo de 20 páxinas e 5000 palabras, organizada conforme a estrutura do TFG ou TFM. Deberá incluír necesariamente os datos 
de identificación (autoría, título do traballo, titulación), un resumo ( $<250$ palabras) e unha bibliografía que non supere as 20 referencias (todas elas citadas no texto). De ser axeitada, recoméndase a seguinte estrutura: título, resumo, introdución, materiais e métodos, resultados e discusión, conclusións e referencias bibliográficas. Neste documento farase mención explícita ás achegas do traballo en relación cos criterios indicados na base III desta convocatoria. No caso de o autor ou autora non considerar a elaboración desta memoria axeitada á temática e formato do traballo, entregará unha breve xustificación desta decisión. Esta opción débese considerar excepcional e poderá ser obxecto de valoración pola Comisión de Avaliación prevista nestas bases.

b) Versión íntegra do traballo que se someteu a lectura e cualificación na correspondente convocatoria de TFG ouTFM.

Todos os documentos indicados nas liñas a e b anteriores, en formato PDF, deben ser enviados por correo electrónico ao enderezo oma@udc. gal, indicando no asunto "Premios UDC Sustentabilidade 2018». De non poder dispor do TFG ou o TFM en formato pdf, como podería ser o caso de audiovisuais, maquetas etc., entregarase no formato orixinal do traballo, directamente ou por envío postal á Oficina de Medio Ambiente, Edificio Xoana Capdevielle. Campus de Elviña, 15008 A Coruña.

Terminado o prazo de solicitude e revisadas as solicitudes, a OMA-UDC fará pública no taboleiro electrónico da UDC a listaxe das solicitudes admitidas e, de ser o caso, non admitidas, indicando as razóns das posibles exclusións. As persoas interesadas disporán dun prazo de 10 días para corrixir as deficiencias indicadas, publicándose a continuación a listaxe definitiva.

\section{Comisión de avaliación e prazo para a resolución}

Os traballos serán avaliados por unha comisión constituída pola persoa titular da Vicerreitoría de Economía, Infraestruturas e Sustentabilidade, Domingo Calvo Dopico, ou persoa en que delegue, que actuará como presidente/a, un experto en educación para a sustentabilidade ambiental membro do PDI da UDC, Pedro Vega Marcote, como vogal, e a persoa encargada da dirección da Oficina de Medio Ambiente da UDC, Manuel Soto Castiñeira, como secretario.

Así mesmo, a Comisión de Avaliación poderalle solicitar un informe científicotécnico previo a unha persoa experta na rama de coñecemento científico (Artes e Humanidades, Ciencias, Ciencias da Saúde, Ciencias Sociais e Xurídicas, Enxeñaría e Arquitectura) en que se encadra a temática do traballo. 
A Comisión de Valoración estará rexida polos criterios de avaliación referidos no punto III destas bases.

A resolución será publicada no taboleiro electrónico da UDC e comunicada persoalmente por correo electrónico ás persoas participantes.

\section{Publicación dos traballos}

A OMA-UDC, coa colaboración do Servizo de Publicacións da UDC, publicará en liña nunha colección dotada de ISBN os traballos premiados e os accésits. Con este obxectivo, os autores e autoras dos traballos premiados comprométense en entregar á OMA os orixinais dos seus traballos en formato editable (texto, imaxe, etc) que lle sexan solicitados.

Os ficheiros dos traballos que non resultaren premiados serán eliminados pasado o prazo de tres meses da resolución.

\section{Publicidade}

Os premios serán entregados durante un acto público organizado pola OMAUDC. As persoas gañadoras aceptan a difusión do seu nome e imaxe, de ser o caso, nas comunicacións de carácter informativo ou divulgativo realizadas pola UDC.

\section{Tratamento de datos de carácter persoal}

De conformidade co artigo 13 do Regulamento (UE) 2016/679 do Parlamento Europeo e do Consello, de 27 de abril, relativa á protección das persoas físicas no que respecta ao tratamento de datos persoais e á libre circulación destes datos e polo que se derroga a Directiva 95/46/CE (Regulamento xeral sobre protección de datos ou RGPD), comunicámoslle que a información proporcionada a través deste formulario será tratada baixo a responsabilidade da Universidade da Coruña (UDC), cuxos contactos son: Oficina de Medio Ambiente, Ed. Xoana Capdevielle, Campus de Elviña, 15008-A Coruña, teléfono 881015 688, correo electrónico oma@udc.gal, co obxectivo de xestionar os premios UDC SUSTENTABILIDADE aos traballos de de fin de grao (TFG) e fin de mestrado (TFM).

Estes datos serán tratados durante o tempo imprescindible para alcanzar este obxectivo e serán conservados durante o período adicional dun ano ao 
remate das accións previstas no respectivo premio UDC SUSTENTABILIDADE aostraballosfinde grao e mestrado.

Ao cubrir este formulario, vostede acepta expresamente dito tratamento con propósito de cumprir a finalidade descrita e terá dereito a retirar ese consentimento en calquera momento, sen efectos retroactivos.

Ten dereito a solicitar ao responsable do tratamento, en calquera momento, o acceso, a rectificación ou a eliminación dos seus datos persoais e a limitación do seu tratamento. Tamén terá o dereito de opoñerse a este tratamento, así como solicitar, coa excepción dos casos de interese público e / ou exercicio dos poderes públicos, a portabilidade dos seus datos. Pode exercer estes dereitos a través dun escrito asinado e unha fotocopia do seu DNI enviados ao seguinte enderezo: Oficina do Medio Ambiente, Ed. Xoana Capdevielle, Elviña Campus, 15008-A Coruña, ou correo electrónico oma@udc.gal, coa referencia "protección de datos".

Ademais, ten dereito a presentar unha reclamación diante da Axencia Española de Protección de Datos (AEPD).

A Coruña, 21 de setembro de 2018

O Vicerreitor de Economía, Infraestruturas e Sustentabilidade Domingo Calvo Dopico 
